\title{
Natur als Bild - Bilder der Natur
}

In den folgenden Ausführungen wende ich mich William Henry Fox Talbots ab 1839 veröffentlichten Äußerungen zur Fotografie zu. Im Zentrum stehen dabei sein Interesse an Botanik, seine 1844-1846 in sechs Teilwerken herausgegebene Schrift The Pencil of Nature sowie die darin hinsichtlich kameraloser Fotografie dargelegten Formulierungen. Aber auch schon frühere Schriften Talbots verdeutlichen die grundlegende Rolle und Bedeutung von Pflanzen- und Spitzenmusterfotogrammen, da er, so meine These, zahlreiche Beobachtungen direkt am Fotogramm machen konnte und anhand dessen Fotografie im Allgemeinen beschrieb. Ein weiterer Aspekt meiner Analyse richtet sich auf die Einordnung seiner Abhandlungen in Konzepte der Naturphilosophie, wie der sich um 1800 etablierenden Biologie. Dabei gilt mein besonderes Interesse dem Begriff der Natur, der Vorstellung einer künstlerisch tätigen Natur sowie Theorien zu Selbstorganisation, Epigenese und Bildungstrieb. Insofern sollen Talbots Ausführungen zur Fotografie in Bezug auf eine sich selbst (ab)bildende Natur gelesen werden, welche das Fotogramm sowie die Fotografie nicht nur als Bilder der Natur, sondern auch durch die Natur festlegten und eine Betrachtungsweise als „wahrhafte“ Bilder etablierten. Meine Argumentation zielt dabei auf einen Vergleich epigenetischer und morphologischer Vorstellungen von Entwicklung mit Talbots theoretischen Aussagen zur Fotografie. Aufgrund dieses schriftlichen Materials lässt sich feststellen, dass die Generierung von Fotografien (mit oder ohne Kamera) als automatischer und sukzessiver Formentstehungs- oder Wachstumsprozess der Natur gedacht wurde, wodurch Natur als Subjekt und handelnde Größe in Erscheinung trat. Dem Fotogramm kommt im Rahmen dieser Konzeption insofern eine bedeutsame Rolle zu, als Talbot nicht nur den Entstehungs- und Verfärbungsprozess des mit einer Glasplatte beschwerten und mit einem flachen Objekt bedeckten Papiers direkt beobachten, sondern aufgrund des sich selbsttätig entwickelnden Bildes auch als solches beschreiben konnte. Die zahlreich anzutreffenden schriftlichen Abhandlungen zu Spitzenmuster- und Pflanzenblattfotogrammen und ihre Adressierung an ein zuvorderst weibliches Publikum machen zudem eine materialitätsorientierte Analyse unabdingbar, um Formen der Vergeschlechtlichung, der Hierarchisierung sowie der Stereotypisierung aufzuzeigen. 


\section{„Dame Nature has become his drawing mistress"}

Am Freitag, den 25. Januar 1839 eröffnete Michael Faraday, Präsident der Royal Institution London, im Anschluss an einen Vortrag Charles Woodwards zur Wellentheorie des Lichts eine Ausstellung mit einer Auswahl an photogenischen Zeichnungen Talbots, die dieser in den vorangegangenen Jahren angefertigt hatte. Diese neuartigen und aufgrund ihrer Entstehungsweise magisch anmutenden Bilder wurden in den Räumlichkeiten der institutseigenen Bibliothek neben anderen Sammlungsobjekten aus dem Bereich der Naturalia und Artificialia erstmals einer breiteren Öffentlichkeit präsentiert. ${ }^{1}$ Ausschlaggebend für diese kurzfristig organisierte Darbietung war die rechtliche Absicherung Talbots im Falle eines Prioritätsstreits, da bis zu diesem Zeitpunkt ungeklärt blieb, ob es sich bei Daguerres zu Beginn des Jahres 1839 kommunizierten „Daguerreotypien“ und bei Talbots Bildgebungsverfahren der „photogenic drawings" um identische Erfindungen handelte. Davon abgesehen sollte diese erste Fotografie- und Fotogrammausstellung jene neuen bildgebenden Verfahren und deren potenzielle Anwendungsgebiete einem größeren Publikum zugänglich machen.

Faradays einführende Worte, mit denen er dieses neue Medium zu charakterisieren suchte, sind paradigmatisch für die frühe Rezeption photogenischer Zeichnungen. So erklärte der englische Gelehrte im Rahmen der Eröffnung: „No human hand has hitherto traced such lines as these drawings display; and what man may hereafter do, now that Dame Nature has become his drawing mistress, it is impossible to predict.“2 Mit dieser Beschreibung wurden Talbots Lichtbilder nicht nur in den Kontext der Zeichenkunst gestellt, sondern über ihre Genauigkeit auch von dieser manuellen Tätigkeit abgesetzt. Ein zweiter bedeutsamer Aspekt lässt sich in der Verwendung des Terminus „Natur“ ausmachen, der als „Dame Nature“ und „drawing mistress" geschlechtsspezifisch konnotiert und personifiziert wird. Sherry Ortner argumentiert in ihrem grundlegenden Aufsatz Is Female to Male as Nature Is to Culture?, dass die universale Verknüpfung von Frau und Natur auf Faktoren ihrer Physiologie sowie der ihr attestierten sozialen Rolle basiere. ${ }^{3}$ Silvia Bovenschen konnte herausarbeiten, dass sich das ideale Weiblichkeitsbild von der gelehrten Frau der Frühaufklärung zu einer „empfindsamen Frau“ Mitte des 18. Jahrhunderts wandelte. Frauen wurden fortan in ihrer Gefühlssphäre betont, aufgrund ihrer Physiologie (u. a. Gebär-

1 Siehe dazu: Arnold 1977, S. 119; Schaaf 1992, S. 47ff.; Weaver 1992, S. 45f.; Wolf 2006, S. 113ff.; Steidl 2012. Bzgl. der Sammlungsobjekte, siehe: Larry Schaaf, „A Wonderful Illustration of Modern Necromancy“. Significant Talbot Experimental Prints in the J. Paul Getty Museum, in: Andrea Belloli (Hg.), Photography. Discovery and Invention, Malibu 1990, S. 31-46, hier S. 31.

2 Anonym, Royal Institution, in: The Literary Gazette and Journal of the Belles Lettres, Arts, Sciences, \&c., Nr. 1150, 2. Februar 1839, S. 74-75, hier S. 75. Siehe dazu: Wolf 2013.

3 Sherry Ortner, Is Female to Male as Nature Is to Culture?, in: Feminist Studies, Jg. 1, Bd. 2, 1972, S. 5-31. 
fähigkeit) der Natur nahegestellt und als Ergänzung des Mannes angesehen. Bovenschen betont zudem, dass "Natur“ oftmals als Projektionsfläche des zu Kontrollierenden gesehen und daher mit der Figur der Frau verknüpft wurde, die wie die Natur selbst „Objekt der männlichen Zugriffe und Beherrschung" sein sollte. ${ }^{4}$ Wie aus Studien Ann Berminghams und Carol Armstrongs zu entnehmen ist, wurde Natur zu Talbots Zeiten allgemein weiblich kodiert. ${ }^{5}$ Zudem galt die Zeichenkunst in der Zeit um 1840 als populäre weibliche Betätigungsform und hielt Einzug in das Erziehungsprogramm für Mädchen aus gehobenem Stand. Kunstbedarfshandlungen wie Ackermann \& Co. in London spezialisierten sich zunehmend auf eine weibliche Käuferschicht, wodurch das Medium der Zeichnung feminisiert wurde. In Bezug auf die Technik des Fotogramms bedeutet die Vergeschlechtlichung der Natur und ihre Determination als „Dame Nature“ und „drawing mistress“ aber auch, dass die zwei Gegenpole Natur und Kultur miteinander in Konkurrenz gesetzt wurden. Eine generative, weibliche Zeichenmeisterin sollte nach den Zielvorgaben eines sich ihrer bedienenden männlichen Wissenschaftlers handeln. Über diese stereotype Adressierung des Weiblichen konnten männliche Eigenschaften wie Genialität oder Schöpferkraft aber auch erst gewonnen werden. Andererseits wird aus dieser Subordination der Natur unter das Regelwerk der Kultur ein hierarchisches Gefälle innerhalb der Geschlechterordnung und damit eine zu dieser Zeit vorherrschende soziale Norm deutlich. Die Einbeziehung geschlechtsbezogener Metaphern wie jene der Zeichenmeisterin Natur stellt darüber hinaus eine innerhalb der Wissenschaften häufig anzutreffende Praxis der bildhaften Umschreibung komplexer oder abstrakter Verfahren dar, die als allgemeinverständliche und nicht weiter erklärungsbedürftige Vermittlungsmöglichkeit von wissenschaftlichen Erkenntnissen oder Techniken herangezogen werden konnte. ${ }^{6}$ Kameralos erstellte photogenische Zeichnungen, so wird zu zeigen sein, wurden anhand von Geschlechtskategorien sowie -charakterisierungen innerhalb und außerhalb des Wissenschaftsfeldes vergeschlechtlicht und somit gegenüber kamerabasierten Verfahren destabilisiert. Auf diese Weise standen Fotogramme für das „Andere“ der Fotografie, wodurch sie gleichermaßen der Verfestigung des fotografischen Kanons dienten.? Die Technik des Fotogramms kann insofern in ein vielschichtiges, ideologisch geprägtes Bezugssystem gesetzt werden, das im Rahmen dieses Kapitels noch näher erläutert werden wird.

4 Silvia Bovenschen, Die imaginierte Weiblichkeit. Exemplarische Untersuchungen zu kulturgeschichtlichen und literarischen Präsentationsformen des Weiblichen, Frankfurt am Main 2003, S. 32.

5 Bermingham 2000; Armstrong 2004.

6 Vgl. dazu: Tanja Paulitz, Mann und Maschine. Eine genealogische Wissenssoziologie des Ingenieurs und der modernen Technikwissenschaften, 1850-1930, Bielefeld 2012.

7 Vgl. dazu: Christina von Braun, Gender, Geschlecht und Geschichte, in: dies./Inge Stephan (Hg.), Gender-Studien. Eine Einführung, Stuttgart 2006, S. 10-51. 
Nach den einführenden Worten Faradays konnten sich an die 300 Gäste selbst ein Bild jener von der Natur erstellten Werke machen. ${ }^{8}$ Es handelte sich dabei um eine Auswahl photogenischer Zeichnungen Talbots aus den Jahren 1834 bis 1836, die neben einzelnen Kameraaufnahmen zahlreiche kameralose Fotografien von flachen Objekten wie Pflanzenblättern, Blumen und Spitzenmustern umfasste. ${ }^{9}$ In den darauf folgenden Tagen veröffentlichte der Herausgeber der Literary Gazette einen Brief Talbots, in dem dieser auf jene erste Verfahrenspräsentation Bezug nahm. Obwohl Talbot darin veranschlagt, dass er nur jene Bilder ausstellen konnte, die er zufällig in London bei sich hatte, gelang es ihm dennoch, ein breites Spektrum unterschiedlicher Exponate vorzulegen:

„Among them were pictures of flowers and leaves, a pattern of lace; figures taken from painted glass; a view of Venice copied from an engraving, some images formed by the Solar Microscope, viz. a slice of wood very highly magnified, exhibiting the pores of two kinds, one set much smaller than the other, and more numerous. Another Microscopic sketch, exhibiting the reticulations on the wing of an insect. Finally: various pictures, representing the architecture of my house in the country; all these made with the Camera Obscura in the summer of $1835 .{ }^{\text {" } 10}$

In Anbetracht der dargebotenen Bandbreite an Motiven und veranschlagten Verwendungsweisen geht Talbot indirekt auf den medialen wie funktionalen Unterschied zwischen kamerabasierter und kameraloser Fotografie ein. Wenngleich seinen Ausführungen zufolge die „bemerkenswerteste“ Anwendung dieser Technik im „Kopieren von Porträts entfernter Objekte“ liege, hebt er dagegen die Vorzüge der direkten Abdruckfotografie hervor:

„[...] but one perhaps more calculated for universal use is the power of depicting exact facsimiles of smaller objects which are in the vicinity of the operator, such as flowers, leaves, engravings, \&c, which may be accomplished with great facility, and often with a degree of rapidity that is almost marvellous. ${ }^{11}$

8 Siehe dazu: Schaaf 1990, S. 31; Wolf 2006, 2013.

$9 \mathrm{Zu}$ potentiellen Ausstellungsobjekten, siehe das Catalogue Raisonné Online-Projekt Larry Schaafs, Bodleian Libraries, University of Oxford: http://foxtalbot.bodleian.ox.ac.uk (2.3.2018).

10 Talbot 1839a, S. 74.

11 Talbot 1839a, S. 73. 
An dieser Stelle wird Talbots Differenzierung der beiden Medien - Fotografie und Fotogramm - deutlich ablesbar. ${ }^{12}$ Kameralose Fotografien erhalten in dieser Perspektivierung aufgrund ihrer einfachen und schnellen Herstellung eine universelle oder allgemeine Nutzbarkeit zugeschrieben. Nicht die Kamerafotografie sah Talbot also als das zukunftsträchtige Medium an. Entsprechend benannte er jene kameralos erstellten photogenischen Zeichnungen als „exakte Faksimiles“, „,ähnlich gemachte“ beziehungsweise naturgetreue Kopien. ${ }^{13}$ Talbot sah die grundlegende Bedeutung der Fotografie folglich im Kopieren flacher Objekte beziehungsweise in der drucktechnischen Vervielfältigung von Stichen. ${ }^{14}$ Mit der Bezeichnung „Faksimile“ setzte Talbot Fotogramme aber auch in ein mediales Konkurrenzverhältnis zu druckgrafischen Techniken wie beispielsweise der Lithografie. Anders als beim Holzschnitt oder Holzstich empfanden Zeitgenossen lithografisch erstellte Kopien von Zeichnungen aufgrund ihrer mechanischen Herstellungsbedingungen als „vollkommene Faksimiles“. ${ }^{15}$ Im Vergleich zu weiteren (manuellen) Reproduktionstechniken der Zeit wurden Lithografien Originalen gleichgesetzt, da sie „die Tatsache ihrer druckgraphischen Vermitteltheit im Bildresultat vergessen “ machten. ${ }^{16}$ Damit setzte die Vorstellung einer „Vervielfältigung des Originals als Original“17 ein, wodurch dem Begriff des Faksimiles

12 Auch in einem weiteren Bericht wird Talbots Verwunderung gegenüber dem Vorzug von kamerabasierten Bildern deutlich: „But perhaps the most curious application of this art is the one I am now about to relate [camera obscura pictures]. At least it is that which has appeared the most surprising to those who have examined my collection of pictures formed by solar light.“ Talbot 1980, S. 28. An anderer Stelle wiederum bezeugt er einen eindeutigen Vorzug der Kamerafotografie, siehe: Talbot, Photogenic Art, in: The Literary Gazette and Journal of the Belles Lettres, Arts, Sciences, \&c., 13. April 1839, S. 235-236.

13 Zum Lemma „Faksimile“ heißt es im „Lexikon des gesamten Buchwesens", hg. v. Severin Corsten, Stuttgart 1989, Bd. 2: „Faksimile, lat. „fac-simile“ - „,mach' es ähnlich“, die drucktechnische Wiedergabe einer unikalen Vorlage, d.h. einer Handschrift, eines Einzelblattes, unter Verzicht auf manuelle Eingriffe [...]“. Siehe dazu ebenfalls: Armstrong 1998, S. $145 \mathrm{ff}$.

14 Siehe dazu: Edwards 2006, S. 33ff. Vgl. dazu den Brief Talbots an Herschel vom 11. Februar 1839: „Although Daguerre is said to succeed admirably with the Camera, it does not follow that he can copy an engraving, a flower, or anything else that requires close contact.", online unter: http://foxtalbot.dmu.ac.uk (2.3.2018). Auch in einer Ausstellung in Birmingham im Zuge eines Treffens der British Association im August 1839 präsentierte Talbot unter dem Titel „Class I: Images obtained by the direct action of light, and of the same size with the objetcs" insgesamt 52 kameralose Fotografien, worunter sich 28 photogenische Zeichnungen botanischer Objekte befanden. Siehe dazu: Gail Buckland, Fox Talbot and the Invention of Photography, Boston 1980, S. 54-55.; Kap. 2, Anm. 46, 181

15 Helmut Krause, Geschichte der Lithographie. Spiegelwelt, gespiegelte Welt, Mannheim 2007, S. 24f. Zit. n. Ulfert Tschirner, Museum. Photographie und Reproduktion. Mediale Konstellationen im Untergrund des Germanischen Nationalmuseums, Bielefeld 2011.

16 Ernst Rebel, Faksimile und Mimesis. Studien zur deutschen Reproduktionsgrafik des 18. Jahrhunderts, Mittenwald 1981, S. 1.

17 Rebel 1981, S. 132. 


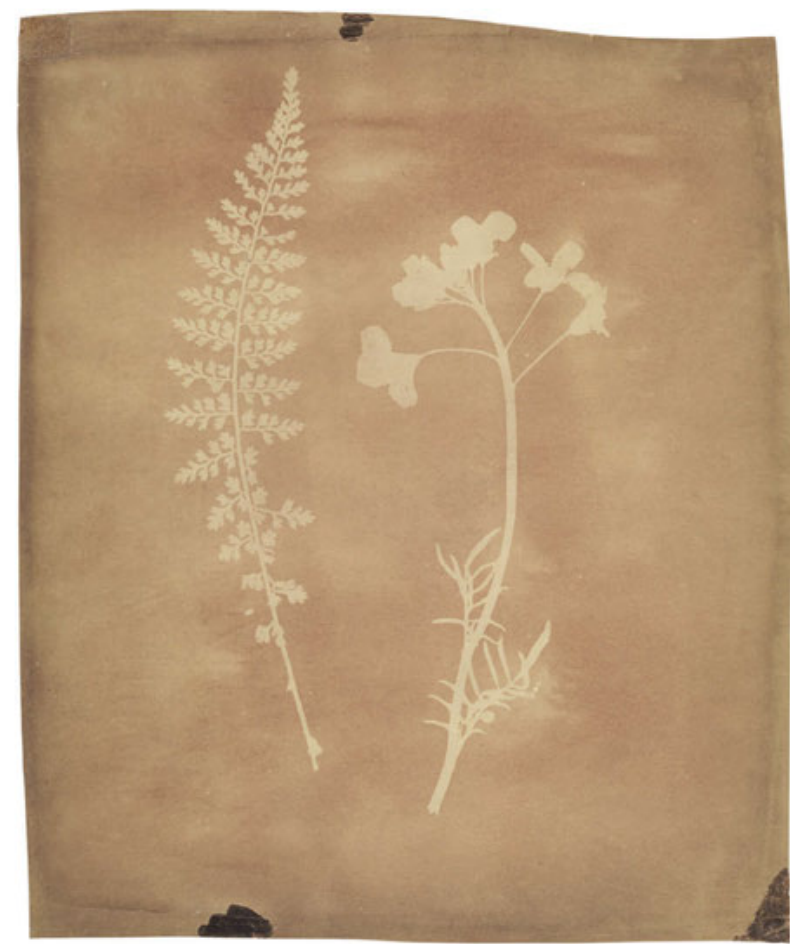

13 William Henry Fox Talbot, Asplenium Halleri, Grande Chartreuse 1821 - Cardamine Pratensis, Photogenic Drawing, Negativ, 20,6 × 17,1 cm, April 1839, The J. Paul Getty Museum, Los Angeles.

stärker als jenem der Kopie zu Beginn des 19. Jahrhunderts das Ideal der „visuellen Ununterscheidbarkeit" ${ }^{\text {"18 }}$ zukam. Talbot griff insofern eine aus dem Bereich der druckgrafischen Bildtechnik stammende Begrifflichkeit auf, um damit gleichsam die Vorteile aber auch fundamental unterschiedlichen Produktionsbedingungen photogenischer Zeichenkunst ins Feld zu führen. Insbesondere aber ist es der Aspekt der Ersetzungsleistung des Originalobjektes durch dessen photogenische Zeichnung, die keiner medialen beziehungsweise handwerklichen Übersetzungsleistung bedarf, welche Talbot an zahlreichen Stellen verhandelt. Talbots Verfahren kameraloser Fotografie kann somit in ein mediales Bezugssystem zur Reproduktionsgrafik und ihrer Verhandlungsweisen von Kopie und Faksimile gesetzt werden.

Anders verhielt es sich mit Aufnahmen, die mit Hilfe einer Camera obscura hergestellt wurden, wie aus seinem Werk The Pencil of Nature hervorgeht. Darin beschreibt 


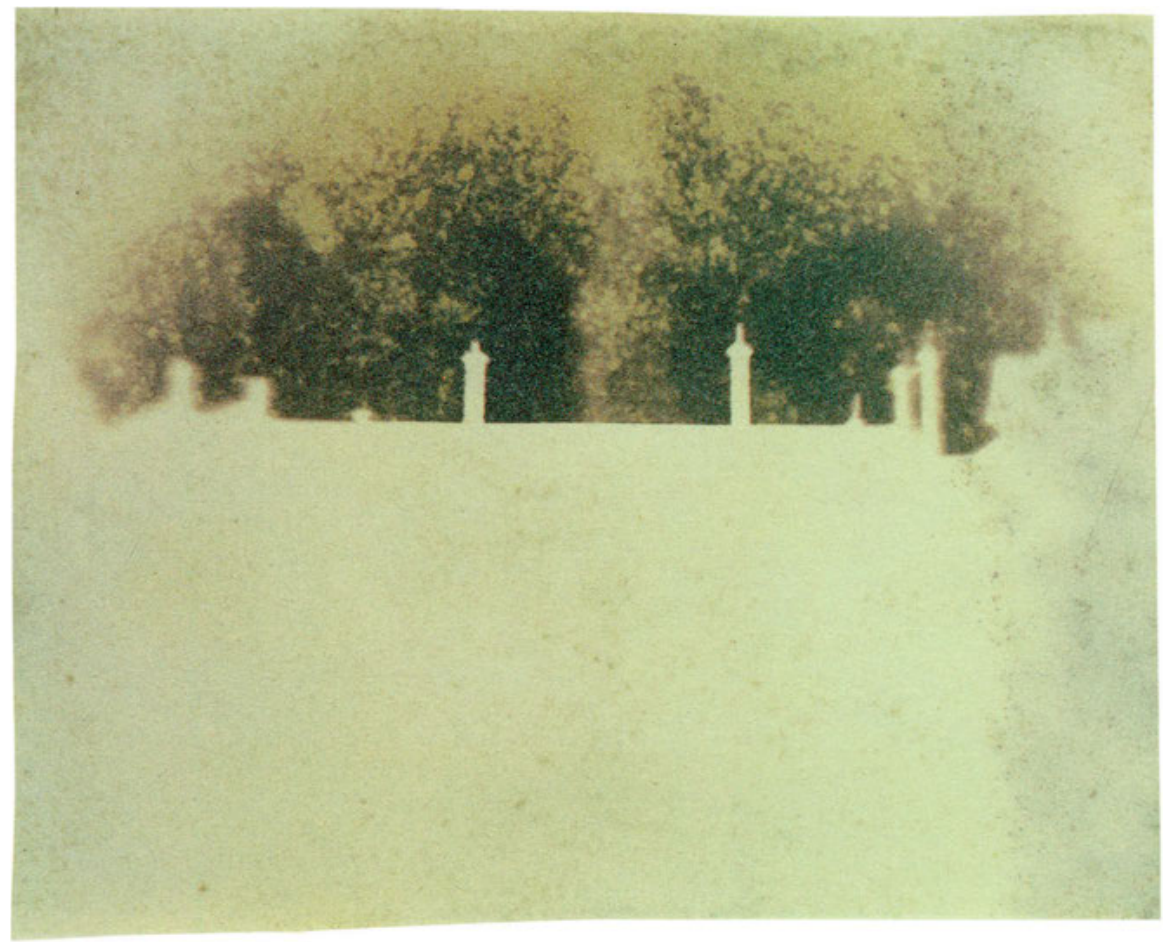

14 William Henry Fox Talbot, Dachlandschaft, Photogenic Drawing, Negativ, 9,3 ×11,6 cm, ca. 1839, Hans P. Kraus Jr., New York.

Talbot die fotochemische Reaktion auf das präparierte Papier in der Kamera rückblickend als zu schwach, um ein differenziertes Bild erzeugen zu können. „The outline of the roof and of the chimneys, \&c. against the sky was marked enough; but the details of the architecture were feeble, and the parts in shade were left either blank or nearly so. ${ }^{{ }^{19}}$ In der Gegenüberstellung von Abbildung 13 und Abbildung 14 lässt sich Talbots Zuschreibungspraxis verdeutlichen: Während die botanischen Pflanzenexemplare durch das Abdruckverfahren klar umrissen werden, zeigt sich in der Aufnahme einer Camera obscura lediglich eine schematische Dachkante mit darauf befindlichen Schornsteinen, wohingegen Details der Fassade ausgespart bleiben. Es kann daher gemutmaßt werden, dass Talbot zu jenem Zeitpunkt photogenischen Zeichnungen von flachen Objekten aufgrund ihrer Einfachheit, ihrer durch Kontakt hergestellten mimetischen Qualität sowie ihrer Reproduktionsmodalität im Format 1:1 universelle Bedeutung und somit Zukunftsträchtigkeit zusprach. Vor allem die attestierte 
Schlichtheit und verfahrenstechnische Verständlichkeit des Fotogramms wird im Laufe dieses Kapitels nochmals unter der Perspektive didaktischer Prämissen zur Sprache kommen.

In diesem am 2. Februar 1839 in der Literary Gazette publizierten Brief beschrieb Talbot allgemein die Technik und ihre Verwendungsmöglichkeiten, er verriet jedoch keine Verfahrensdetails. Für die allgemeine Leserschaft stellten die rein deskriptiven Ausführungen sicherlich eine Herausforderung dar. Um sein Verfahren dennoch verständlich zu machen, kennzeichnete Talbot es als „Kunst der photogenischen Zeichnung“. Gleichzeitig betonte er die Unterschiede und Vorteile seiner neuen Erfindung gegenüber manuellen künstlerischen Reproduktionstechniken. Die bildlichen Ergebnisse, die er als „specimens of this art“ und somit als Muster oder Proben einer neuen Kunst bezeichnete, seien grundlegend von jenen mit Hilfe einer Camera obscura oder Camera lucida gezeichneten Bildern zu differenzieren. Talbot dazu: „From all these prior ones the present invention differs totally in this respect that, by means of this contrivance, it is not the artist who makes the picture, but the picture which makes itself. ${ }^{“ 20}$ Es entstanden also Bilder, die aufgrund ihrer Selbsttätigkeit von allen bisherigen künstlerischen Bildproduktionen zu differenzieren seien. Nicht ein Künstler sei somit für die Anfertigung photogenischer Zeichnungen verantwortlich, sondern die Bilder erzeugten sich von selbst. Andererseits nennt er die Abbildung seines Landsitzes Lacock Abbey, die erste Aufzeichnung eines Hauses und damit eines Objektes, welches „sein eigenes Porträt gemalt habe“ “. ${ }^{21}$ Dieser sicherlich auch für zeitgenössische Leser/innen Erstaunen erregenden Formulierung, fügt Talbot Folgendes hinzu: „A person unacquainted with the process, if told that nothing of all this was executed by the hand, must imagine that one has at one's call the Genius of Aladdin's Lamp. And indeed, it may almost be said, that this is something of the same kind. It is a little bit of magic realized: - of natural magic." ${ }^{\text {"22 }}$ Mit der Kennzeichnung als autopoietisches Bildverfahren rückt Talbot es in den Kontext von Magie und damit, so möchte ich behaupten, in den Bezugsrahmen der „nützlichen Belustigung“ wie der um 1800 virulenten Silbernitratexperimente..$^{23}$ Es handelt sich gemäß Talbots Darlegungen somit um eine Methode der „natürlichen Magie“, die sich der „Kräfte der Natur“ zu bedienen weiß. ${ }^{24}$

In einem weiteren Bericht, der am 31. Januar 1839 vor der Royal Society verlesen und im Eigenverlag publiziert wurde, verdeutlicht Talbot den Wert seiner kameralos hergestellten Bilder abermals. Im dritten Paragraf seiner Ausführungen kommt er

Talbot 1839a, S. 73.

Ebenda, S. 74.

Ebenda.

Siehe dazu: Nickel 2003.

Talbot 1839a, S. 74. 


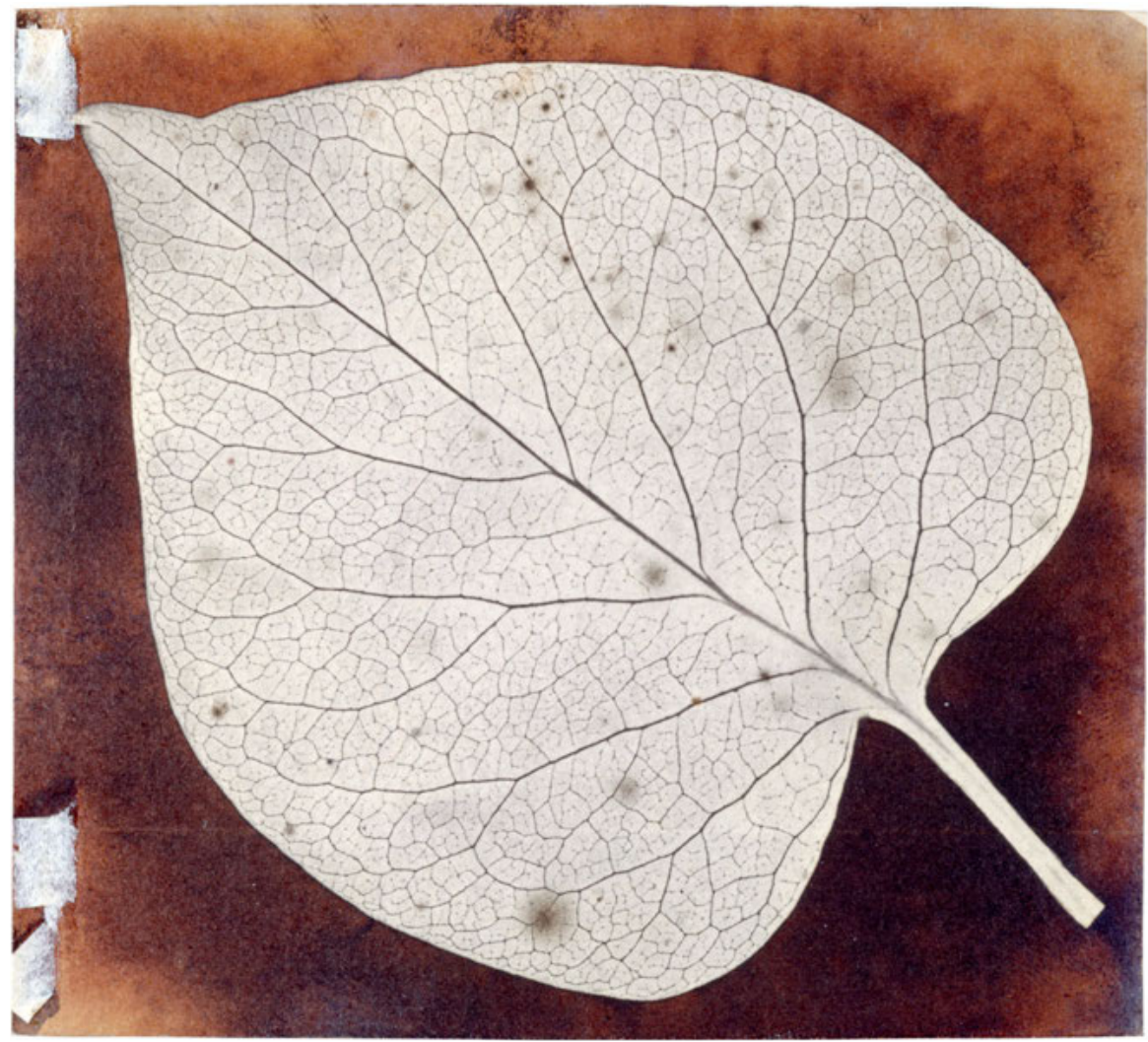

15 William Henry Fox Talbot, Pflanzenblatt, Photogenic Drawing, Negativ, 8,9 × 8,6 cm, ca. 1840, Victoria \& Albert Museum, London.

auf die ersten Versuche zu sprechen, jenen „natürlichen Prozess“ für Bildgebungszwecke zu nutzen: „The first kind of objects which I attempted to copy by this process were flowers and leaves, either fresh or selected from my herbarium. These it renders with the utmost truth and fidelity, exhibiting even the venation of the leaves, the minute hairs that clothe the plant, \&c. \&c. " ${ }^{25}$ Eines dieser Beispiele ist in Abbildung 15 zu sehen, das ein Pflanzenblatt mit feinster Nervatur zeigt. Zur Erzeugung botanischer Abbildungen bediente sich Talbot nicht nur frischer Pflanzenteile, die er aller Wahrscheinlichkeit nach aus seinem eigenen Garten in Lacock Abbey bezog, sondern auch getrockneter Exemplare seines persönlichen Herbariums. So lag es ihm auch nicht fern, diese Technik dem reisenden Naturforscher ans Herz zu legen, der den aufwendigen Prozess des Trocknens, Sammelns und Transportierens durch photoge- 
nische Zeichnungen ersetzten könne: „He [the naturalist] would only have to take a sheet of this paper, throw the image upon it, and replace it in his portfolio." ${ }^{\text {26 }}$ Laut Talbot konnten Naturobjekte durch die derart ermittelten Bilder nicht nur vollständig ersetzt werden; photogenische Abbildungen würden zudem den zeitaufwendigen Prozess der Handzeichnung unnötig machen. Aufgrund der Darstellung feinster Details wie Pflanzenaderung oder -behaarung erwiesen sich jene Bilder für viele Naturwissenschaftler/innen, wie noch zu zeigen sein wird, als naturgetreue Reproduktionen. Auch noch einige Jahre später widmete Talbot in The Pencil of Nature einem kameralos ermittelten Pflanzenblatt ein gesondertes Kapitel. Darin weist er auf die „natürliche Größe“ des repräsentierten Objektes hin, welches in einem zur Kamerafotografie vergleichsweise „viel einfacheren Prozess“ hergestellt werde. ${ }^{27}$ In diesem einer Werbeschrift nahekommenden Werk lässt sich eine bereits veränderte Bedeutungszuschreibung der beiden fotografischen Methoden ablesen, indem Talbot sein Werk fast zur Gänze mit Kameraaufnahmen versieht.

\section{Photogenische Zeichnungen und Botanik}

Kameralose Fotografien stehen am Beginn Talbots fotochemischer Experimente und spielen als eigenständige Bildkategorie, wie noch zu zeigen sein wird, eine fundamentale Rolle in der theoretischen Auseinandersetzung mit dem Medium Fotografie. Zur Herstellung derselben präparierte Talbot Schreibpapier mit herkömmlichem Kochsalz und bepinselte es nach der Trocknung mit fotosensiblem Silbernitrat. Im Anschluss daran legte er flache Gegenstände wie Spitzenmuster, Blätter, Federn und dergleichen auf die lichtempfindliche Schicht. Mit Hilfe einer Glasscheibe presste er die Objekte am Papier flach und setzte beides anschließend dem Sonnenlicht aus. Je nach Opazität, Transluzenz oder Transparenz der Gegenstände verfärbte sich die Trägerschicht proportional zur Intensität des Lichteinfalls durch die Reduktion der Silberionen zu Silber, wohingegen die vollständig abgedeckten Stellen die ursprüngliche Farbe des Papiers beibehielten. Das nicht reduzierte Silbersalz konnte Talbot durch das Fixiermittel Natriumthiosulfat wasserlöslich machen und auswaschen. ${ }^{28} \mathrm{Nach}$ der Fixierung zeigte sich das bildliche Resultat in Form von hellen Schatten gegenüber der belichteten, zumeist dunkleren Fläche im Format 1:1, das als ein Negativ zu bezeichnen ist. Je nach Lichtdurchlässigkeit lassen sich vereinzelt Binnendetails erkennen, zuvorderst jedoch ermöglicht die den Gegenstand konturierende Linie dessen Identifikation.

Ebenda, S. 26.

Talbot 1844-1846 (2011), o.S.

Eine chemische Beschreibung Talbots frühester Versuche mit Fotogrammen findet sich bei: Ware 1994, 2008. 
Im Falle von Talbots botanischen Fotogrammen, bei der eine Pflanze in direkten Kontakt mit der fotosensiblen Trägerschicht tritt, um unter Lichteinfluss ein Bild zu hinterlassen, liegt der Vergleich mit der Technik des Naturselbstdrucks nahe. ${ }^{29}$ Wie bereits erörtert, wurde zur Herstellung eines solchen Blattes eine Pflanze mit Ruß oder Druckerschwärze bedeckt, um anschließend unter Druckausübung einen Abzug auf Papier zu erhalten. Als geübtem Botaniker dürfte Talbot die Technik des Naturselbstdrucks bekannt gewesen sein. Insbesondere zu seiner Zeit galt das „Botanisieren" als beliebte Freizeitbeschäftigung, welche auch in seinem familiären Umfeld praktiziert wurde. ${ }^{30}$ Bereits in jungen Jahren galt sein hauptsächliches Interesse neben der Chemie vor allem der Botanik. ${ }^{31}$ Während seiner Schulzeit in Harrow erstellte Talbot in den Jahren 1814-1815 gemeinsam mit einem Mitschüler eine Übersicht mit dem Titel Plants Indigenous to Harrow: Flora Haroviensis, die heute im Archiv der Harrow School aufbewahrt wird. ${ }^{32}$ Den Einstieg in die Pflanzentaxonomie erhielt er nach dem Vorbild William Hookers über die Identifikation von Moospflanzen, einer Pflanzengattung, die nicht nur als schwer bestimmbar galt, sondern lediglich in den für Expeditionen ungünstigen Wintermonaten zur Blüte kam. ${ }^{33} 1826$ unternahm Talbot eine größere Forschungsreise zu den Ionischen Inseln, im Zuge derer er mehrere neue Pflanzenspezies ausmachen konnte. ${ }^{34}$ In Lacock Abbey, ab 1827 Wohnsitz der Familie, legte er einen botanischen Garten und ein Gewächshaus mit heimischen und exotischen Pflanzen an, die ihm als Materialfundus für sein Herbarium und seine photogenischen Zeichnungen dienten. ${ }^{35}$ Zudem stand er in regem Austausch und Briefkontakt mit namhaften Botanikern seiner Zeit, wie etwa Lewis Weston Dillwyn, James

29 Siehe dazu: Steidl 2012.

30 Arnold 1977, S. 255.

31 Vgl. Arnold 1977, S. 34-35, 254-266; Schaaf 1992, S. 12; Douglas Nickel, Nature's Supernaturalism. William Henry Fox Talbot and Botanical Illustration, in: Kathleen Howe (Hg.), Intersections. Lithography, Photography, and the Traditions of Printmaking, Albuquerque 1998, S. 15-23; Russel Roberts, „The Order of Nature“, in: Coleman 2001, S. 367-368; Anne Secord, Talbot's First Lens. Botanical Vision as an Exact Science, in: Brusius/Dean/Ramalingam 2013, S. 41-66.

32 Es handelt sich hierbei um einzelne, lose Blätter in Form einer Liste, die Talbot gemeinsam mit seinem Schulkollegen Walter Calverley Trevelyan erstellte.

33 Siehe dazu: Mirjam Brusius, Beyond Photography. An Introduction to William Henry Fox Talbot's Notebooks in the Talbot Collection at the British Library, in: eBLj 2010, Article 14, online unter: http://www.bl.uk/eblj/2010articles/pdf/ebljarticle142010.pdf (5.3.2018); Secord 2013.

34 Vgl. Graham Smith, Talbot and Botany. The Bertoloni Album, in: History of Photography, Jg. 17, Nr. 1, 1993, S. 33-48, hier S. 34.

35 Talbots Garten in Lacock Abbey wurde 1999 durch den National Trust wiederhergestellt. Zumeist zog Talbot Pflanzen aus Samen und Knollen heran, die er entweder auf seinen Reisen sammelte, im Austausch mit anderen Botanikern zugesandt bekam oder über den Handel bezog. Siehe dazu: Arnold 1977, S. 260f.; Katie Fretwell, Fox Talbot's Botanic Garden, in: Apollo, 


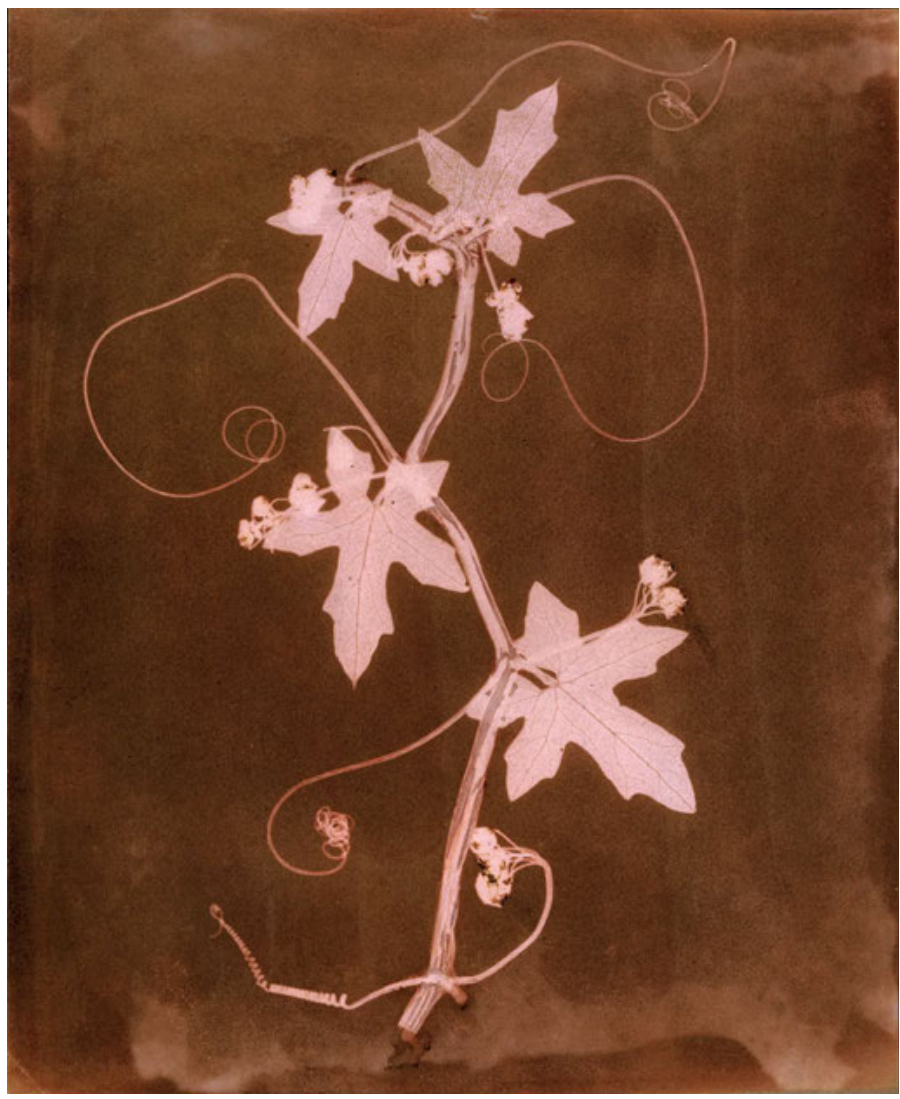

16 William Henry Fox Talbot, Botanische Studie, Photogenic Drawing, Negativ, $22,4 \times 18,3 \mathrm{~cm}$, ca. 1835 , Victoria \& Albert Museum, London.

Dalton, William Hooker, Antonio Bertoloni, Carl Friedrich Philipp von Martius und John Lindley. ${ }^{36} 1829$ wurde Talbot schließlich zum ordentlichen Mitglied der Linnean Society gewählt, ein deutliches Zeichen der Anerkennung seiner Leistungen auf dem Gebiet. Auch ab ca. 1850/51 beschäftigte er sich mit der Vervielfältigung botanischer Abdruckfotografien im Verfahren des „Photoglyphic Engraving“. 37

Vergleicht man Talbots photogenische Zeichnung einer weißen Zaunrübe mit einem Naturselbstdruck der gleichen Spezies, angefertigt von Mitgliedern der Regensburgischen Botanischen Gesellschaft (Abb. 16 und 17), lässt sich feststellen, dass auf

Jg. 159, Nr. 506, 2004, S. 25-28; Mirjam Brusius, Fotografie und museales Wissen. William Henry Fox Talbot, das Altertum und die Absenz der Fotografie, Berlin 2015. Talbots Herbarien befinden sich heute in der British Library sowie in der Bodleian Library.

36 Siehe dazu: Smith 1993, S. 34ff.; Siegel 2014.

37 Arnold 1977, S. 267ff.; Schaaf 1985, 2003; Secord 2013. 
17 Bryonia Alba, Naturselbstdruck, aus: David Heinrich Hoppe und Johann Mayr, Ectypa Plantarum Ratisbonensium, oder Abdrücke derjenigen Pflanzen, welche um Regensburg wild wachsen, Erstes Hundert, Regensburg 1781.

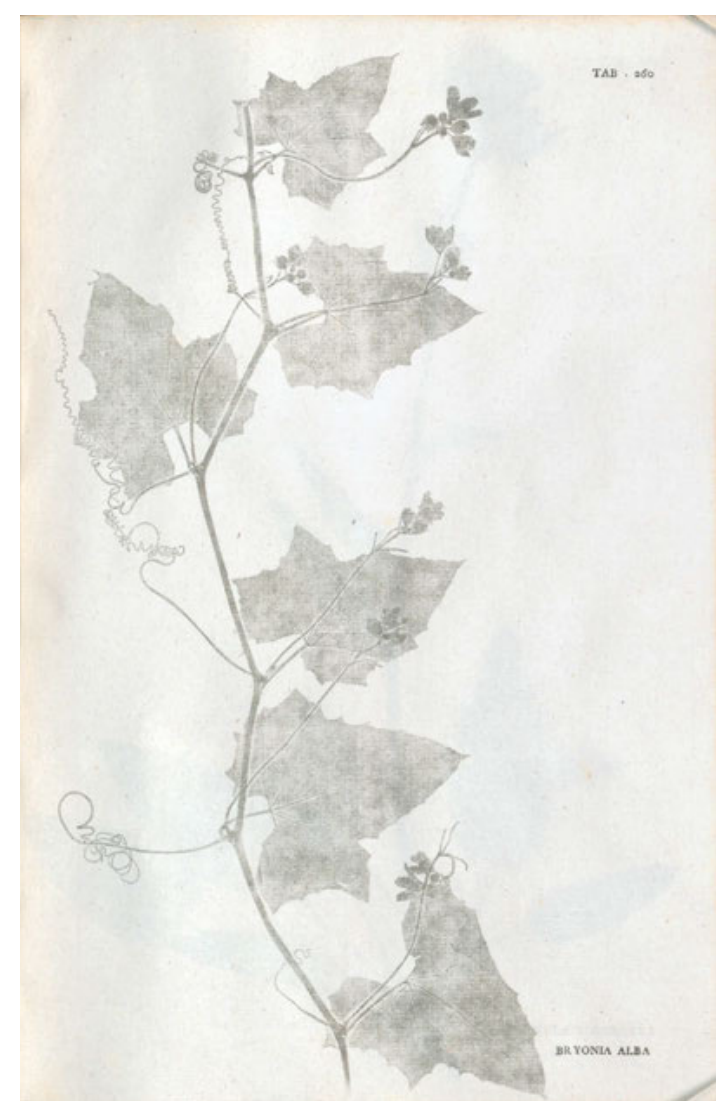

beiden Abbildungen die begrenzende Konturenlinie wie die Licht- und Schattenwirkung gegenstandsbezeichnend wirken. Im Falle von Talbots photogenischer Zeichnung handelt es sich bei der Art der Darstellung um ein Negativ, wohingegen das in der Technik des Naturselbstdrucks hergestellte Blatt im Vergleich zum Fotogramm umgekehrte Licht- und Schattenwerte aufweist. Leitendes Argument für die Verwendung des Naturselbstdrucks war die von den Pflanzen selbst abgenommene und von jeglicher künstlerischer Handfertigkeit losgelöste Abbildung, womit der Akzent auf der mechanischen Herstellungsweise beziehungsweise auf der Naturtreue der Darstellung lag. Obwohl es sich um zwei voneinander zu differenzierende Techniken handelt, kann dennoch gemutmaßt werden, dass Talbot das Verfahren des Naturselbstdrucks als Modell zur Herstellung kameraloser Pflanzenfotografien gewählt hatte. Beide Techniken bedienen sich eines Naturobjektes als Matrize, um direkte Abdrücke zu erzeugen. Sowohl der Naturselbstdruck als auch die photogenische Zeichnung haben zum Ziel, botanisches Sammlungsgut auf einfache und ökonomische Weise 
abzubilden und die Bilder zu vervielfältigen..$^{38}$ Zudem wird beiden Verfahren das Potenzial zugeschrieben, für jedermann durchführbar zu sein. In diesem Zusammenhang ist Talbots Prognose eines ,universellen“ Gebrauchs photogenischer Zeichnungen zu nennen, die keine kostenintensive Apparatur notwendig machten und an bekannte sowie populäre Techniken wie jene des Naturselbstdrucks anschlossen. Rezeptionsästhetisch betrachtet kommt den durch direkte Berührung ermittelten „Kontaktbildern“ ein spezifischer Bildwert zu, der eine innerbildliche Präsenz wie eine Repräsentation des Objektes vermittelt. Diese „Vergegenwärtigung“ im Bild wird durch das Wissen um die Herstellungsbedingungen, den teilweise stark akzentuierten mimetischen Effekt sowie durch die Größengleichheit von Objekt und Bild erzeugt. Genannte Charakteristika stehen im starken Gegensatz zur Kamerafotografie. Es soll daher im Laufe dieses Kapitels versucht werden, spezifische Beschreibungen des Fotogramms jenen der Kamerafotografie gegenüberzustellen.

Zur Herstellung botanischer Fotogramme verwendete Talbot getrocknetes oder frisches Pflanzenmaterial und arrangierte es einem Herbariumblatt gleich bildmittig auf der Trägerschicht. Er bediente sich also nicht nur desselben Materials, sondern auch eines den Pflanzeninventarien ähnlichen Anordnungsschemas. Das Sammeln und Trocknen von Naturobjekten, das Arrangieren und Fixieren von Pflanzenproben am Blatt, ihr anschließendes Einfügen in Herbarien, der Austausch von Pflanzenproben sowie die beständige Suche nach mechanischen Vervielfältigungsmöglichkeiten stellten allesamt Praktiken der Botanik dar. Talbots vegetabile Fotogramme beziehungsweise Wedgwoods und Davys ephemere Abbildungen von Insektenflügeln sind zudem im Kontext einer Sammlungs- und Austauschpraxis der Zeit der Aufklärung zu sehen, in deren Rahmen getrocknete Pflanzen, präparierte Insekten und Anderes in Naturalienkabinetten systematisch aufbewahrt wurden. Vor allem das mit Hilfe des Fotogramms ermöglichte Anordnungsschema auf dem Papier und sein Darstellungspotenzial werden im folgenden Kapitel am Beispiel Anna Atkins' und Johann Carl Enslens näher erörtert.

Die Bedeutung, die Talbot kameralosen Fotografien botanischer Objekte einräumte, lässt sich auch an seinem Engagement kurz nach der öffentlichen Bekanntgabe seiner Erfindung bemessen. An den deutschen Botaniker Carl Friedrich Philipp von Martius sandte er eine Kopie seiner in der Zeitschrift The Athenaeum veröffentlichten Schrift Some Account of the Art of Photogenic Drawing mit der Bitte die darin ent-

38 Zu zeitgenössischen Reproduktionsverfahren in Bezug auf die Fotografie: Frank Heidtmann, Wie das Foto ins Buch kam, Berlin 1984; Trevor Fawcett, Graphic versus Photographic in the Nineteenth-Century Reproduction, in: Art History, Jg. 9, Bd. 2, 1986, S. 185-212. Für die Botanik: Wilfried Blunt/William Stearn, The Art of Botanical Illustration, Woodbridge 2000. Allgemein: Geoffrey Wakeman, Victorian Book Illustration. The Technical Revolution, Newton Abbot 1973. 
haltenen Verfahrensangaben an die Bayerische Akademie der Wissenschaften weiterzutragen, da diese „kleine Entdeckung“, so Talbot, „den Naturforschern und vorzuglich den Botanikern vortheilhaft seyn“ wird. ${ }^{39}$ Im Zuge der Vorbereitungen der Antarktisexpedition Kapitän James Clark Ross' 1839 erklärte Talbot sich bereit, die daran beteiligten Naturforscher Robert McCormick sowie Hookers Sohn Joseph Hooker in der photogenischen Zeichenkunst zu schulen, damit diese botanische Objekte auf hoher See fixieren konnten. Und obwohl sich die dafür notwendigen Apparaturen später an Bord der Erebus ${ }^{40}$ befanden und McCormick Talbots Verfahren kameraloser Fotografie als , art which promises to be of incalculable value“ bezeichnete, das besonders geeignet wäre, die „evanescent forms“ mariner Algenpflanzen darzustellen, konnten aufgrund ungeklärter Umstände schlussendlich keine Fotografien oder Fotogramme an Bord hergestellt werden. ${ }^{41}$ Auch anlässlich der 1847 durchgeführten Indienexpedition Joseph Hookers hielt man sich an den botanischen Usus, exotische Pflanzen in Form von Zeichnungen festzuhalten - und dies obwohl Talbot versuchte, sein Verfahren für reisende Naturwissenschaftler zu vereinfachen. ${ }^{42}$

Im Austausch mit führenden Botanikern seiner Zeit bestand sein Ziel zudem in der kollektiven Herausgabe botanischer Werke mit photogenischen Zeichnungen. An Antonio Bertoloni, einen renommierten italienischen Botaniker, mit dem Talbot bereits seit 1826 in regem Austausch stand, sandte er wenige Monate nach der ersten Verlautbarung Proben seines neuen Verfahrens, um ihn von den Potenzialen dieser neuen Illustrationstechnik zu überzeugen..$^{43}$ Bertoloni selbst war zu dieser Zeit mit

39 Brief Talbot an Carl Friedrich Philipp von Martius, 9. Februar 1839, online unter: http:// foxtalbot.dmu.ac.uk (9.2.2018). Nach einem weiteren Briefaustausch sandte er von Martius 1842 photogenische Zeichnungen botanischer Objekte, die nach wie vor in der Akademie der Wissenschaften verwahrt werden. Siehe dazu: Siegel 2014, S. 138.

40 Joseph Hooker erwähnt dies 1846 in einem Vortrag vor der Royal Institution of South Wales, siehe dazu: Glenn Stein, Photography Comes to the Polar Regions - Almost, online unter: http://www.antarctic-circle.org/stein.htm (3.3.2018).

41 Brief McCormick an Talbot, 31. Juli 1839, online unter: http://foxtalbot.dmu.ac.uk (3.3.2018).

42 Talbot schlug hierfür bspw. die Verwendung von vorpräpariertem Papier, einem Kopierrahmen sowie einem einfachen Auswaschvorgang vor. Vgl. dazu den Brief Talbots an William Hooker, 21. Dezember 1847, online unter: http://foxtalbot.dmu.ac.uk (3.3.2018).

43 Diese Lichtbilder werden heute im Metropolitan Museum of Art, New York gemeinsam mit einzelnen Briefen aus dem Briefverkehr Talbots, seines Onkels, William Thomas Fox Strangways sowie Bertolonis, in einem Album mit dem Prägestempel „Album di disegni fotogenici“ verwahrt. Des Weiteren ließ Talbot Bertoloni Exemplare seiner Schrift "Some Account" zukommen, die in italienischen Medien erörtert wurde. Vgl. dazu: Malcom Daniel, L'Album Bertoloni, in: Giuseppina Benassati/Andrea Emiliani (Hg.), Fotografia \& Fotografi a Bologna, 1839-1900, Ausst.-Kat. Bologna 1992, S. 73-78; Smith 1993; Beth Saunders, The Bertoloni Album. Rethinking Photography's National Identity, in: Sheehan/Zervigón 2015, S. 145-156. 


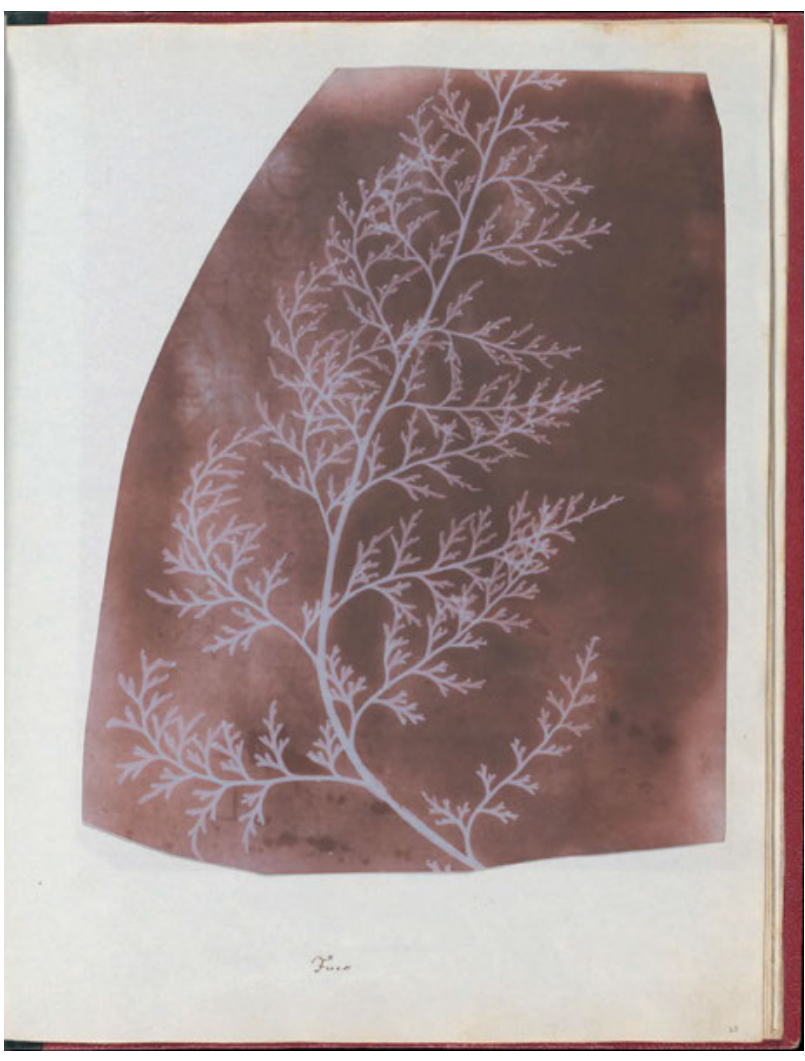

18 William Henry Fox Talbot, Fuco, Photogenic Drawing, Negativ, $22 \times 17,5 \mathrm{~cm}, 1839$, aus: Album di disegni fotogenici, The Metropolitan Museum of Art, New York.

den Vorbereitungsarbeiten seines zehnbändigen Werkes Flora italica beschäftigt. ${ }^{44}$ Zwischen Juni 1839 und Juni 1840 schnürte Talbot fünf Päckchen mit insgesamt sechsunddreißig Fotografien, die er seinem Kollegen in Italien zukommen ließ. Unter den versandten Abbildungen befanden sich fünfzehn kameralose Fotografien botanischer Objekte, die restlichen Aufnahmen (mit und ohne Kamera) sollten dem Naturwissenschaftler die Nützlichkeit und Präzision dieser neuen Technik veranschaulichen. In einem ersten Brief, dem Talbot acht photogenische Zeichnungen beilegte, erklärte er mit voller Überzeugung, „Je crois que ce nouvel art de mon invention sera d'un grand sécours aux Botanistes“, um im Postskriptum direkt auf die mögliche Verwendbarkeit eines der beigelegten Fotogramme für Bertolonis Atlantenwerk einzugehen. ${ }^{45}$ In einem weiteren Brief bezieht sich Talbot auf die mediale

44 Antonius Bertoloni, Flora italica. Sistens plantas in Italia et in insulis circumstantibus sponte nascentes, Bononiae 1833-1854.

45 Brief Talbot an Bertoloni, Juni 1839, online unter: http://foxtalbot.dmu.ac.uk/ (5.3.2018). 
19 William Henry Fox Talbot, Cordella o Nastro a velo, Photogenic Drawing, Negativ, $21,6 \times 18 \mathrm{~cm}$, 1839, aus: Album di disegni fotogenici, The Metropolitan Museum of Art, New York.

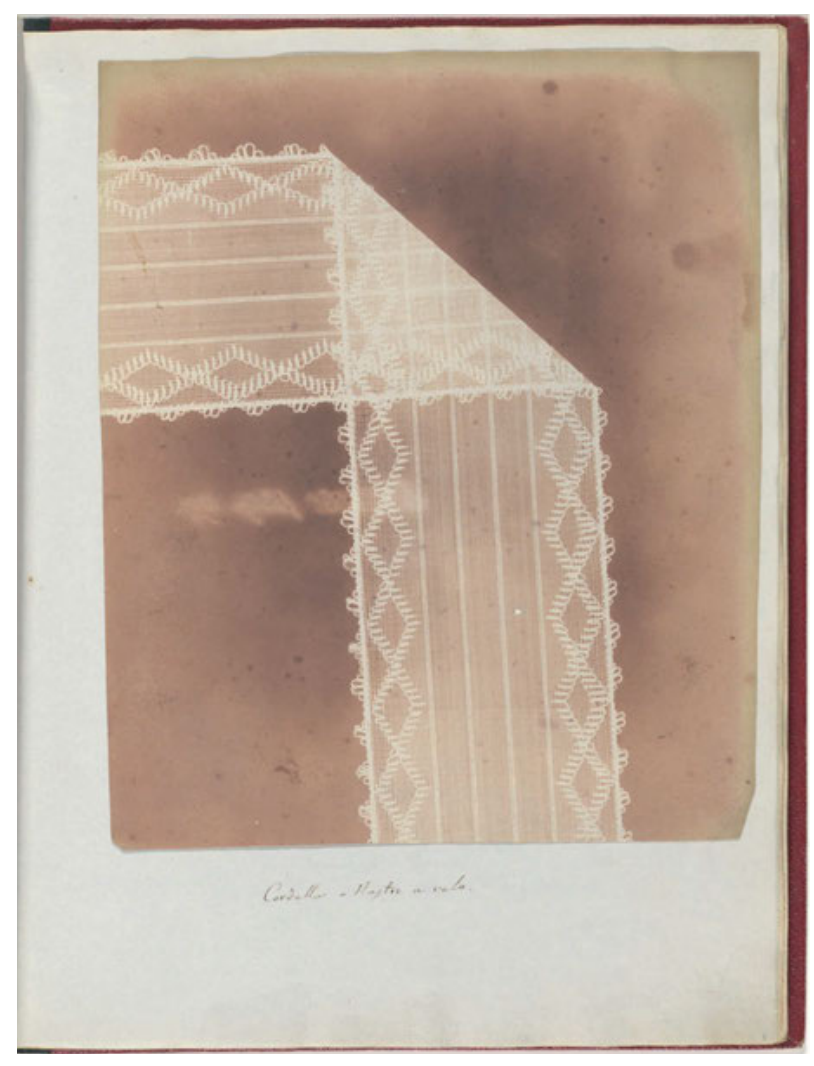

Funktionsweise seiner Kontaktkopien, welche kleinste Details zur Anschauung bringen konnten. Am Beispiel der beigefügten Abbildungen einer Gräserart beziehungsweise eines Spitzenmusters vermerkt er: „Puis il y a une Graminée et un morceau de dentelle, et un autre de crêpe, grandeur naturelle, pour en montrer combien l'image est nettement dessiné. ${ }^{{ }^{46}}$ Talbot hebt damit die Möglichkeit seines Verfahrens hervor, Objekte wie Pflanzen und Spitzenmuster im Format 1:1 zu visualisieren, aber auch den Detailreichtum sowie die erzielbare Schärfe und Präzision der Darstellungen. Eines der versandten botanischen Exemplare, die Talbot zur Abbildung brachte, war ein durch Bertoloni mit „Fuco“ betiteltes Blatt (Abb. 18). Darauf hebt sich von einem dunkelbraun-violetten Untergrund die Darstellung einer Algenpflanze ab, die sich durch eine stark umrissene Konturenlinie auszeichnet und kaum wahrnehmbare Details wie jene der Pflanzenaderung sichtbar macht. Zudem weist diese photogenische Zeichnung eine unregelmäßige Schnittkante auf, die sowohl der Krümmung 
der Algenpflanze folgt wie auch der Größe des Albums angepasst erscheint. Abbildung 19 zeigt ein an Bertoloni versandtes Blatt mit dem Abdruck eines Spitzenbandes, das Talbot vor der Belichtung im rechten Winkel auf dem Papier drapiert hatte. Dadurch generierte er eine Überschneidungsfläche, die den mimetischen Effekt noch verstärkt, da sich selbst in der doppelt übereinander gelegten Stoffschicht einzelne Strukturen klar voneinander differenzieren. Trotz Talbots Bemühungen um eine gemeinsame Veröffentlichung kam dieses ambitionierte Projekt jedoch nicht zustande.

1839 sandte er ähnliche Proben seiner photogenischen Zeichnungen auch an den renommierten Botaniker und Direktor der Botanical Gardens in Kew Sir William Jackson Hooker. ${ }^{47}$ Bereits im März 1839 schrieb Talbot an Hooker: „What do you think of undertaking a work in conjunction with me, on the plants of Britain, or any other plants, with photographic plates, 100 copies to be struck off, or whatever one may call it, taken off, the objects. ${ }^{\text {"48 }}$ Hooker hegte jedoch Zweifel ob der Verwendbarkeit dieser von den Pflanzen „abgenommenen“ Bilder als adäquates botanisches Illustrationsmittel. So vermerkte er in seinem Dankesbrief:

„I am extremely obliged to you for your kindness in sending me the specimens of photogenic drawing. They are very curious and ingenious. [...] Plants should be represented on paper, either by outline or with the shadows of the flower (which of course express shape) distinctly marked. Your beautiful Campanula hederacea was very pretty as to general effect - but it did not express the swelling of the flower, nor the calyx, nor the veins of the leaves distinctly. When this can be accomplished, as no doubt it will, it will surely become available for the publication of good figures of plants." ${ }^{\text {"49 }}$

Eine wissenschaftliche Zeichnung botanischer Objekte sollte laut Hooker entweder in Umrisslinienzeichnung oder durch eine formgebende Schattierung ausgeführt werden. Beide Abbildungsarten hatten die Aufgabe, unterschiedliche Teile und strukturelle Qualitäten der jeweiligen Spezies voneinander differenziert zu veranschaulichen. Als ehemaliger Professor für Botanik an der Universität Glasgow und botanischer Illustrator hielt Hooker unter anderem Einführungsvorlesungen, die durch selbst angefertigte Kreidezeichnungen an der Tafel und Wandbilder illustriert wurden. Zudem publizierte Hooker 1822 ein in Umrisszeichnungen gehaltenes Werk, um Grundkennt-

47 Siehe dazu: Nickel 1998; Walter Lack, Photographie und Botanik. Die Anfänge, in: Bildwelten des Wissens, Bd. 1,2 (Oberflächen der Theorie), Berlin 2003, S. 86-94, S. 86-94.

48 Brief Talbot an Hooker, 26. März 1839, online unter: http://foxtalbot.dmu.ac.uk (5.3.2018).

49 Brief Hooker an Talbot, 21. Juni 1839, online unter: http://foxtalbot.dmu.ac.at (5.3.2018). Das Bild der Campanula hederacea ist heute nicht mehr erhalten. 
nisse der Botanik zu vermitteln. ${ }^{50}$ Dabei stand für Hooker die Visualisierung charakteristischer Details im Vordergrund, die den Studierenden helfen sollte relevante Merkmale besser zu memorisieren. Was eine botanische Illustration leisten musste, war nicht die Darstellung der Pflanze in ihrer individuellen, sondern vielmehr in ihrer charakteristischen Form. ${ }^{51}$ Die Aufgabe eines Zeichners lag somit in der Absonderung nebensächlicher Details und in der Hervorhebung beziehungsweise Vergrößerung essentieller Bestandteile, um botanische Exemplare idealtypisch zu repräsentieren. Zur hinreichenden Identifizierung einer Pflanzenart wurden zudem unterschiedliche Stadien im Pflanzenwachstum - Knospe, Blüte, Samenstand - zusammengeführt und durch das Medium der Zeichnung visualisiert. Wie Nickelsen herausarbeiten konnte, erfüllte die botanische Handzeichnung nicht nur klassifikatorische Aufgaben, sondern sie diente auch als Beobachtungsevidenz beziehungsweise Referenz für wissenschaftliche Debatten. ${ }^{52}$ Auch wenn Talbots photogenische Zeichnungen - je nach Lichtdurchlässigkeit der Objekte - in der Lage waren, jene von Hooker angesprochenen Partikularitäten wie Knospen, Blüten oder Pflanzennervatur differenziert darzustellen, bestand ihre generelle Bildleistung in der einheitlichen Abbildung der Umrisslinie einer Pflanze ohne erkennbare Binnenzeichnung.

Am Beispiel einer auf den 13. November 1838 datierten photogenischen Zeichnung Talbots von einer Astrantia Major (Große Sterndolde), sowie einer Lithografie des deutschen Botanikers Albert Gottfried Dietrich aus seinem Werk Flora Regni Borussici von 1843 sollen die an eine botanische Zeichnung gestellten Anforderungen aus der Zeit um 1840 verdeutlicht werden (Abb. 20, 21). Talbots photogenische Zeichnung einer Großen Sterndolde stellt eine individuelle Pflanze als weißliches Schattenbild auf braunem Untergrund dar. Mit insgesamt vier Blütenständen in unterschiedlicher Ausrichtung sowie einem differenziert erkennbaren Blattkranz ist dieser Doldenblütler nicht zentral, sondern in der linken Bildhälfte platziert. Der Pflanzenstängel ragt zudem über den unteren Bildrand hinaus. Zu den klassifikatorischen Informationsträgern dieser Abbildung zählen neben der Umrisslinie die marginal zu erkennenden Binnendetails. Aufgrund letzterer wird eine eindeutige taxonomische Identifikation erschwert. Konträr dazu präsentiert sich die Illustration aus Dietrichs Werk, die in teilweise kolorierter Umrisszeichnung ein typisches Exemplar einer Großen

50 William Jackson Hooker, Botanical Illustrations, Edinburgh 1822. Vgl. dazu: Jim Endersby, Imperial Nature. Joseph Hooker and the Practices of Victorian Science, Chicago/London 2008, S. 113ff. Siehe ebenfalls: Joseph Dalton Hooker, A Sketch of the Life and Labours of Sir William Jackson Hooker, with Portrait, in: Annals of Botany, Jg. 16, Bd. 4, 1902, S. 9-221.

51 Vgl. dazu: Lorraine Daston/Peter Galison, The Image of Objectivity, in: Representations, Bd. 40, 1992, S. 81-128; Nickel 1998; Nickelsen 2000.

52 Kärin Nickelsen, „Abbildungen belehren, entscheiden Zweifel und gewähren Gewissheit“ Funktionen botanischer Abbildungen im 18. Jahrhundert, in: Wiener Zeitschrift zur Geschichte der Neuzeit, Jg. 7, Heft 1, 2007, S. 52-68. 


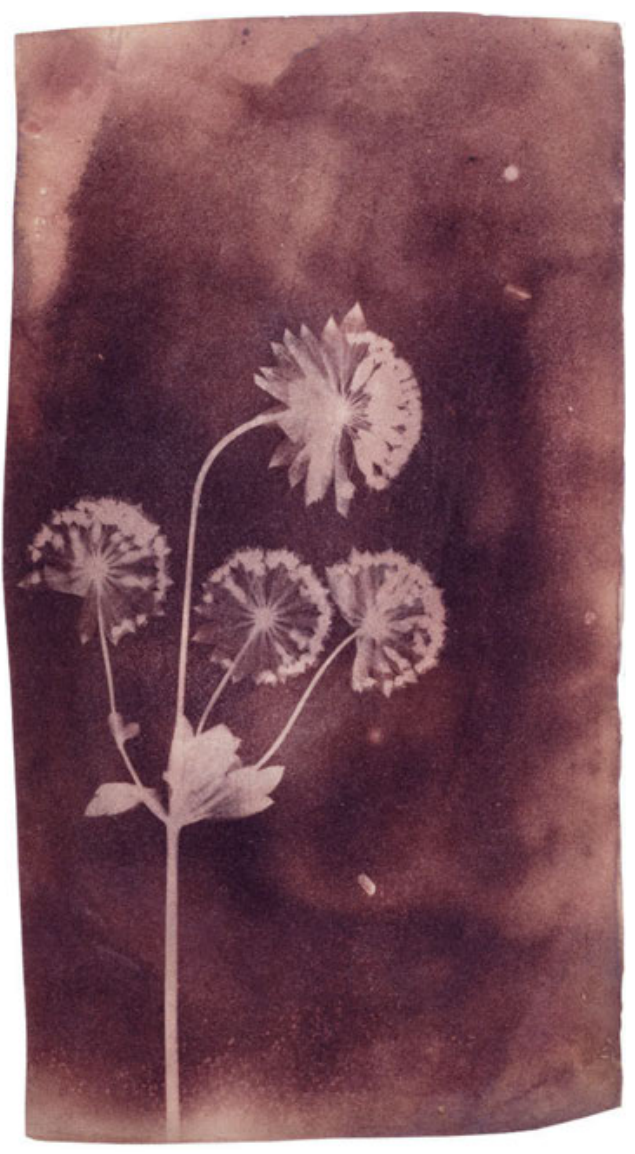

20 William Henry Fox Talbot, Astrantia Major, Photogenic Drawing, Negativ, $17,3 \times 9,5 \mathrm{~cm}, 13$. November 1838 , Victoria \& Albert Museum, London.

Sterndolde zu vermitteln versucht. Dazu wurden all jene essenziellen und somit charakteristischen Teile zusammengeführt, die zur Identifikation jener Pflanze nötig erscheinen. In schwarzer Umrisszeichnung finden sich die schematische Darstellung des Wurzelstocks ausgeführt sowie in vergrößerter Form drei unterschiedliche Entwicklungsstadien einzelner Dolden. Den größten Teil der Abbildung nimmt jedoch der in der Bildmitte befindliche, farbig gefasste oberirdische Pflanzenteil ein, der aufgrund seiner Wuchshöhe von ca. 30-100 Zentimeter in zwei getrennten Teilen einem unteren Segment mit Wurzelansatz sowie einem oberen Abschnitt mit Blütenstand und Frucht - auf dem Blatt arrangiert wurde. Wenngleich das Fotogramm eine singuläre Pflanze monochrom im Maßstab 1:1 abbilden kann, vermag eine durch Künstlerhand erstellte Illustration farbig gefasste Vergrößerungen oder Verkleinerungen vorzunehmen und eine Pflanze in ihrer charakteristischen Form durch Hervorhebung essenzieller Teile darzustellen. Bereits in Publikationen, die mit Natur- 
21 Astrantia Major, kolorierte Lithografie, aus: Albert Gottfried Dietrich, Flora Regni Borussici. Flora des Königreichs Preussen oder Abbildung und Beschreibung der in Preussen wiederwachsenden Pflanzen, Bd. 11, Berlin 1843.

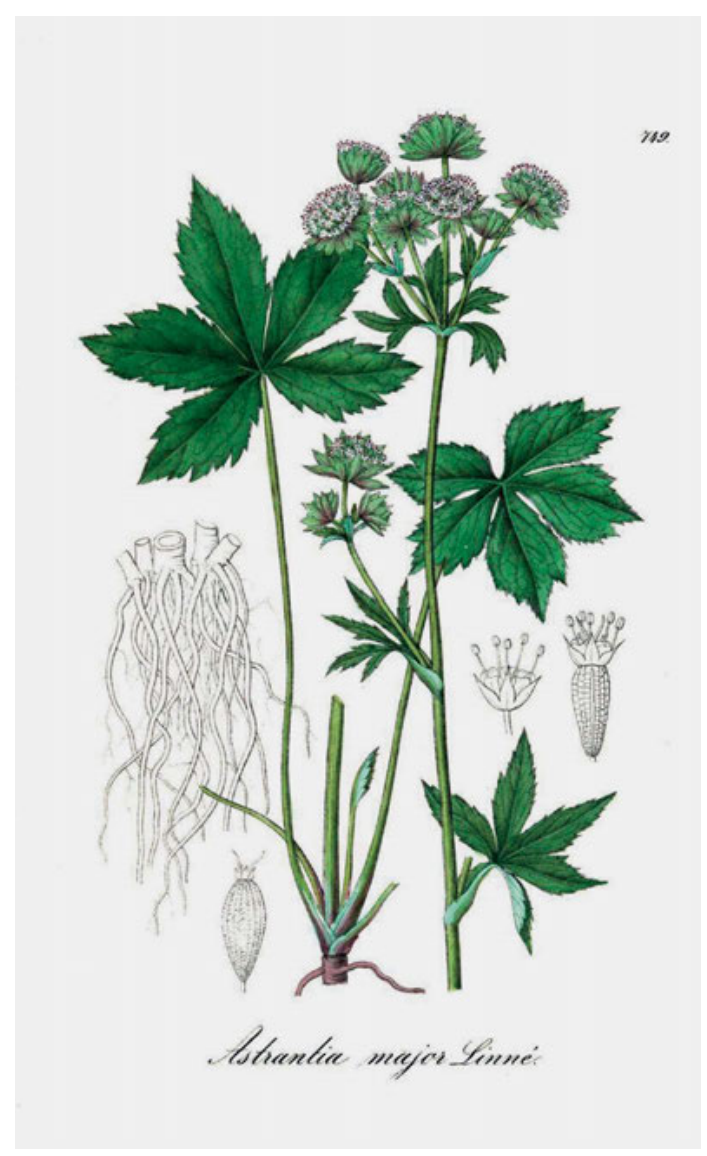

selbstdrucken ausgestattet wurden, führte man die automatische und somit „neutrale" Fertigung als eminenten Vorteil gegenüber der Zeichnung an. Die dadurch gewonnene Arbeitseffizienz und Kostenreduktion bedeutete einen Wettbewerbsvorteil, der sicherlich auch im Rahmen der Etablierung des Fotogramms als Reproduktionsmedium eine Rolle spielte. Abgesehen davon führte die Maßstabsgleichheit von Objekt und Kopie wie die autorlose Herstellung zur Argumentation über Konzepte wie Authentizität beziehungsweise "Naturwahrheit“. ${ }^{53}$ Automatisch gezeichnete oder gedruckte Werke entsprachen daher dem wissenschaftlichen Credo der NichtIntervention; sie sollten einen unverfälschten, unmittelbaren Zugang zur Natur ermöglichen ${ }^{54}$ Abgesehen von diesem Authentizitätsversprechen erfüllten kamera-

53 Vgl. ansatzweise Talbots Argumentation in: Talbot 1844-1846 (2011), Plate VII „Leaf of a Plant“.

54 Vgl. dazu: Nickelsen 2000; Lenné 2002; Wortmann 2003; Klinger 2010; Daston/Galison 2011. 
los angefertigte Fotografien jedoch nicht die allgemeinen botanischen Darstellungskonventionen. Für Hooker stellten sie somit kein hinreichendes Illustrationsmittel dar, eine gemeinsame Publikation kam daher nicht zustande.

\section{Patterns of Lace}

Um 1839 sprach Talbot vor allem kameralosen Fotografien eine visuelle Naturtreue und Genauigkeit zu, die er an den zahlreichen Fotogrammen von Spitzenmustern mit kontrastreichem Erscheinungsbild aufzeigt. Wie weit diese mimetische Zuschreibungsweise ging, verdeutlicht Talbot in seinem in Eigenverlag herausgegebenen Bericht an die Royal Society mit einer Formulierung, die an die von Plinius notierte Legende des Zeuxis gemahnt: ${ }^{55}$

„Upon one occasion, having made an image of a piece of lace of an elaborate pattern, I showed it to some persons at the distance of a few feet, with the inquiry, whether it was a good representation? When the reply was, ,That they were not to be so easily deceived, for that it was evidently no picture, but the piece of lace itself. ${ }^{\text {." } 56}$

In der Legende des Zeuxis vermochten bildliche Darstellungen einen Trompe-l'œilEffekt herzustellen, der gemalte Trauben beziehungsweise einen Vorhang als reale Gegenstände erscheinen ließ. In Talbots Erzählung ist es die photogenische Zeichnung eines Spitzenmusters, welches den Eindruck eines stofflichen Gewebes erzeugt und insofern als Simulakrum zu bezeichnen ist. Im Hinblick auf den Augentrug innerhalb der frühneuzeitlichen Malerei spricht Hartmut Böhme von einem „veristischen Illusionseffekt", welcher eine Ununterscheidbarkeit zwischen künstlerischem Werk und Naturvorbild - zumindest für einen gewissen Moment - evoziert. ${ }^{57}$ Diese den Fotogrammen von Spitzenstoffen vergleichbare Sinnestäuschung beruht auf mehreren Faktoren. So zeigt sich die strukturelle Beschaffenheit des Spitzengewebes im photogenischen Abdruckbild als kontrastreiches Linien- und Flächenmuster und

55 Gaius Plinius Secundus, Naturkunde, hg. v. Roderich König, Bd. 35 (Farben, Malerei, Plastik), München 1997, S. 57f.

56 Talbot 1980, S. 24.

57 Hartmut Böhme, Das reflexive Bild. Licht, Evidenz und Reflexion in der Bildkunst, in: Gabriele Wimböck/Karin Leonhard/Markus Friedrich (Hg.), Evidentia. Reichweiten visueller Wahrnehmung in der Frühen Neuzeit, Münster 2007, S. 331-365, hier S. 357. Siehe dazu ebenfalls: Gottfried Boehm, Die Lust am Schein im Trompe-l'œil, in: Bärbel Hedinger (Hg.), Täuschend echt. Illusion und Wirklichkeit in der Kunst, Ausst.-Kat. Bucerius Kunst Forum Hamburg, München 2010, S. 24-29. 


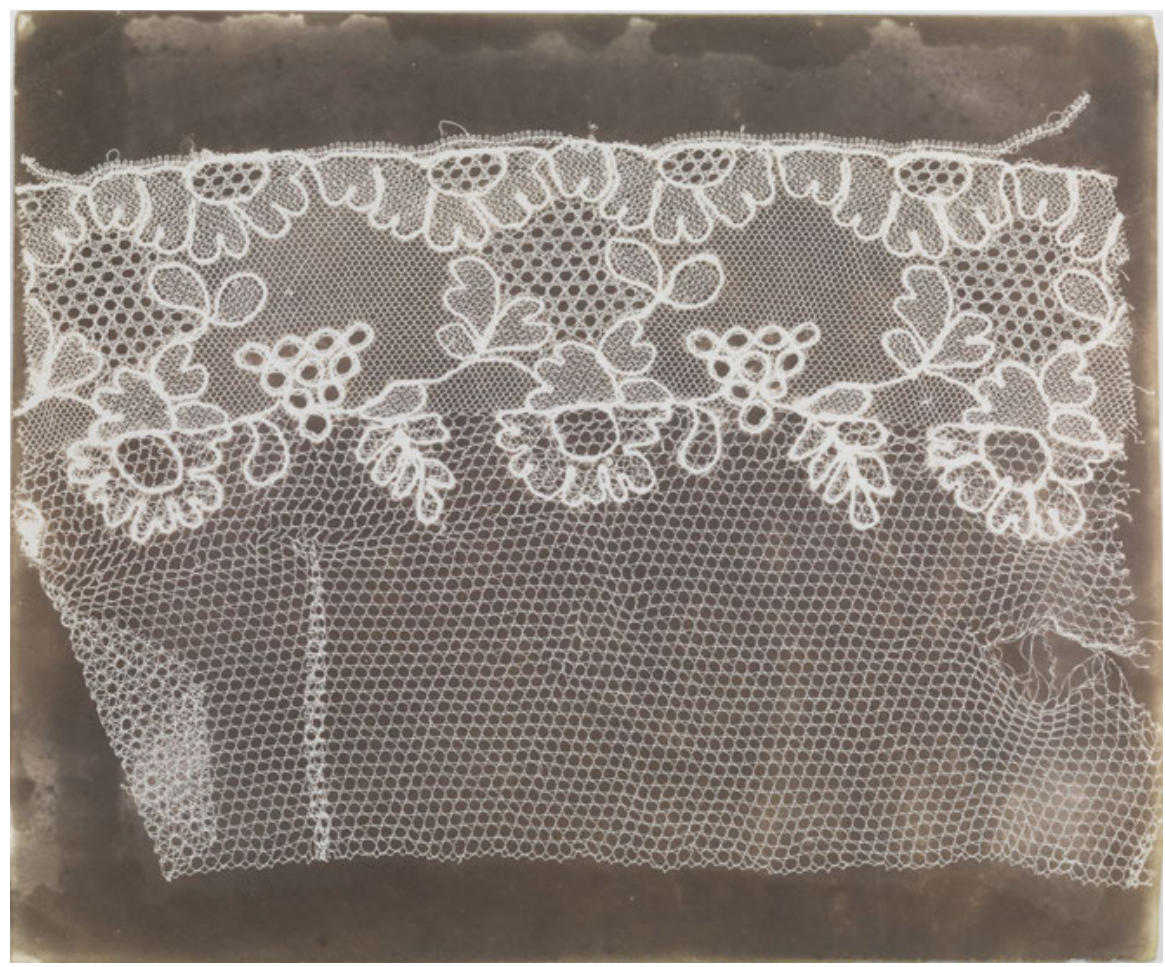

22 William Henry Fox Talbot, Spitzenmuster, Photogenic Drawing, Negativ, $18 \times 22,5 \mathrm{~cm}$, ca. 1840, Victoria \& Albert Museum, London.

erweckt dadurch den Eindruck eines realen Objektes. ${ }^{58}$ Zudem erscheint im Fotogramm - das im eigentlichen Sinne ein Negativ ist - der Abdruck der Spitzen in ihrer originalen Farbigkeit und vermittelt insofern den Eindruck eines positiven Bildes. Wie in Abbildung $22 \mathrm{zu}$ sehen, hebt sich von dem dunkelbraunen, leicht gefleckten Untergrund des 1840 hergestellten Fotogramms von Talbot ein weißes, aus unterschiedlich groben Maschen gesponnenes Fadennetz ab. Mit applizierten Blüten und Blättern formt dieses Liniengeflecht ein Stoffmuster, welches zentral auf der Bildfläche positioniert ist. Zerfranste Kanten, lose Fäden, sich auflösende Endnähte und Einrissspuren bezeugen den einstigen Gebrauch des filigranen Alltagsobjekts. Fast stilllebengleich verstärken die gezielt gesetzten Umstülpungen und Faltungen im Gewebe den Trompe-l'œil-Effekt der Darstellung und veranschaulichen dessen 


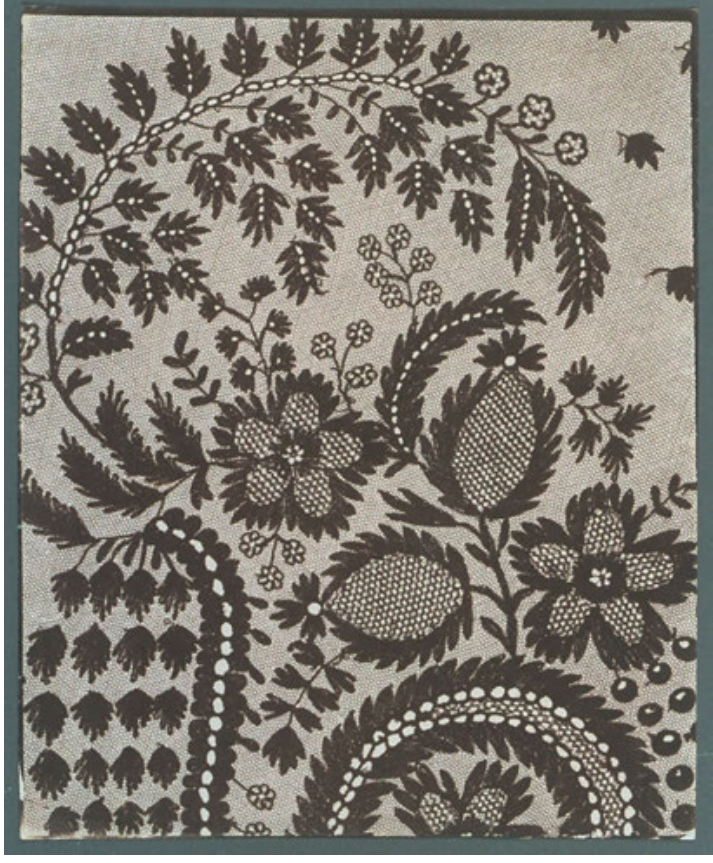

23 William Henry Fox Talbot, Spitzenmuster, Photogenic Drawing, Negativ, $22,7 \times 18,7 \mathrm{~cm}$, ca. 1840 , Victoria \& Albert Museum, London.

„Greifbarkeit"“.59 Aufgrund des räumlich nicht zuordenbaren Hintergrundes scheint dieses weiße Musterwerk fast schwerelos auf der Bildfläche positioniert. Das klar umrissene, weiße Schattenbild hebt sich von dem kontrastierenden Untergrund deutlich ab und betont damit abermals die bereits erörterte Bild-Grund-Relation. Im Gegensatz zum Bildgrund erkennt Talbot das sich farblich differenzierende Motiv als das eigentliche Bild an. Mit dieser Charakterisierung wird der Realitätseffekt des Fotogramms einmal mehr akzentuiert, da nur der abgebildete Gegenstand und nicht die ihn umgebende und durchbrechende Bildfläche beziehungsweise der Bildhintergrund als „Bild“ angesehen wird. Dieses Changieren zwischen Objekt und Bild erzeugt ein Spannungsmoment, das nur in direkter Anschauung oder durch ein sich vergewisserndes Berühren aufgelöst werden kann. Der den Fotogrammen eingeschriebene Realitätseffekt ist jedoch nicht nur medial sowie motivisch bedingt, sondern wird zusätzlich durch Talbots formale Anordnung des Spitzenmusters auf dem Bildgrund gesteigert. Außerdem verwendete er als Abdruckmaterial teilweise gerissene

59 Ein Zusammenhang zwischen Fotogrammen von Spitzenmustern und der frühneuzeitlichen Trompe-l'œil Malerei lässt sich in der vorrangigen Darstellung flacher Motive ausmachen, die aufgrund ihrer Flächigkeit auf einfache Weise einen augentrügerischen Effekt evozieren konnten, siehe dazu: Boehm 2010, S. 26. 
24 William Henry Fox Talbot, Spitzenmuster, Photogenic Drawing, Negativ, $14,1 \times 13,8 \mathrm{~cm}$, 1840, Victoria \& Albert Museum, London.

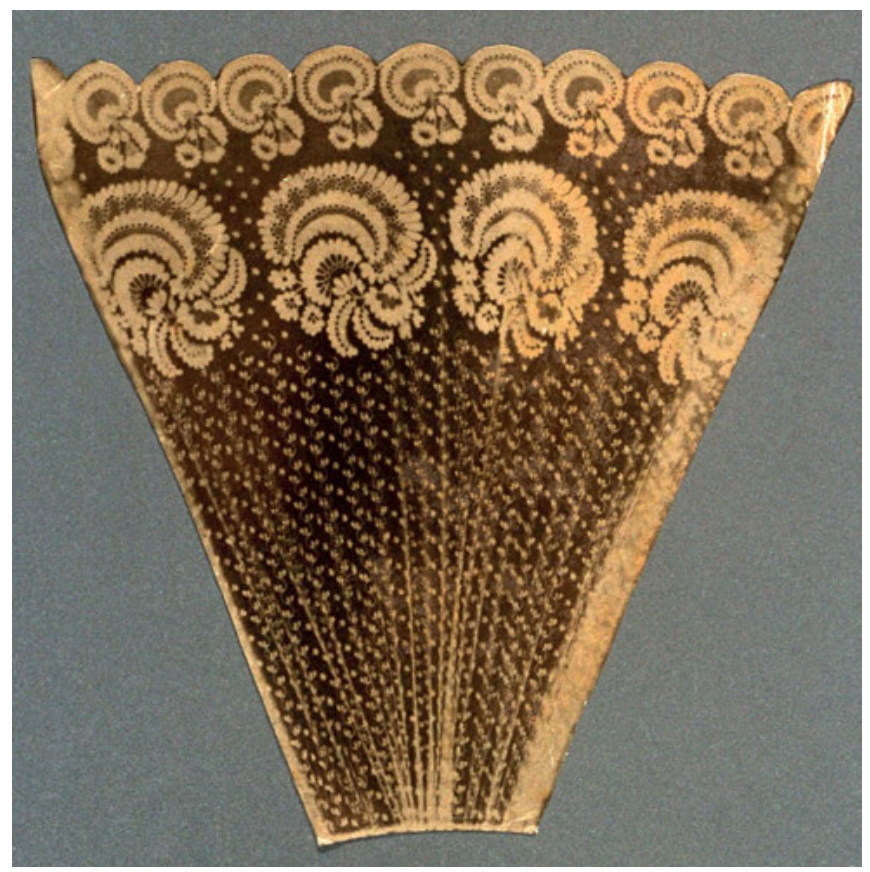

und löchrige sowie in Falten gelegte Spitze, um den Wirklichkeitseindruck zu steigern (Abb. 22). Variationen nahm Talbot insofern vor, als er die gesamte Bildfläche mit dem Stoffgewebe füllte, das eigentliche Objekt „Spitze“ somit auflöste und nur mehr seine Musterung zur Abbildung brachte (Abb. 23). Batchen sprach in diesem Zusammenhang daher nicht von der Darstellung eines Spitzenmusters, sondern von dessen „patterning“, womit der bildfüllende Einsatz der Musterung sowie die Auflösung des Bildes an sich angesprochen sind. ${ }^{60}$ Talbot selbst wiederholte in zahlreichen seiner schriftlichen Äußerungen die Formulierung der „patterns of lace“, Musterungen von Spitzenstoffen also, welche in dieser Nennung Eingang in zeitgenössische Rezensionen gefunden haben. ${ }^{61}$ Auf diese Weise konnte einmal mehr die Funktion der Technik des Fotogramms zur Herstellung eines Simulakrums und damit einer materiellen Verdopplung betont werden.

Eine zusätzliche Verstärkung des Realitätseffektes wurde durch das gezielte Drapieren eines Spitzenstoffes auf der fotosensiblen Schicht sowie durch das nachträgliche Ausschneiden des photogenisch fixierten Musters entlang der Außenkante voll-

60 Geoffrey Batchen, Patterns of Lace, in: Coleman 2001, S. 354-357, hier S. 355 (2001b).

61 Siehe dazu: Geoffrey Batchen, Electricity Made Visible, in: Wendy Chun/Thomas Keenan (Hg.), New Media. Old Media, A History and Theory Reader, New York 2006, S. 27-44, Anm. 11. 


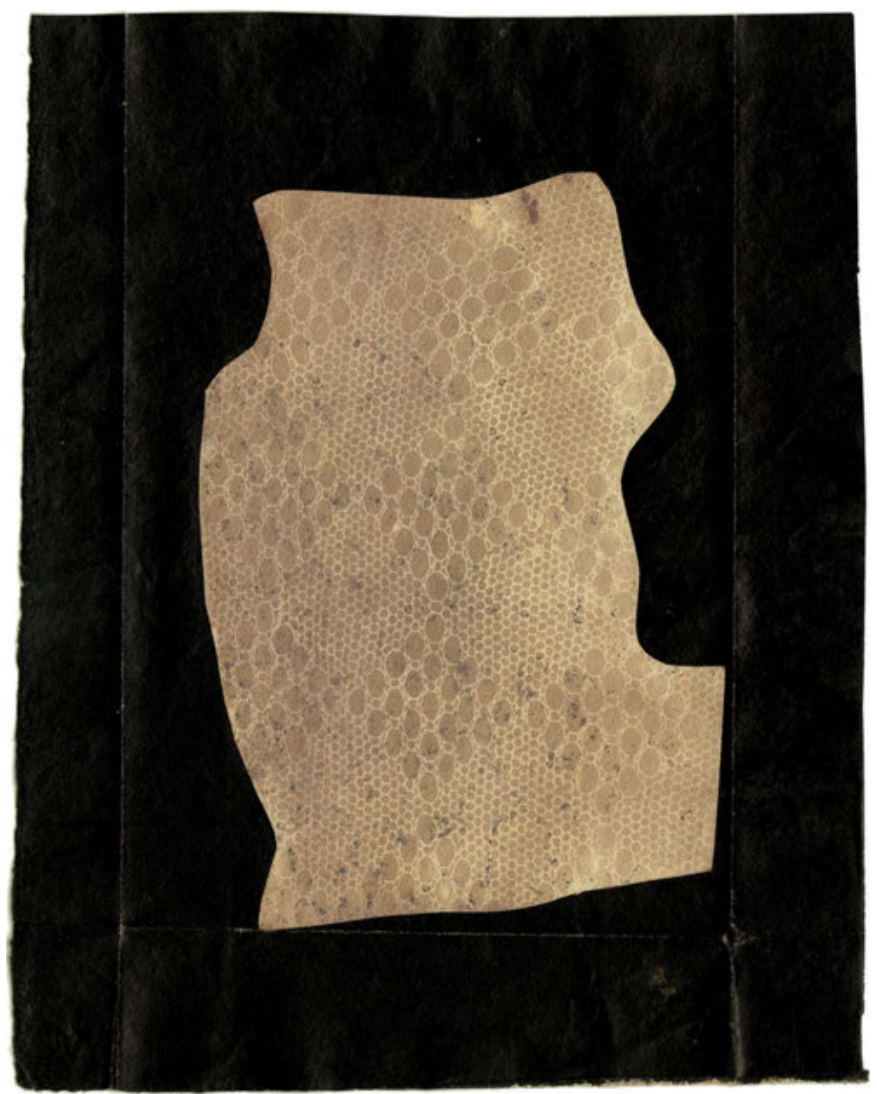

25 William Henry Fox Talbot, Spitzenmuster, Photogenic Drawing, Negativ, 8,9 ×6,2 cm, auf schwarzem Papier montiert: $12,4 \times 9,8 \mathrm{~cm}$, ca. 1834, National Museum of American History, Smithsonian Institution, Washington.

zogen. Bildpraktiken, die eine dreidimensionale Wirkung zur Folge hatten (Abb. 24). ${ }^{62}$ In einem weiteren Beispiel verstärkt nicht nur die wellenlinienförmig zurechtgeschnittene Konturenlinie den räumlichen Effekt des Fotogramms, sondern auch die Applikation auf schwarzem Untergrund (Abb. 25). ${ }^{63}$ Auf diese Weise knüpften Talbot und

62 In den Sammlungen des Victoria \& Albert Museum London (ehemals National Media Museum Bradford) befinden sich weitere photogenische Zeichnungen von Spitzenmustern, deren Ränder der Musterung folgend zurechtgeschnitten wurden (Inv.-Nr. 1937-1390, 1937-1518).

63 Möglicherweise wurde diese photogenische Zeichnung im Rahmen der Verfahrenspräsentation Talbots an der Royal Institution in London am 25. Januar 1839 präsentiert. Siehe dazu: 
seine Familienmitglieder an die bereits erörterte Tradition des Ausschneidens von vorgefertigten Grafiken entlang einer Konturenlinie an.

In seinen photogenischen Zeichnungen versuchte Talbot, Abbildungsqualitäten wie Detailgenauigkeit sowie mimetische Effekte darzustellen, weshalb er oftmals auf die Verwendung von Spitzenstoffen zurückgriff. Damit wurden Alltagsgegenstände dekontextualisiert und zu wissenschaftlichen Objekten transformiert. In materialitätsorientierter Perspektivierung sind Spitzenstoffe im 19. Jahrhundert jedoch als zutiefst „weiblich“ kodiertes Material zu bezeichnen. Klöppeln und Stickkunst wurden mit Aristokratie, Damenmode sowie weiblicher Konsumkultur verbunden. ${ }^{64}$ Die Einbeziehung dieses weiblich konnotierten Materials hatte daher einen Rückkopplungseffekt auf die Rezeption der Technik, wie ich im Laufe dieses Kapitels noch näher ausführen werde. Die Beschäftigung mit Spitzenstoffen war für Talbot keine einmalige Angelegenheit. Im Rahmen seiner 1858 patentierten ,photoglyphic engravings“, einem Verfahren der drucktechnischen Reproduktion von Fotografien, verwendete er als Motiv ebenso Spitzenmuster oder Stoffe, die er in mehreren Schichten überlagerte, um die Detailgenauigkeit des Verfahrens zu demonstrieren. ${ }^{65}$ Seine Objektwahl begründete Talbot in The Pencil of Nature mit dem medialen Apriori kameraloser Fotografie, da jene Technik insbesondere geeignet sei, „flache Objekte komplizierter Form und Umriss“ darstellen zu können. ${ }^{66}$ Andererseits wollte Talbot sein Verfahren unter Stoffhändlern bekannt machen, um diese von der Brauchbarkeit seiner Technik für die Stoffindustrie zu überzeugen. In der Zeit um 1839 stattete man Warenkataloge für Werbezwecke mit eingeklebten Stoffmustern aus, welche, so Talbots Hoffnung, durch die vervielfältigbare Methode photogenischer Zeichnungen ersetzt werden konnten.$^{67}$ Batchen wies nach, dass es sich im Falle des Originals der photogenisch reproduzierten Spitze in The Pencil of Nature um einen maschinell gefertigten Stoff aus Nottingham handelte, einem damaligen Zentrum der britischen „lace industry“. ${ }^{68} \mathrm{Ab} 1837$ setzte man in England Lochkartenwebstühle nach dem Prinzip von Joseph Marie Jacquard ein, die eine Imitation handgefertigter Ware ermöglichten

Geoffrey Batchen, William Henry Fox Talbot, London 2008; ders., A Philosophical Window, in: History of Photography, Jg. 26, Bd. 2, 2002, S. 100-112; ders. 2001 b.

64 Vgl. Parker 2010.

65 Vgl. Schaaf 2003.

66 Talbot 1844-1846 (2011), o.S.

67 Brief Talbot an William Jackson Hooker, 23. Januar 1839, Antwortbrief Hookers, 20. März 1839, online unter: http://foxtalbot.dmu.ac.uk (6.3.2018). Siehe dazu: Schaaf 1992, S. 47, Anm. 7; Nickel 1998; Batchen 2001b, S. 356. Mit photogenischen Zeichnungen ausgestattete Warenkataloge um 1840 konnten nicht nachgewiesen werden. Eine umfassende Sammlung an viktorianischen Spitzenmusterkatalogen beherbergt unter anderem die Nottingham Trent University in Großbritannien.

68 Batchen 2001b, S. 356. 
und so die Produktion von Spitzenstoffen kostengünstiger werden ließ. ${ }^{69}$ Die Verwendung des britischen Stoffmusters sei daher, so Batchen, ,a proudly English artifact“, womit Talbot sich einmal mehr in Opposition zur französischen Daguerreotypie stellte. ${ }^{70}$ Diese Behauptung lässt sich insofern untermauern, als neben der allgemeinen Rivalität zwischen England und Frankreich zumindest bis 1830 ein strenges Importverbot für Spitzenstoffe bestand. ${ }^{11}$ Einen weiteren Aufschwung erhielt die Textilindustrie durch das für Queen Victoria 1844 aus größtenteils maschinell hergestellter britischer „Honiton Spitze“ angefertigte Brautkleid, das die Königin auch zum Zweck der Ankurbelung der landeseigenen Produktion erzeugen ließ.72

Carol McCusker hingegen vertritt die These, dass die Reproduktion von Spitzenmusterfotogrammen vor allem dem Einfluss zuzurechnen sei, den die weiblichen Familienmitglieder auf Talbot gehabt haben dürften. Unter anderem versorgten seine Mutter Elisabeth Feilding sowie seine Cousinen Theresa Digby und Charlotte Traherne Talbot mit Stoffproben aus ihrem eigenen Bestand. Diese forderten sie danach als photogenische Abbildungen in zahlreichen Briefen an, sammelten sie und verschenkten sie ihrerseits an Verwandte, Wissenschaftler und prominente Persönlichkeiten. ${ }^{73}$ In einem an Talbot gerichteten Brief bezeichnete Theresa Digby Caroline Edgcumbe, Talbots Halbschwester und „lady-in-waiting“ der britischen Königin, als Herstellerin eines Spitzenfotogramms, welches Queen Victoria vorgelegt wurde und großes Interesse auf sich zog. ${ }^{74}$ Auch ein Spitzenmusterfotogramm aus Talbots Hand wurde der Queen dargeboten, woraufhin Elisabeth Feilding an Talbot zu berichten wusste: „I understand the Queen being no Botanist admires most the riband you sent her. Therefore I have I [sic!] mind to send you a bit of beautiful Point Lace which I

69 Ebenda. Durch die Rivalität mit Frankreich kam es zu einem Spionagefall, bei dem der Inhaber einer Textilfabrik den Lochkartenmechanismus Frankreichs nachbauen ließ, siehe dazu: Birgit Schneider, Textiles Prozessieren. Eine Mediengeschichte der Lochkartenweberei, Zürich/Berlin 2007, S. 296f.

70 Batchen 2001b, S. 356.

71 Siehe dazu: John Nye, The Myth of Free-Trade Britain and Fortress France. Tarifs and Trade in the Nineteenth Century, The Journal of Economic History, Jg. 51, Nr. 1, 1991, S. 23-46.

72 Siehe dazu: Elaine Freegood, „Fine Fingers“. Victorian Handmade Lace and Utopian Consumption, in: Victorian Studies, Jg. 45, Nr. 4, 2003, S. 625-647, hier S. 626.

73 Carol McCusker, Silver Spoons and Crinoline: Domesticity \& the „Feminine“ in the Photographs of William Henry Fox Talbot, in: dies./Michael Gray/Artur Ollman (Hg.), First Photographs. William Henry Fox Talbot and the Birth of Photography, New York 2002, S. 17-22. Siehe dazu auch: Batchen 2001b. Vgl. Briefverkehr: Charlotte Traherne an Talbot, 28. Februar 1839; Theresa Digby an Talbot, 8., 13. April 1839; Elisabeth Feilding an Talbot, 18., 30. April 1839, 12. Mai 1839, 29., 30. Juni 1839, 3. August 1839, 24. August 1841, 23. August 1844, online unter: http://foxtalbot.dmu.ac.uk (6.3.2018)

74 Theresa Digby an Talbot, 8. April 1839. Siehe dazu: Anne Lyden (Hg.), A Royal Passion. Queen Victoria and Photography, Ausst.-Kat. J. Paul Getty Museum, Los Angeles 2014. 
think would have great success - shall I? I wish you would send me some more to lay on my table." ${ }^{\text {"75 }}$

In einer ermahnenden Nachricht vom 30. Juni 1839 hebt Talbots Mutter den augentrügerischen Effekt bestimmter Muster aus ihrer Sammlung hervor, den Talbot in der Produktion photogenischer Zeichnungen allem Anschein nach noch nicht berücksichtigt hatte: „I wish you would do some worked muslin \& lace I sent you - the veracity of those is level with the meanest capacity \& is consequently popular people claim ,how natural is that bit of lace! "“76 Zudem war Constance Talbot, Talbots Ehefrau, spätestens ab Mai 1839 mit der Anfertigung eigener Fotografien beschäftigt. ${ }^{77}$ Anhand des Briefverkehrs seiner weiblichen Verwandtschaft wird deutlich, dass Talbots Umfeld an der Verbreitung der neuen Erfindung beteiligt war. Deutlich wird aber auch, dass die Autorschaft photogenischer Zeichnungen in vielen Fällen unklar bleiben muss. So nennt Feilding in mehreren Schreiben die Bediensteten Nicolas Hennemann sowie Charles Porter als Produzenten von Spitzenmusterfotogrammen. ${ }^{78}$ Andererseits rät Talbots Mutter von der Verwendung konkreter Stoffproben für die Herstellung von Fotogrammen ab und will diese durch eigene textile Vorschläge ersetzt wissen, wodurch Feilding neben weiteren weiblichen Verwandten Talbots als Koautorin genannt werden müsste. ${ }^{79}$ Auch Naomi Rosenblum stellt für die Frühzeit der Fotografie beziehungsweise in Bezug auf das familiäre Umfeld Talbots fest:

"It may no longer be possible to determine whether the camera images that have survived from Talbot's group were done in tandem or were exclusively the work of the women or the men. From the earliest days the finished photograph has resulted from cooperative efforts more often than is generally recognized." 80

Die Analyse photogenischer Zeichnungen von Spitzenmustern im „Æuvre Talbots“ sollte nicht nur mediale Aspekte wie Detailgenauigkeit und Verdopplung als ausschlaggebende Faktoren für den Abdruck von Textilien zeigen. Auch der Einfluss der

75 Elisabeth Feilding an Talbot, 18. April 1839, online unter: http://foxtalbot.dmu.ac.uk (6.3.2018).

76 Elisabeth Feilding an Talbot, 30. Juni 1839, online unter: http://foxtalbot.dmu.ac.uk (6.3.2018).

77 Constance Talbot an Talbot, 21. Mai 1839, online unter: http://foxtalbot.dmu.ac.uk (6.3.2018). Darin erwähnt Constance Talbot die Herstellung von Kamerafotografien. Weitere Forschungsergebnisse zu ihrer bis dato marginalisierten Rolle als Fotografin sind durch die Aufarbeitung des 2014 durch die Bodleian Libraries Oxford angekauften persönlichen Archivs William Henry Fox Talbots zu erwarten.

78 Elisabeth Feilding an Talbot, 24. August 1841, 23. August 1844, online unter: http://foxtalbot. dmu.ac.uk (6.3.2018).

79 Elisabeth Feilding an Talbot, 23. August 1844, online unter: http://foxtalbot.dmu.ac.uk (6.3.2018).

80 Rosenblum 1994, S. 40. 
weiblichen Verwandtschaft auf Talbot sowie ökonomische Motive werden aus dem begleitenden Briefverkehr deutlich. Aufgrund der großen Anzahl an Spitzenmusterfotogrammen spricht Batchen daher von sogenannten ,signature images“ beziehungsweise von einer "feminine presence“, die in jenen Bildern ablesbar sei..$^{81}$ Zudem sollte durch die Einbeziehung eines Spitzenmusterfotogramms in The Pencil of Nature, so formuliert Batchen ansatzweise, vermutlich die weibliche Leserschaft adressiert werden. Diese nur vage formulierte Hypothese verlangt jedoch nach einer eingehenderen Erörterung. Anhand der Analyse unterschiedlicher Rezensionen sowie Handbücher zur Fotografie um 1840 soll in den folgenden Unterkapiteln die weibliche Kodifizierung von Talbots Spitzenmusterfotogrammen untersucht und damit geschlechterspezifische Determinationen freigelegt werden.

\section{Fac-Similes}

Nicht nur Talbot ordnete seine kameralos hergestellten photogenischen Zeichnungen als simulakrale Darstellungen ein, auch zeitgenössische Rezensenten betonten die Naturtreue jener Abbildungen. Kurz nach der öffentlichen Bekanntgabe beschäftigten sich zahlreiche, auch internationale Zeitschriften mit der neuartigen bildgebenden Erfindung Fotografie. Neben ersten chemischen Rezepturen und Anleitungen zur Herstellung von lichtempfindlichen Papieren wurden nicht nur Daguerres bildliche Ergebnisse mit jenen Talbots verglichen; man versuchte auch mögliche Anwendungsgebiete kameraloser Bilder aufzuzeigen. Für den Zusammenhang dieser Arbeit sind insbesondere zwei Publikationsformate von entscheidender Bedeutung, da sie nicht nur beispielhafte Problemfelder aufspannen, sondern auch die ersten druckgrafisch reproduzierten Abbildungen kameraloser Fotografien zeigten.

Das zu dieser Zeit populäre Wochenblatt The Mirror of Literature, Amusement and Instruction publizierte 1839 mehrere Artikel, die sich den formalen Qualitäten sowie den unterschiedlichen chemischen Rezepturen kameraloser wie kamerabasierter Fotografie widmeten.$^{82}$ Gemäß der unterhaltsamen Belehrung wurden solche Verfahren auf anschauliche und instruktive Weise vermittelt. Am 20. April 1839 - somit kurz nach der ersten Verlautbarung von Fotografie - erschien auf dem Titelblatt der Zeitschrift eine Reproduktion einer ohne Kamera hergestellten photogenischen

81 Batchen 2001b, S. $354 f$.

82 Anonym, A Treatise on Photogenic Drawing, in: The Mirror of Literature, Amusement and Instruction, 20. April 1839, S. 243-244; Anonym, The New Art - Photography, in: The Mirror of Literature, Amusement and Instruction, 1839, S. 261-262, 281-283, 317-318, 333-335. Zu Auflagenhöhe und Zielsetzung der zwischen 1822 und 1847 publizierten Zeitschrift siehe: Jonathan Topham, The Mirror of Literature, Amusement and Instruction and Cheap Miscellanies in Early Nineteenth-Century Britain, in: Geoffrey Cantor u.a. (Hg.), Reading the Magazine of Nature. Science in the Nineteenth-Century Periodical, Cambridge 2004, S. 37-66. 


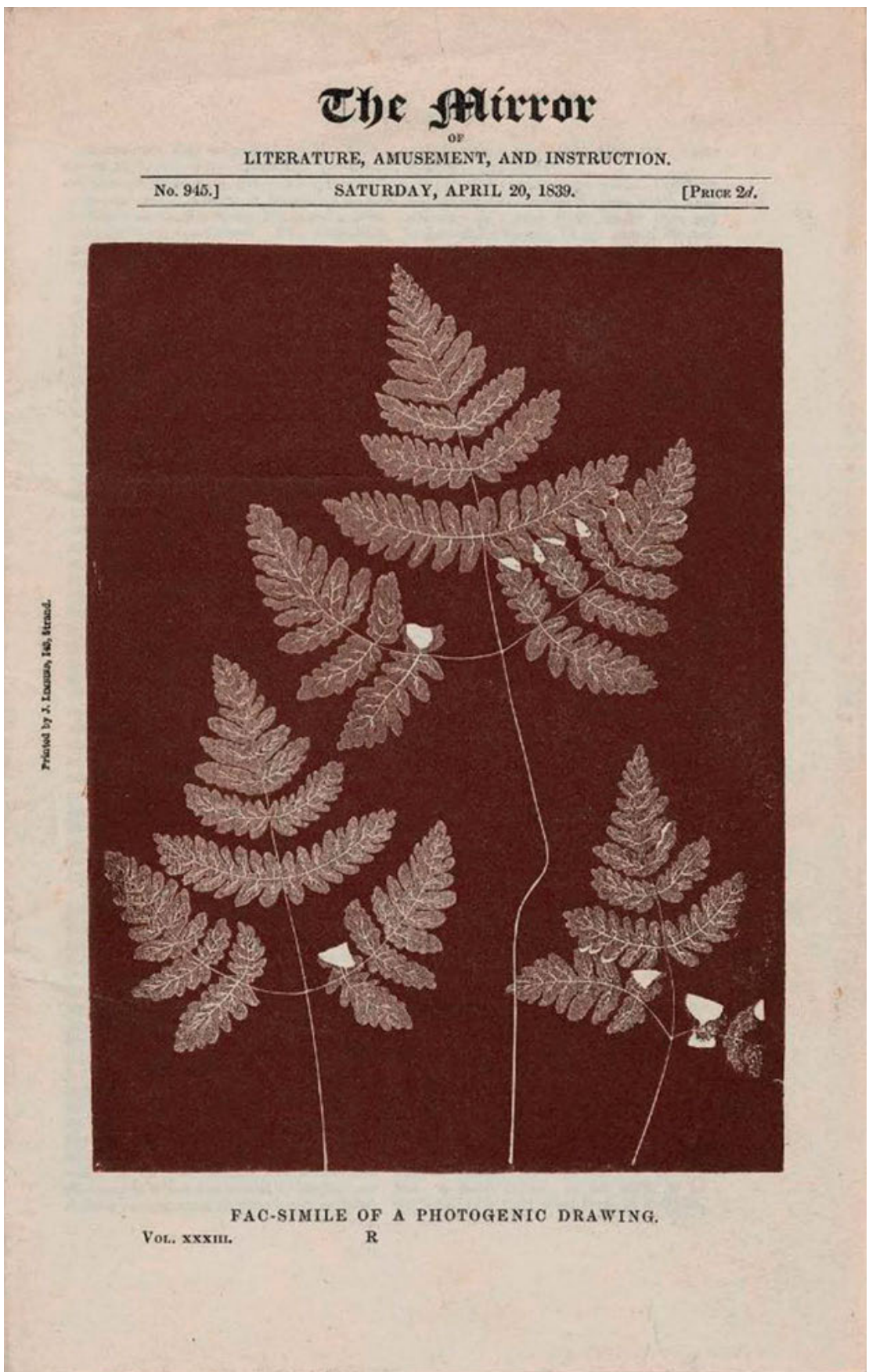

26 J. Limbird, Fac-simile of a Photogenic Drawing, Titelblatt, aus: The Mirror of Literature, Amusement and Instruction, 20. April 1839. 
Zeichnung (Abb. 26). ${ }^{83}$ Diese Veröffentlichung stellte nicht nur die erste jemals publizierte Fotografie, sondern präziser gesprochen, das erste Fotogramm dar. Auf dieser in Holzstich ausgeführten Abbildung treten aus dunkelbraunem Hintergrund drei Farnpflanzen unterschiedlicher Größe schematisch hervor. Besonders deutlich wird dieser Schematismus an den dünn gezogenen hellen Linien, welche Blattspindel und Spreiten definieren. Die weißen Auslassungen an den Blattenden kennzeichnen jene im Zuge des Trocknungs- oder Abdruckvorgangs umgeknickten Blätter der Originalpflanze. Dadurch konnten die spezifischen Abbildungsmodalitäten der Fotogrammtechnik - Opazität, Transluzenz und Transparenz - visualisiert und von einer konventionell hergestellten drucktechnischen Reproduktion abgesetzt werden. Als Bezugnahme auf die originale Färbung der photogenischen Zeichnung ist die rötlichbraune Farbigkeit der Abbildung zu verstehen. Es handelte sich - wie die Bildunterschrift vermerkt - um ein „Faksimile einer photogenischen Zeichnung“ und insofern um eine originalgetreue Kopie einer kameralosen Fotografie, wie dies Talbot bereits zu Beginn des Jahres 1839 deklariert hatte. ${ }^{84}$ Obwohl ein weiteres Medium in dieser Präsentation zwischengeschaltet wurde - ein Holzstich, den ein Stecher nach einem Fotogramm des Arztes und Naturwissenschaftlers Golding Bird angefertigt hatte reagierte die Leserschaft mit größtem Interesse und Erstaunen auf den mimetischen Realitätsanspruch der Reproduktion. In der darauf folgenden Ausgabe wurde insofern vermerkt:

„The fac-simile in our last number has produced a much greater sensation than we had anticipated; but still we are not surprised at this excitement, for the engraving gave a most accurate idea of the photogenic picture, which represents the fern with such extreme fidelity that not only its veins, but the imperfections, and accidental foldings of the leaves of the specimen are copied, - the greater opacity on the folded parts being represented by the large white patches on our fac-simile." ${ }^{\text {"85 }}$

83 Womöglich handelte es sich dabei um einen Abzug eines Holzträgers, der in einem ersten Schritt lichtempfindlich gemacht, mit botanischen Objekten belegt und anschließend direkt bearbeitet werden konnte. Siehe dazu: Anonym, The New Art - Photography, 18. Mai 1839, S. 317-318, hier S. 317 (To take a photographic copy on box-wood); Robert Doty, The First Reproduction of a Photograph, in: Image, Jg. 11, Nr. 2, 1962, S. 7-8; Gernsheim 1983, S. 705.

84 Talbot selbst bezeichnet seine kameralos hergestellten Fotografien von Pflanzenblättern oder Spitzenmustern als „facsimiles“, siehe dazu: Talbot 1839a, S. 73. Vgl. ebenfalls Aragos Verwendung des Begriffs in seiner Rede vom 15. Juni 1839, in: Daguerre 1839.

85 Anonym, The New Art - Photography, in: The Mirror of Literature, Amusement and Instruction, 27. April 1839, S. 262-263, hier S. 262. 
Golding Bird, von dem die Originalvorlage zu dieser Reproduktion stammte, setzte sich für die Etablierung dieser Technik im Rahmen botanischer Forschung ein. In einer Abhandlung des Magazine of Natural History, das in großen Teilen in der am 20. April 1839 erschienenen Ausgabe mit genanntem Titelblatt wiederabgedruckt wurde, bespricht Bird die chemischen Herstellungsbedingungen photogenischer Zeichnungen und die möglichen Anwendungsgebiete im Bereich der Botanik..$^{86}$ Überzeugt von den Potenzialen der kamaralosen Fotografie Talbots im Gegensatz zu Daguerres Verfahren der Bilderzeugung und kamerabasierter Fotografie im Allgemeinen, führt Bird aus: ,[...] I feel that the application of this heliographic or photogenic art will be of immense service to the botanist, by enabling him to procure beautiful outline drawings of many plants, with a degree of accuracy which, otherwise, he could not hope to obtain. “87 Bird, ganz im Gegensatz zu Hooker, attestierte Talbots Abbildungstechnik einen wesentlichen Nutzen für die botanische Forschung. Mit ihrer Hilfe ließen sich Zeichnungen in Umriss erstellen, die seiner Ansicht nach von beispielhafter Genauigkeit geprägt seien. Aufgrund der Vervielfältigungsmöglichkeit getrockneter Pflanzenproben konnten die so hergestellten Blätter durch Botaniker/innen auf einfache Weise gesammelt und ausgetauscht werden. Als abzudruckende Objekte empfahl Bird getrocknete Herbarpflanzen, aber auch an die Blattgröße angepasste frische Pflanzenproben, die mit Hilfe des Gewichts einer Glasplatte auf die Trägerschicht gepresst wurden. Jedoch nicht alle Pflanzenexemplare ließen sich gleichermaßen genau abdrucken. Als besonders geeignet erwiesen sich Farne, Gräser und Doldengewächse. „On looking at them“, so Bird, „one must be struck with the extreme accuracy with which every scale, nay, every projecting hair, is preserved on the paper; the character and habit of the plant is most beautifully delineated, and if the leaves be not too opake, the venation is most exquisitely represented." ${ }^{\text {"88 }}$ In einem nachträglich erstellten Vorwort für das Jahr 1839 konstatiert der Herausgeber der Zeitschrift rückblickend einen aktuellen "thirst for botanical knowledge“. Dieser Wissensdurst spiegle sich vor allem im Bereich des an Frauen ausgerichteten Curriculums, das Botanik als geeigneten Lehrstoff vorsah. In direktem Anschluss erinnert der Autor an die Berichte über die Technik photogenischer Zeichnungen, die er als ,accomplishment“ und „very pleasing and astonishing art“ bezeichnet. ${ }^{89}$ In diesem Zusammenhang interessiert mich die damalige Analogisierung von Botanik, photogenischer Zeichen-

86 Golding Bird, Observations on the Application of Heliographic or Photogenic Drawing to Botanical Purposes, in: Magazine of Natural History, April 1839, S. 188-192.

87 Anonym, A Treatise on Photogenic Drawing, in: The Mirror of Literature, Amusement and Instruction, 20. April 1839, S. 243-244, hier S. 243.

88 Ebenda, S. 244.

89 John Limbird, Preface, in: The Mirror of Literature, Amusement and Instruction, Nr. 33, 1839, o.S. 


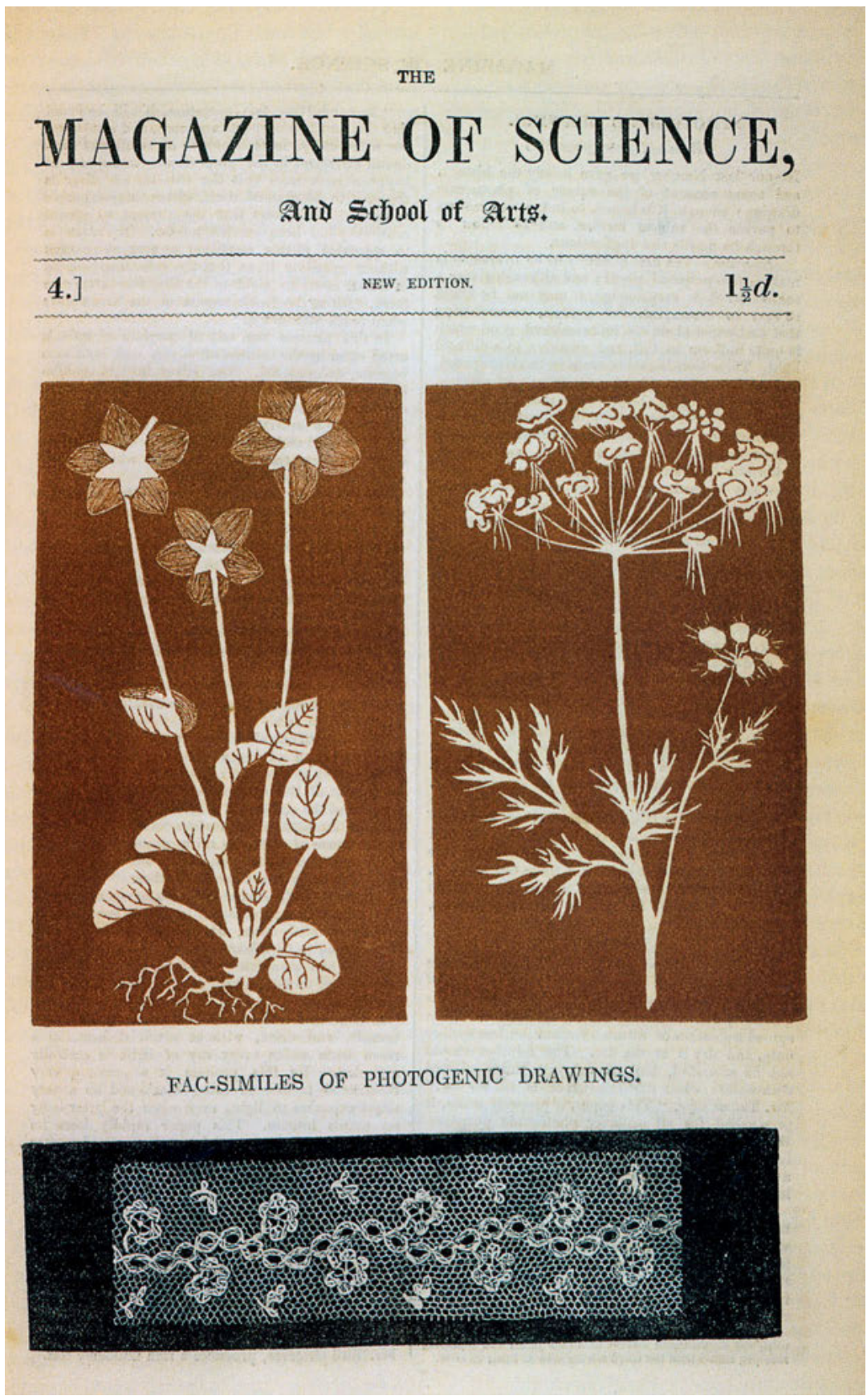

27 G. Francis, Facsimiles of Photogenic Drawings, Titelblatt, aus: The Magazine of Science and School of Arts, 27. April 1839. 
kunst und weiblichen Befähigungen, die in einer anderen Zeitschrift nochmals explizit erläutert wurden.

Nur wenige Tage nach der ersten Veröffentlichung photogenischer Zeichnungen auf einem Zeitschriftencover brachte auch The Magazine of Science and School of Arts die Darstellung von drei in Holzstich ausgeführten, schematischen Zeichnungen auf ihrer Titelseite heraus (Abb. 27).90 Den oberen Teil des Blattes nehmen Reproduktionen zweier hochformatiger Pflanzenbilder ein, die auf dunkelbraunem Grund eine hauptsächlich auf Konturenlinien beruhende Zeichnung - mit vereinzelter grober Strichführung zur Andeutung von Binnendetails - zeigte. In botanischer Manier findet sich in der linken Illustration eines Sumpf-Herzblattes (Parnassia palustris) auch der Wurzelballen visualisiert; in der rechten Reproduktion einer Hundspetersilie (Aethusa cynapium) wurde darauf hingegen verzichtet. Zum unteren Seitenende hin wird das Blatt durch die Darstellung eines Spitzenstoffes mit Blumenmuster auf schwarzem Untergrund begrenzt. Der zwischen die Reproduktionen gesetzte Vermerk „Fac-Similes of Photogenic Drawings“ belegt, dass es sich um originalgetreue Kopien photogenischer Zeichnungen handelt. In einem mehrteiligen Artikel zur photogenischen Zeichenkunst in der vorangegangenen Heftnummer wird erstmals explizit Bezug auf die bereits bestehende Tradition der Beschäftigung mit Silbernitrat zu Unterhaltungszwecken genommen. Als geeignete Objekte für kameralose Reproduktionen werden unter anderem Spitzen- oder Baumwollstoffe, getrocknete Farn- und Algenpflanzen sowie Gräser genannt. ${ }^{91}$ Nach der Besprechung unterschiedlicher Herstellungs- und Anwendungsweisen kameraloser wie kamerabasierter Fotografie, kommt der Autor zu dem Schluss:

„We have hitherto considered this art as applicable only to the delineation of flat and trivial objects, and as rather conducive to amusement than utility; but as paper acts not only by direct but reflected light, it may be made subservient to much more important uses, by the assistance of such lenses and mirrors as reflect the images given to natural objects upon a screen or medium. The chief

90 George Francis, Drucker der Zeitschrift, beschrieb den Vorgang als direkt auf dem Druckstock ausgeführten Lichtabdruck, der in einem zweiten Schritt entlang der fixierten Konturen geschnitten wurde, siehe dazu: ders., Important Application of Photogenic Drawing, in: The Magazine of Science and School of Arts, 27. April 1839, S. 28; ders., Chemical Experiments, London 1842, S. 120ff. Dazu: Gernsheim 1983, S. 705 (Gernsheim gibt die Reproduktionstechnik - zumindest in der deutschen Version seines Werkes - als Holzschnitt an); Wendel Bridson, Printmaking in the Service of Botany, Pittsburgh 1986, S. 140f.

91 Anonym, Photogenic Drawing, in: The Magazine of Science and School of Arts, 20. April 1839, S. $18-20,26-28$. 
instruments of this character are the camera obscura and the solar microscope. The former is applicable to take views of scenery [...].“992

Entscheidend an dieser Stelle ist die Definition des Fotogramms als bildliches Reproduktionsmedium flacher, „trivialer“ Objekte. Diese Darstellungsfähigkeit kameraloser Fotografie schien dem anonymen Autor zufolge weniger von konkretem Nutzen zu sein, als vielmehr der Belustigung zu dienen. Wichtiger und zukunftsträchtiger wurden dagegen die mit Hilfe einer Camera obscura beziehungsweise eines Mikroskops produzierten Bilder erachtet. Die Gegenüberstellung der nutzbaren Technik „Kamerafotografie“ und des unterhaltsamen Verfahrens „Fotogramm“ offenbart eine Einstufung des letzteren als minderwertige Technik. Spitzenmuster und Pflanzenblätter verweisen zudem auf die „weibliche“ Sphäre und die damit assoziierten Betätigungsfelder. ${ }^{93}$ Sowohl Handarbeit als auch die hobbymäßige Beschäftigung mit Botanik zählten neben der Zeichenkunst und dem Erlernen von Musikinstrumenten zum Erziehungsprogramm junger Frauen der höheren Mittel- und Oberschicht der viktorianischen Ära. Zum einen war dies der seit der Aufklärung vorangetriebenen geistigen und moralischen Erbauung geschuldet, zum anderen aber auch dem Wunsch, bei privaten Präsentationen dieser Fertigkeiten männliche „Sehnsüchte zu erwecken“ und am Heiratsmarkt zu reüssieren. ${ }^{94}$ Verstärkt durch ein breites kommerzielles Angebot an einschlägiger Literatur wurden im häuslichen Rahmen ausführbare Tätigkeiten wie Handarbeit und „Botanisieren“ von Frauen oftmals miteinander verknüpft - beispielsweise in Form von ornamental gestalteten Pflanzenalben. ${ }^{95}$ Zudem wurde im Falle der Zeichenkunst und der Handarbeit nach Vorlagen gearbeitet und damit die „weibliche“ Tätigkeit des Kopierens im Gegensatz zur „männlichen“ genialen Kreation betont. ${ }^{96}$ Diese über die verwendeten Materialien geschlechtsspezifisch determinierten Kategorisierungen werde ich im folgenden Kapitel nochmals expliziter ansprechen.

Eine weitere Hierarchisierung wird über die fehlende perspektivische Raumordnung des Fotogramms vorgenommen: Das fixierte Bild einer Camera obscura entspricht dabei den seit der Renaissance zentralperspektivisch geschulten Sehgewohn-

92 Anonym, Photogenic Drawing, in: The Magazine of Science and School of Arts, 4. Mai 1839, S. 34-35, hier S. 34.

93 Zum Problemfeld „weiblicher Kunstfertigkeiten“ siehe: Parker/Pollock 1981; Parker 2010.

94 Bermingham 2000, S. 184.

95 Solche Arbeiten wurden unter anderem mit dem Begriff „fancy work“ belegt, siehe dazu: Shteir 1996; dies., Gender and „Modern” Botany in England, in: Osiris, Bd. 12, 1997, S. 29-38; Bermingham 2000, S. 145ff.; Ann Shteir, „Fac-Similes of Nature“. Victorian Wax Flower Modelling, in: Victorian Literature and Culture, Jg. 35, Bd. 2, 2007, S. 649-661.

96 Vgl. dazu: Bermingham 2000; v. a. auch die zeitgenössische Rezeption sowie künstlerische Darstellungen der „korinthischen Magd“, S. 160ff. 
heiten der Rezipienten/innen, indem es einen auf ein punktförmiges, neutrales Betrachtersubjekt ausgerichteten räumlichen Eindruck der Außenwelt vermittelt. ${ }^{97}$ Zudem stellte das zentralperspektivisch orientierte Modell ein etabliertes System der bildlichen Interpretation des Seheindrucks dar. Der traditionelle Vergleich zwischen der Funktionsweise und dem Aufbau von Auge und Camera obscura trug zu einer Analogisierung zwischen dem menschlichen Sehen und der durch die Camera obscura erzeugten Bilder bei ${ }^{98}$ So bezeichnete Niépce 1816 seine fototechnisch hergestellten Aufnahmen der Camera obscura als ,rétines“, wohingegen Talbot in The Pencil of Nature explizit Auge und Kamera sowie Netzhaut und Papier analogisierte..$^{99}$ Die Einbeziehung der Camera obscura in die Fotografie ermöglichte ein dem Seheindruck analoges Bild und wurde somit als „naturnah“ gewertet. ${ }^{100}$ Dies kann das flächige Konturenbild des Fotogramms jedoch nicht leisten, weshalb es in jenem Magazin als weniger zukunftsträchtige Technik erachtet wurde ${ }^{101}$ Eine weitere Interpretationsebene erhält die Camera obscura als Visualisierungstechnik eines „erkennenden“ oder „denkenden“ Subjektes, welches mit dem männlichen Geschlecht gleichgesetzt wurde, das den Blick auf ein als weiblich kodifiziertes Objekt richtete. Folgt man dieser Analyse, so steht die mit der technischen Apparatur der Camera obscura verbundene Geistigkeit des Mannes an oberster Stufe, von der aus die kameralose Technik geschlechtscharakteristisch definiert und damit konsekutiv herabgestuft wurde. ${ }^{102}$ Paradigmatisch hierfür ist die die Gegenüberstellung von „Zeitvertreib“ oder „Belustigung" und "wichtigeren Verwendungsweisen“, die als implizite Geschlechtsdifferenzierungen in einen weiblich dominierten privaten und einen männlich konnotierten öffentlichen Bereich beziehungsweise als triviales Hobby gegenüber einer produktiven Visualisierungstechnik gelesen werden können. Die geschlechtsbezogene Aufspaltung der fotografischen Verfahren Talbots und ihre unterschiedliche Hierarchisierung diente letztlich der Konstruktion beziehungsweise Abgrenzung des wissenschaftlichen Gebiets der Fotografie in Reinform. Die in dieser anonymen Rezen-

97 Vgl. dazu: Olaf Breidbach u.a. (Hg.), Camera Obscura. Die Dunkelkammer in ihrer historischen Entwicklung, Stuttgart 2013.

98 Vgl. dazu: Gunthert 2000; Hoffmann 2001; Wolf 2004; Fiorentini 2006; Stiegler 2006, S. 27ff.; ders. 2011.

99 Vgl. Stiegler 2011, S. 75ff.; Siegel 2014, S. 54, 57.

100 Siehe dazu: Martin Jay, Downcast Eyes. The Denigration of Vision in Twentieth-Century French Thought, Berkeley 1993; ders., Photo-unrealism. The Contribution of the Camera to the Crisis of Ocularcentrism, in: Stephen Melville (Hg.), Vision and Textuality, Durham 1995, S. 344-360; Snyder 2002; Wolf 2004.

101 Innerhalb der Rezeption von Fotografie bzw. der Fotografiegeschichtsschreibung stellen diese und ähnliche Rezensionen den Beginn jener Marginalisierungstendenzen des Fotogramms dar, auf die ich bereits eingegangen bin.

102 Vgl. dazu: Schade/Wenk 2005. 
sion dargelegte Struktur der Vergeschlechtlichung steht am Beginn einer Kanonverfestigung der Fotografie unter Ausschluss des „Anderen“. ${ }^{103}$

Darauf, dass „mathematisch“ erzeugte Bilder jedoch nicht mit unserer Sehwahrnehmung vergleichbar sind, wies Erwin Panofsky bereits 1927 hin. Ein zentralperspektivisch erzeugtes Bild beschreibt der Kunsthistoriker dabei als ein Gefüge, dass „den psychophysiologischen Raum gleichsam in den mathematischen umzuwandeln“ im Stande sei und eine „Abstraktion von der Wirklichkeit“ bedeute. ${ }^{104}$ Hubert Damisch wiederum möchte in seiner Studie zum Ursprung der Perspektive selbige nicht im Cassirerschen Sinne als „symbolische Form“ bestimmt wissen, sondern in einem erweiterten Zusammenhang als Denkform und Paradigma. ${ }^{105}$ In Damischs zuvor erschienenen Fünf Anmerkungen zu einer Phänomenologie des photographischen Bildes vermerkt der Philosoph und Kunsthistoriker, dass es sich im Falle des fotografisch fixierten Bildes nicht um etwas natürlich Gegebenes handle. Vielmehr behauptet er: „Die Prinzipien, die zur Konstruktion eines Photoapparates - und zuvor zu der einer camera obscura - hinführen, sind nämlich an eine konventionelle Vorstellung von Raum und Objektivität gebunden, deren Ausarbeitung der Erfindung der Photographie vorausgeht und an die sich die Photographen in ihrer überwiegenden Mehrheit lediglich angepaßt haben." ${ }^{106}$ In solchen Ausführungen zum zentralperspektivisch organisierten Raum im Bild findet sich ein möglicher Ansatz für die fragwürdige Naturalisierung der auf eine/n Betrachter/in bezogenen Darstellung, für die metaphorische Inkorporierung des kamerabasierten Bildes sowie für die damit zusammenhängende Marginalisierung kameraloser Fotografie. Es soll daher betont werden, dass Talbot sowie viele seiner zeitgenössischen Rezensenten in der Frühzeit des Fotografischen einen eminenten Nutzen und somit einen Vorteil des Fotogramms gegenüber der Kamerafotografie feststellten. Kameralose Fotografie wurde als universale Reproduktionstechnik gewertet, welche in der Lage war, Objekte im Maßstab 1:1 zu „kopieren“. In der Fotografiehistoriografie findet dieser Aspekt jedoch kaum Beachtung, da allgemein von der Prämisse der technischen Unzulänglichkeit kameraloser gegenüber kamerabasierter Fotografie ausgegangen wird.

103 Vgl. Paulitz 2012.

104 Erwin Panofsky, Die Perspektive als „symbolische Form“, in: Hariolf Oberer (Hg.), Aufsätze zu Grundfragen der Kunstwissenschaft, Berlin 1985, S. 101. Dazu ebenfalls: Thomas Cohnen, Fotografischer Kosmos. Der Beitrag eines Mediums zur visuellen Ordnung der Welt, Bielefeld 2008, S. $61 \mathrm{ff}$.

105 Hubert Damisch, Der Ursprung der Perspektive, Zürich 2010.

106 Hubert Damisch, Fünf Anmerkungen zu einer Phänomenologie des photographischen Bildes, in: ders., Fixe Dynamik. Dimensionen des Photographischen, Berlin 2004, S. 7-12, hier S. 10. 


\section{Ackermann's Photogenic Drawing Box}

Einen bedeutenden Schritt zur Etablierung und Kommerzialisierung kameraloser Fotografie steuerte das auf Kunstdrucke sowie Künstlerbedarf spezialisierte Unternehmen Ackermann \& Co. bei. Bereits kurz nach der öffentlichen Bekanntgabe der Fotografie durch Talbot entwickelte es ein käuflich erwerbbares Set, bestehend aus unterschiedlichen Instrumenten und Chemikalien, um damit Laien die einfache Herstellung von Fotografien ohne Kamera zu ermöglichen. In Form eines Behältnisses samt Anleitung sowie Vorlagenmaterial bot die Firma ihr Verkaufskonzept unter dem Namen „Ackermann's Photogenic Drawing Box“ in den Londoner Geschäftsstellen bereits Anfang 1839 an. ${ }^{107}$ Gleichzeitig wurden zu Werbezwecken zahlreiche Inserate in namhaften Journalen geschaltet. So versuchte man in The Literary Gazette vom 6. April 1839 die Aufmerksamkeit der Leser und vor allem Leserinnen durch folgende Textbotschaft zu gewinnen:

„Ackermann's Photogenic Drawing-Box, for copying objects by means of the Sun, containing the various requisites and instructions for carrying out this most important and useful discovery; particularly recommended to Botanists, Entomologists, and the scientific; sufficiently clear to enable Ladies to practice this pleasing Art. Price, per box 21s. N.B. The Prepared Paper may be had separately, 2s. per Packet.، ${ }^{\prime 108}$

Demzufolge beinhaltete die Drawing Box nicht nur eine erstmalige Zusammenstellung aller notwendigen Utensilien und eine Anleitung zur Ausführung der neuen Erfindung, sondern sie zeichnete sich zudem durch ihre einfache Verständlichkeit aus, die es sogar Damen erlaube, diese "gefällige“ Kunstform auszuüben ${ }^{109}$ Und obwohl Entomologen und Wissenschaftler im Allgemeinen explizit angesprochen werden, erhält das fotochemische Prozedere durch die Verknüpfung des stereotypen Bildes der „Frau“ und der Figur der Einfachheit eine geschlechtsspezifische Konnotation. Die geschlechtsbezogene Metaphorik dient dabei der bildhaften Erklärung eines technischen Verfahrens, das auf tradierte Vorstellungen eines Geschlechterverhältnisses rekurriert. Die Kategorie Geschlecht ist somit symbolisch daran beteiligt, Ver-

107 Siehe dazu: John Ford, Rudolph Ackermann, in: Oxford Dictionary of National Biography, online unter: http://www.oxforddnb.com (6.3.2018). Da Rudolph Ackermann 1834 verstarb, ist die Entwicklung der nicht patentierten Box seinen Erben zuzuschreiben. Siehe ebenfalls: John Ford, Ackermann 1783-1983. The Business of Art, London 1983.

108 Inserat veröffentlicht in: The Literary Gazette and Journal of Belles Lettres, Arts, Sciences, \&c, 6. April 1839, S. 222.

109 Am Rande sei hier auf George Eastmans Kodak-Kamera verwiesen, zu deren Vertrieb ab 1888 die Einfachheit der Technik das Argument für eine weibliche Käuferschicht darstellte. 
fahrensweisen wie jene der photogenischen Zeichnung systematisch einzuordnen. Einen ähnlichen Vergleich machte auch Daguerre auf seinem Anfang 1839 gedruckten Flugzettel, wenn er bezüglich seiner fotografischen Methode vermerkt: „Les gens du monde y trouveront l'occupation la plus attrayante; et quoique le résultat s'obtienne à l'aide de moyens chimiques, ce petit travail pourra plaire beaucoup aux dames. ${ }^{{ }{ }_{110}}$ Diese Beschreibungen unterschiedlicher fotografischer Verfahren markieren ein kulturell gefestigtes Feld der Vergeschlechtlichung von Technik, welches eine sozial zugeschriebene weibliche Technikdistanz mit einer männlich dominierten Technikaffinität kontrastiert. ${ }^{111}$ Gleichzeitig wird auf diese Weise die Sphärentrennung der Geschlechter auf die Ebene eines technischen Artefakts verlagert, um damit letztlich eine differenzstiftende Ordnung herzustellen.

Heute ist keine Box dieser Art mehr erhalten, jedoch lassen sich leicht abgewandelte „Nachfolgemodelle“ ausfindig machen. ${ }^{112}$ Die einstmals beigefügte Anleitung ist im Victoria \& Albert Museum (Sammlung Royal Photographic Society London) verfügbar und wurde als Nachdruck wiederaufgelegt. ${ }^{113}$ Darin wird vorab auf grundlegende Arbeiten Talbots beziehungsweise auf die eigene Aufbereitungsleistung für eine nichtwissenschaftliche Öffentlichkeit verwiesen. ${ }^{114}$ Zum breiten Anwendungsspektrum des bildgebenden Verfahren heißt es: „[...] we have no hesitation in recommending it [the art of photogenic drawing] as a means by which exact copies may be made of the most intricate patterns of needle-work; for the accurate delineation of the leaves and other parts of a plant, and the representation of many subjects of Natural History. ${ }^{{ } 115}$

110 Vgl. dazu: An Announcement by Daguerre, in: Image. Journal of Photography of the George Eastman House Jg. 8, Nr. 1, März 1959, S. 32-36, hier S. 34; Siegel 2014, S. 38-40.

111 Siehe dazu: Paulitz 2012; Angelika Saupe, Vergeschlechtlichte Technik - über Geschichte und Struktur der feministischen Technikkritik, online unter: http://www.gender.hu-berlin.de/ publikationen/gender-bulletins/texte-25 (5.3.2018).

112 Ein ähnliches Konzept verfolgte möglicherweise der Händler Romain Talbot mit einer sogenannten „Sonnencopirmaschine“, die Hermann Vogel als „Spielzeug“ bezeichnete, siehe dazu: Vogel 1873, S. 23.

113 Ackermann \& Co 1977, siehe dazu: John Hannavy, Books and Manuals on Photography: 1840s, in: ders. 2008, S. 177-178.

114 Bereits 1816 wurde in der hauseigenen Zeitschrift ein Artikel publiziert, der auf Silbernitratexperimente Wedgwoods und Davys eingeht. Siehe dazu: Anonym, Singular Method of Copying Pictures, and Other Objects, by the Chemical Action of Light, in: The Repository of Arts, Literature, Fashions, Manufactures, \&c, 1. Oktober 1816, Bd. 10, S. 203-204.

115 Ackermann \& Co 1977, S. 1. Vgl. dazu Daguerres veranschlagte Anwendungsgebiete seiner Erfindung, in: An Announcement by Daguerre, in: Image. Journal of Photography of the George Eastman House, Jg. 8, Bd. 1, März 1959, S. 32-36, Vgl. ebenfalls Aragos Analyse des ökonomischen Potenzials der Daguerreotypie im Zuge seiner Rede vor der Pariser Deputiertenkammer am 3. Juli 1839: Arago 1839. 


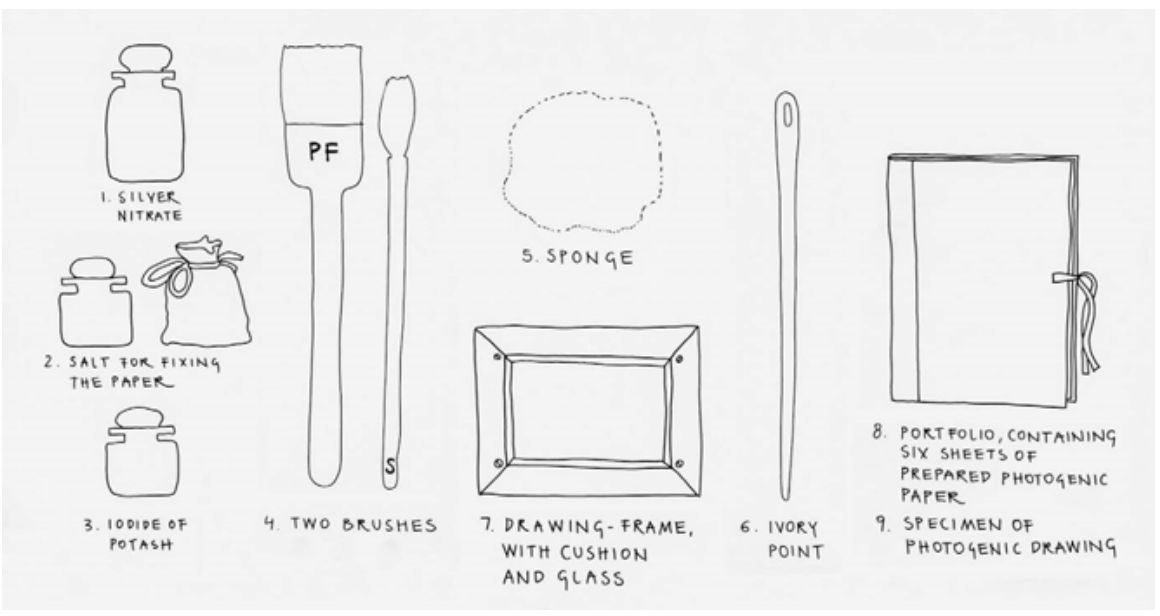

28 Schema des Inhalts einer Ackermann's Photogenic Drawing Box, 1839 (Illustration: Helga Aichmaier).

Als grundlegende Funktion der Technik nannte man die Herstellung von Kopien. Wissensgebiete wie Botanik, Entomologie, aber auch das Praxisfeld der Handarbeit bekämen damit ein exaktes Abbildungsverfahren an die Seite gestellt. Auch die weibliche Leserschaft wurde über die Möglichkeit einer Arbeitserleichterung adressiert: „[...] by means of Photogenic Drawing, the most elaborate effort of the most skilful female hand, whether it has been directed to the production of the richest lace, or an elaborate piece of tambour-work, can be copied in the space of a few seconds, without the least injury to the delicate fabric."

Die in diesem Zitat angesprochene ,talentierte weibliche Hand“ verweist im Feld der Stickkunst auf eine Praxis, die als „geschlechtscharakteristische“ Beschäftigungsform von Frauen angesehen wurde und das feminine Ideal einer häuslichen Produktivität und damit einer weiblichen Tugend umschrieb - im Gegensatz zu männlichen Attributen wie Rationalität und öffentlicher Sphäre. ${ }^{117}$ Filigranste Produkte weiblichdekorativer Handwerkstätigkeit - in diesem Fall Spitzenstoffe - konnten mit Hilfe der photogenischen Zeichnung unbeschadet zur Kopie gebracht beziehungsweise ersetzt werden. Insbesondere der bereits angesprochene Begriff der Kopie ist hinsichtlich einer genderspezifischen Perspektivierung entscheidend: Über die damals vorherrschende Geschlechterdichotomie stellte man das männliche Genie weiblichen reproduktiven Anlagen gegenüber. Im Feld der Kunst bedeutete dies, dass allein dem

116 Ackermann \& Co 1977, S. 2.

117 Paulitz 2012; Parker 2010. Zum Begriff der „Geschlechtscharakteristik“: Hausen 1976, S. 363393. 


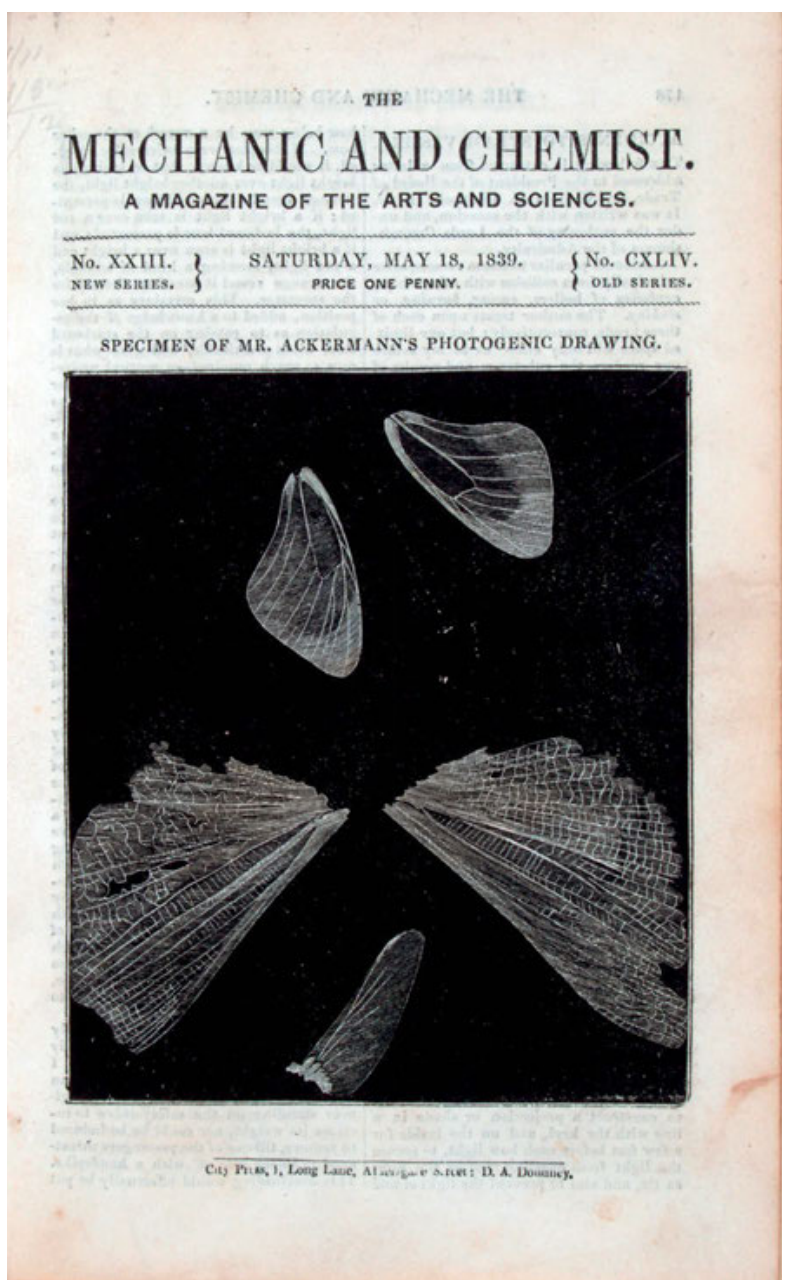

29 Specimens of Mr. Ackermann's Photogenic Drawing, Titelblatt, aus: The Mechanic and Chemist.

A Magazine of the Arts and Sciences, 18. Mai 1839.

männlichen Künstler die Fähigkeit der geistreichen Erfindung attestiert wurde und weibliche Erzeugnisse in den Bereich des Kunsthandwerks und minderwertiger Kunstgenres wie der Blumenmalerei fielen. Um nun einen Spitzenstoff anzufertigen, arbeiteten Frauen nach einer Mustervorlage, wodurch im Falle der photogenischen Zeichnung im zweifachen Sinne von einer Kopie gesprochen werden kann. ${ }^{118}$ Vor

118 Vor allem die Tätigkeit des Kopierens nach einer Vorlage wurde als zutiefst weibliche Eigenschaft gesehen. Dementsprechend standen weibliche „Kunstproduktionen“ in der Hierarchie der Künste an untergeordneter Stelle. Siehe dazu: Parker/Pollock 1989; Bermingham 2000; Parker 2010. 
allem in der viktorianischen Ära war es der Bereich „weiblicher Kunstproduktion“, der mit dem Akt des augentrügerischen "Nachahmens" verbunden wurde und unter anderem Objekte wie Blumenbouquets aus Wachs oder Muscheln hervorbrachte. ${ }^{119}$ Unter diesem Aspekt können auch photogenische Kopien von Spitzenmustern als Trompe-l'œil identifiziert werden, indem sie unter Ausblendung ihrer eigenen Materialität eine reale Textilie vortäuschen. Die weibliche Leserschaft wurde daher in mehrfacher Hinsicht auf die Ausübung dieses reproduktiven Verfahrens hin adressiert. Im Feld der Botanik wiederum ließen sich gemäß Ackermanns Anleitung mit nur wenigen Blättern photogenischen Papiers Zeichnungen erstellen, welche Herbarexemplare in Naturtreue und Detailgenauigkeit übertreffen würden. Der Entomologe wiederum könne eine Sammlung exakter Umrisszeichnungen von Insektenteilen erhalten, die ihm nicht nur die spezifische, sondern auch die generische Zuordnung derselben erlauben würde. Neben Fläschchen, die mit Silbernitrat und Kaliumiodid gefüllt waren, enthielt Ackermann's Photogenic Drawing Box Salz für den Fixiervorgang, zwei Pinsel und einen Schwamm zum Auftragen der Flüssigkeiten, ein Stäbchen aus Elfenbein zur Ausrichtung der Objekte am Papier, einen Kopierrahmen, eine Mappe mit sechs Blättern photogenischen Papiers sowie als Orientierungsvorlage eine bereits ausgeführte photogenische Zeichnung (Abb. 28). ${ }^{120}$ Eine solche durch Ackermann hergestellte Vorlage zierte das Titelblatt der am 18. Mai 1839 erschienenen Ausgabe der Zeitschrift The Mechanic and Chemist mit der vergrößerten Darstellung von Insektenflügeln (Abb. 29). Im anschließenden Artikel wird weniger auf das Titelblatt, denn auf Ackermanns photogenischen Zeichenkasten eingegangen. Betont wird darin vor allem die durch das Set gewährleistete allgemeine Zugänglichkeit und Nachvollziehbarkeit des Verfahrens:

„[...] we have now the satisfaction of informing our readers that Messrs. Ackermann and Co., 96, Strand, have arranged an apparatus or photogenic drawingbox, which (by attending to the directions that accompany it) will enable any person to produce a picture more true to nature than the performance of any human hand, and that, too, in a very short space of time, varying with the intensity of the light, and also with the different methods of preparing the paper. ${ }^{{ }_{121} 1}$

119 Vgl. dazu Schwartz’ Begriff der „Culture of the Copy“: Schwartz 1996. Zu der in Anführungsstrichen gesetzten Thematik weiblicher Kunstproduktion im 19. Jahrhundert, siehe: Parker/ Pollock 1981.

120 In Bezug auf die beigefügten Materialien, siehe: Ackermann \& Co 1977, S. 3.

121 Anonym, Photogenic Drawing, in: The Mechanic and Chemist. A Magazine of the Arts and Sciences, Bd. 23, 18. Mai 1839, S. 182-183. 


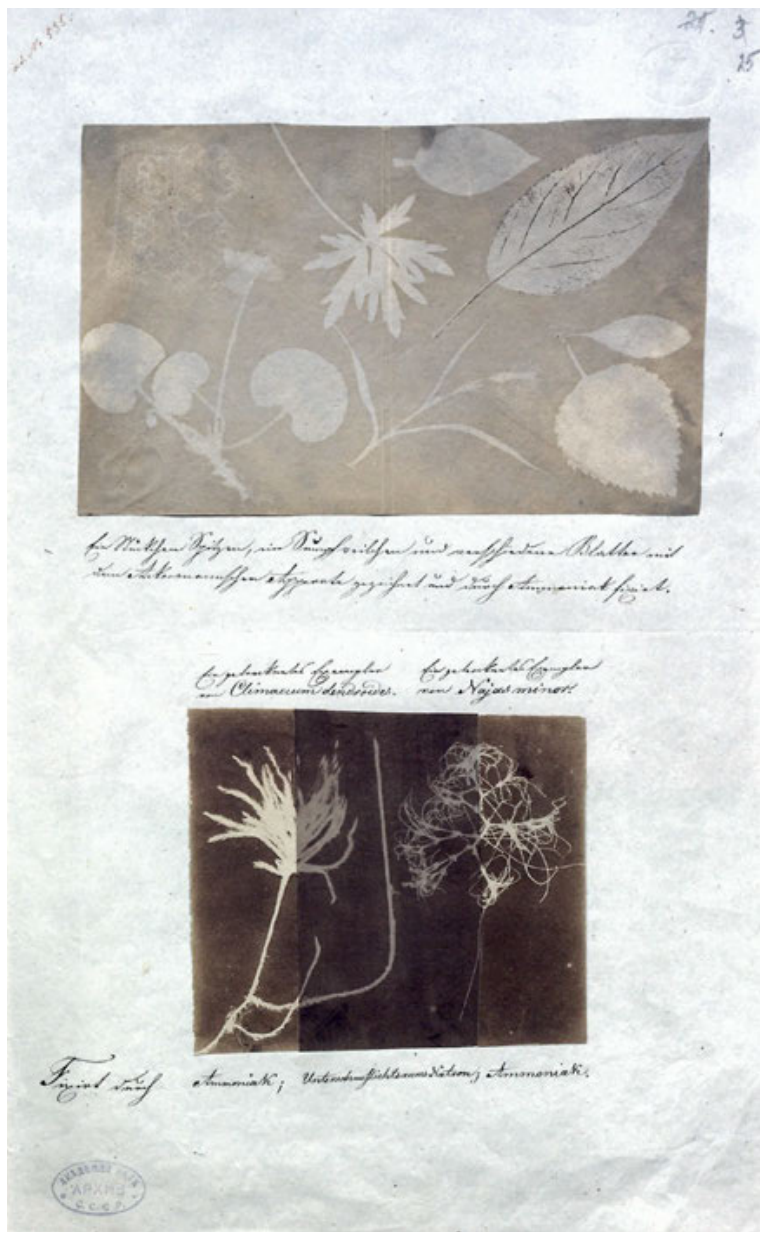

30 Julius Fritzsche, Photogenic Drawing, Negative, Mai 1839, Teil des wissenschaftlichen Berichtes an die Russische Akademie der Wissenschaften, Russische Akademie der Wissenschaften, St. Petersburg.

Mit dieser Box sei es demnach jedermann möglich, naturgetreue Bilder innerhalb kürzester Zeit anzufertigen. ${ }^{122} \mathrm{Zu}$ einem anderen Urteil kam hingegen der Chemiker

122 Vgl. dazu auch Daguerres Anfang 1839 erstellten Flugzettel, auf dem zu lesen ist: „Chacun, à l'aide du DAGUERRÉOTYPE fera la vue de son château ou de sa maison de campagne [...].“, An Announcement by Daguerre, in: Image. Journal of Photography of the George Eastman House Jg. 8, Nr. 1, März 1959, S. 32-36, hier S. 34. Vgl. dazu Talbots Brief an Herschel, in dem er seine Erfindung als ,every man his own printer and publisher“ anpreist, Brief vom 21. März 1839, online unter foxtalbot.dmu.ac.uk (6.3.2018). Vgl. ebenfalls die Rede Aragos vom 3. Juli 1839. Darin heißt es: „Le daguerréotype ne comporte pas une seule manipulation qui ne soit à la portée de tout le monde; il ne suppose aucune connaissance du dessin; il n'exige aucune dextérité manuelle. En se conformant de point en point à des prescriptions très-simples et très- 


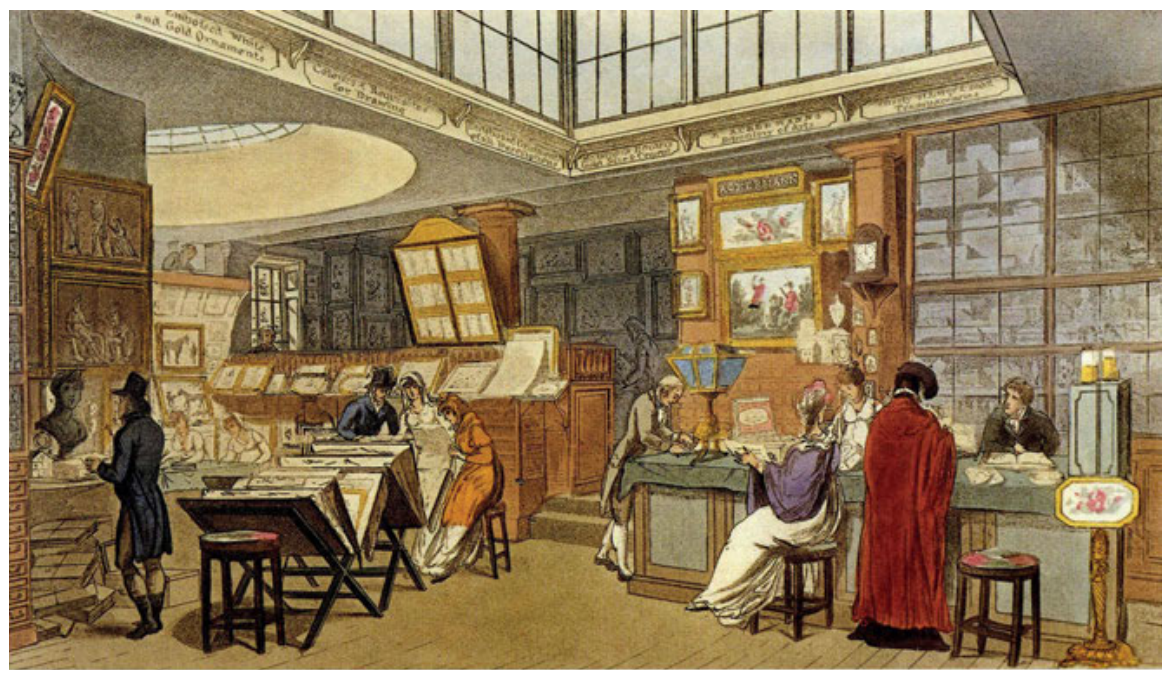

31 Augustus Pugin und Thomas Rowlandson, Ackermann's Repository of Arts, 101 Strand, Illustration, aus: The Repository of the Arts, Januar 1809.

Carl Julius Fritzsche, der im Auftrag der Russischen Akademie der Wissenschaften einen Bericht über die neuesten Entwicklungen im Bereich der Fotografie samt experimenteller Proben vorlegte (Abb. 30). Zur Herstellung photogenischer Zeichnungen verwendete er Ackermann's Photogenic Drawing Box und bewertete diese in einem am 23. Mai 1839 abgefassten Brief:

„Man bedient sich dabei eines Rahmens in welchem man das Papier mit den darauf liegenden Gegenständen zwischen ein Kissen und eine Glasplatte einpreßt; daraus ergiebt sich aber daß nur flache blattartige Gegenstände dazu genommen werden können, und für alle anderen Gegenstände ist daher der Apparat unbrauchbar. [...] Aus dem Gesagten ergiebt sich nun von selbst, daß die vorliegende Methode und der Apparat nur von sehr beschränkten Nutzen für die Wissenschaft seyn kann; der Botaniker kann sich ihrer dann mit Vortheil bedienen, wenn es sich darum handelt getreue Zeichnungen von Originalexemplaren aus Herbarien zu haben, kaum aber möchte sie für den Zoologen einigen Werth haben, so wie auch wohl im Allgemeinen ihr praktischer Nutzen nur sehr gering seyn wird." ${ }^{123}$

peu nombreuses, il n'est personne qui ne doive réussir certainement et aussi bien que $\mathrm{M}$. Daguerre lui-même.“, Arago 1839, S. 36.

123 Der Bericht befindet sich im Archiv der Russischen Akademie der Wissenschaften. Ackermann's Box wurde Fritzsche durch Joseph Hamel zur Verfügung gestellt, der im Auftrag der 
Fritzsche stellte dem Set für wissenschaftliche Zwecke ein negatives Urteil aus. Für die Etablierung der Technik des Fotogramms sowie ihre allgemeine Zugänglichkeit ist die Box jedoch von enormer Bedeutung, zumal sich bei Ackermann \& Co. bereits der Verweis auf einen konkreten „Apparat“ zur Erzeugung photogenischer Zeichnungen findet. ${ }^{124}$ So heißt es in der Anleitung: „The apparatus employed to copy the above objects consists of a wooden frame, like that of a small looking-glass, in which a plate of clear glass is placed, resting on a rabbet in the usual manner, over which is a cushion of silk, fixed to the backboard, and pressed upon the glass, when necessary." ${ }^{\text {"125 }}$ Einem hölzernen Rahmen eines kleinen Handspiegels mit Fuge gleich, stattete man jenen Kopierrahmen mit einer Glasplatte sowie einer mit Seide überzogenen Rückwand aus und funktionierte damit einen Alltagsgegenstand in ein wissenschaftliches Instrumentarium um. Wenn man gemäß dieser Beschreibung zudem die verwendeten Materialien näher betrachtet - größtenteils künstlerisches Werkzeug wie Pinsel, Schwämme und Papier - kann einmal mehr der Bezug zur Zeichenkunst hergestellt werden.

Wie Bermingham herausarbeiten konnte, förderte die Kunstbedarfshandlung Rudolph Ackermann (vgl. Abb. 31) die Nachfrage nach künstlerischem Equipment für den Amateurbereich. Aufgrund der Kommerzialisierung der Zeichenkunst beziehungsweise ihrer Etablierung als beliebte Freizeitbeschäftigung und „accomplishment" junger Damen, bestand die Käuferschicht in erster Linie aus einem weiblichen Publikum. ${ }^{126}$ Die zwischen 1809 und 1829 vertriebene hauseigene Zeitschrift The Repository of Arts, Literature, Commerce, Manufacture, Fashions and Politics rangierte spätestens ab dem Jahre 1812 unter den führenden Frauenmagazinen. ${ }^{127}$ Diese Unterhaltungsschrift bot neben Abhandlungen zu Fragen der Ästhetik und Kunstkritik auch Klöppel- und Stickvorlagen, Stoffmusterproben, Modeentwürfe sowie Hinweise zu käuflich erwerbbaren Warenangeboten. Im „Repository of Arts“, wie auch das Verkaufslokal bezeichnet wurde, konnte sich die Amateurwelt mit Künstlerbedarf sowie mit vorgefertigten Bastelmaterialien, darunter ebenfalls Ausschneidebögen, versorgen. Im

Russischen Akademie der Wissenschaften Aufklärungsreisen zum Themengebiet der Fotografie unternahm. Vgl.: Schaaf 1998, S. 40, Anm. 48; Jelena Barchatowa, Die ersten Photographien in Rußland, in: David Elliott (Hg.), Rußische Photographie 1840-1940, Ausst.-Kat. Rheinisches Landesmuseum Bonn, Berlin 1993, S. 24-29; Serge Plantureux, Niépce, Daguerre, or Talbot? The Quest of Joseph Hamel to Find the Real Inventor of Photography, Checy 2004.

124 Laut Batchen verwendete Talbot bereits 1835 einen Kopierrahmen, siehe dazu: Batchen 2002, S. 159 (ohne Quellenangabe); Schaaf 1992, S. 59.

125 Ackermann \& Co 1977, S. 5. Siehe ebenfalls: Ware 1994, S. 11-15. In Anleitungsbüchern zur Fotografie findet sich spätestens 1841 der Hinweis auf sogenannte „printing frames“, ,,copying frames" oder nur ,frames".

126 Bermingham 2000, S. $127 \mathrm{ff}$.

127 Vgl. ebenda, S. 140. Konkrete Auflagenzahlen konnten nicht ermittelt werden. 
weiteren Angebot und vergleichbar mit der Photogenic Drawing Box führte Ackermann \& Co aufwendig verarbeitete Kästchen aus Mahagoni mit Utensilien für Aquarellmalerei, Schachteln mit Materialien zur Herstellung von Wachsblumen, aber auch in einem hölzernen Kistchen aufbewahrte Drehscheiben zur Anfertigung eines Phantasmaskops. ${ }^{128}$ Insbesondere die Aufbewahrungsform von Ackermann's Photogenic Drawing Box ist im Hinblick auf die Etablierung fotografischen Wissens aufschlussreich ${ }^{129}$ Historisch betrachtet ist dieses Set zur Herstellung kameraloser Fotografien mit Chemiebaukästen Ende des 18. und Anfang des 19. Jahrhunderts vergleichbar. Jene sogenannten „Probierkabinette“ oder „Experimentierkästen“ wurden in erster Linie als Ergänzung zu Anleitungsbüchern der Chemie vertrieben, unter anderem durch den Spielwarenhändler Georg Hieronymus Bestelmeier. ${ }^{130}$ Vor allem in England im ersten Drittel des 19. Jahrhunderts erfuhren Kästchen dieser Art unter interessierten Laien eine Hochkonjunktur, da die Vermittlung naturwissenschaftlichen Wissens dem Bildungsideal der Aufklärung entsprach. ${ }^{131}$ Probierkabinette wurden eingesetzt, um Experimente nach Anleitung nachzuvollziehen sowie durch den Praxisvollzug zur Wissensvermittlung beizutragen. Vorrangig dienten sie jedoch der Unterhaltung, da mit ihnen erstaunliche oder auch magisch anmutende Effekte erzielt werden konnten. Durch die Aufbereitung wissenschaftlicher Erkenntnisse auf einfache und anschauliche Weise kam ihnen eine didaktische Funktion zu. Ackermann \& Co erkannte das kommerzielle Potenzial kameraloser Fotografie und entwickelte ein transportables „Fotografielaboratorium“, das alle notwendigen Utensilien zur Herstellung und Fixierung von Fotogrammen samt Anleitung sowie „Vorsichtsmaßnahmen“ zur Vermeidung potenzieller Fehlerquellen umfasste. Fotografieneulinge konnten damit auf einfache Weise sowohl fotosensibles Papier herstellen, als auch bereits präparierte Bögen gemäß einer beiliegenden Vorlage mit flachen Objek-

128 Vgl. ebenda, S. 127ff. Zu viktorianischen Aquarellkästen, siehe: Nina Fletcher Little: Artists' Boxes of the Early Nineteenth Century, in: American Art Journal, Jg. 12, Bd. 2, 1980, S. 25-39.

129 Zur wissenschaftshistorischen Bedeutung von Aufbewahrungsformen siehe: te Heesen 1997.

130 Vgl. dazu: Brian Gee, Amusement Chests and Portable Laboratories. Practical Alternatives to the Regular Laboratory, in: Frank James (Hg.), The Development of the Laboratory, London 1989, S. 37-59; Georg Schwedt, Kabinettstücke der Chemie. Vom chemischen „Probir-Cabinet“ zum Experimentierbaukasten, in: Kultur \& Technik, Bd. 2, 1992, S. 42-47; Elisabeth Vaupel, Liliput-Labors. Vom Reiselabor zum Lernmittel für Autodidakten, in: Kultur \& Technik, Bd. 2, 2001, S. 42-45; dies., Ein Labor wie eine Puppenstube. Kurze Geschichte der chemischen Experimentierkästen, in: Praxis der Naturwissenschaften - Chemie in der Schule, Bd. 54, 2005, S. 2-6; Florian Öxler/Christoph Friedrich, Experimentierkästen „ohne den geringsten Nutzen“? Eine Diskussion Ende des 18. Jahrhunderts, in: Chemie in unserer Zeit, Jg. 42, Bd. 4, 2008, S. 282-289; Viola van Beek, „Man lasse doch diese Dinge selber einmal sprechen“. Experimentierkästen, Experimentalanleitungen und Erzählungen zwischen 1870 und 1930, in: NTM, Jg. 17, Bd. 4, 2009, S. 387-414.

131 Vgl. dazu: Gee 1989; Vaupel 2001. 
ten selbst belegen. Mit der Aufbewahrungsart in Form eines kleinen tragbaren Kästchens samt Utensilien und Anleitung schließt Ackermann \& Co. an die bekannte Praxis der Wissensvermittlung chemischer Probierkabinette an. Der britischen Kunstbedarfshandlung kommt daher das Verdienst zu, die Technik des Fotogramms für ein Laienpublikum nicht nur aufbereitet und käuflich erwerbbar gemacht, sondern auch popularisiert zu haben. Im Unterschied zu George Eastmans Kodakkamera und dem damit allgemein verbundenen Beginn der Amateurfotografie ab 1888 bestand die Vermarktungsform eines vorgefertigten sowie einfach verständlichen Sets zur Ausübung von Fotografie bereits 1839 und damit Jahre vor der Markteinführung der amerikanischen Boxkamera. ${ }^{132}$ Es soll daher betont werden, dass Ackermann \& Co. nur wenige Monate nach der öffentlichen Bekanntgabe den Versuch einer breitenwirksamen und vor allem anschaulichen Einführung eines fotografischen Verfahrens - in Form kameraloser Fotografie - initiiert hatten. ${ }^{133}$ Welcher Personenkreis Ackermann's Photogenic Drawing Box in erster Linie bezogen hat, lässt sich aufgrund fehlender Quellen nicht nachweisen. ${ }^{134}$ Es kann jedoch die Vermutung aufgestellt werden, dass spätestens ab der Markteinführung des Sets das grundsätzliche Erlernen der fotografischen Technik oftmals anhand der theoretischen Erläuterung kameraloser Fotografie erfolgte. Auf diesen Aspekt möchte ich in folgendem Unterkapitel näher eingehen.

\section{„How to Commence Photography“}

Zur Verdeutlichung der Stellung beziehungsweise Rezeption kameraloser Fotografie in der Frühzeit ziehe ich Handbücher zur Theorie und Praxis der Fotografie mit Publikationsdatum zwischen 1839 bis 1858 heran. Auf diese Weise soll zum einen die didaktische Funktion des Fotogramms - aufgrund seiner Einfachheit und Anschaulichkeit in der Vermittlung von Fotografie - verdeutlicht und zum anderen aufzeigt werden, welche Praxisfelder mit kameraloser Fotografie verknüpft waren und als zukunftsträchtig erachtet wurden.

132 Zum Konzept der Marketingstrategien Eastmans, siehe: Kamal Munir, The Birth of the Kodak Moment. Institutional Entrepreneurship and the Adoption of New Technologies, in: Organization Studies Jg. 26, Bd. 11, 2005, S. 1665-1687.

133 Mit der Einführung eines auf Einfachheit und Nachvollziehbarkeit setzenden Sets kann Ackermann \& Co. in pädagogische Konzepte des 18. und 19. Jahrhunderts eingereiht werden. Weiterführende Literatur dazu: te Heesen 1997, S. 50ff.

134 Auch der relativ hohe Preis der Box von 21 Shilling lässt einen eingeschränkten Personenkreis als potenzielle Käuferschicht vermuten. 1 Pfund (=20 Shilling) entsprach dem durchschnittlichen Wocheneinkommen eines Arbeiters in der Landwirtschaft um 1850, Quelle: Department of Employment and Productivity, British Labour Statistics. Historical Abstract 1886-1968, London 1971. 


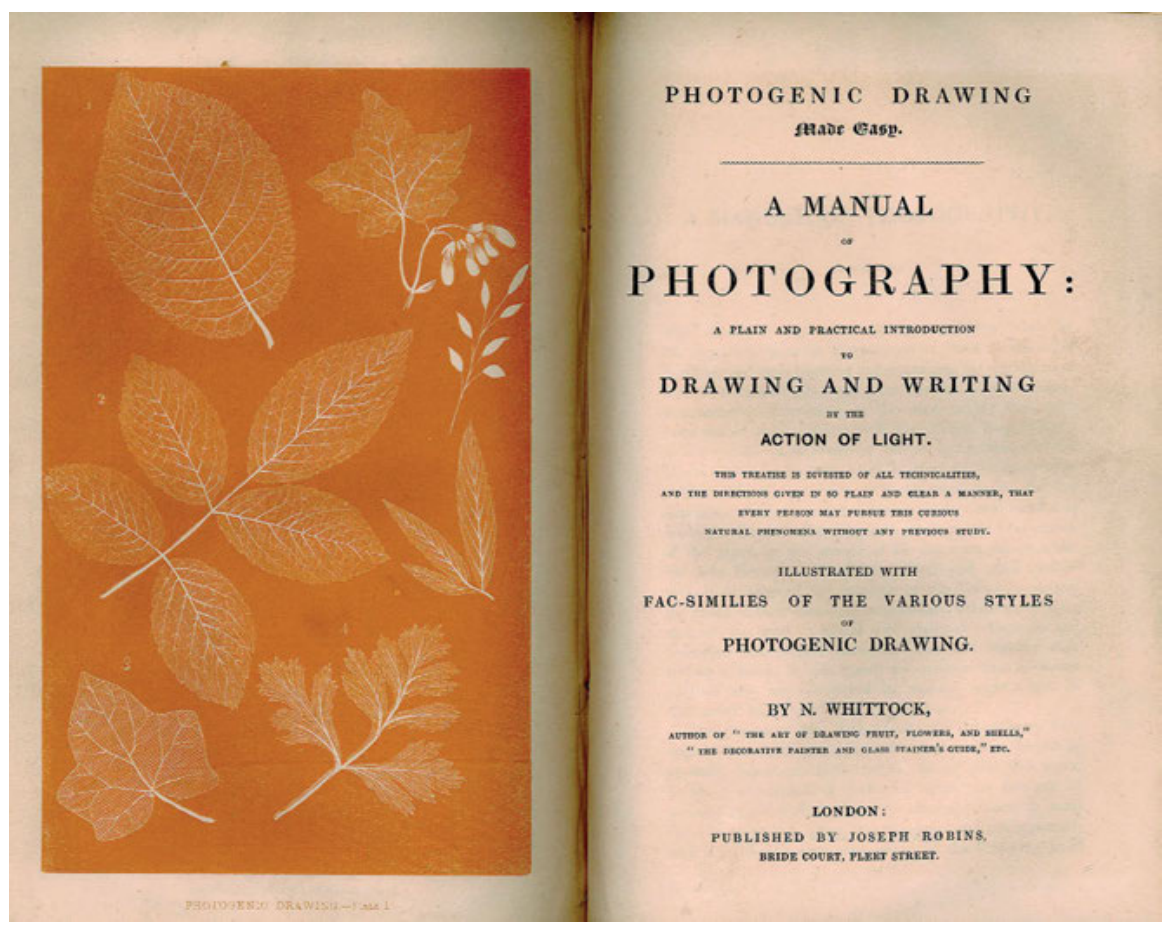

32 Illustration photogenischer Zeichnungen unterschiedlicher Blätter, aus: Nathaniel Whittock, Photogenic Drawing Made Easy, London 1843, Plate I.

In der vermutlich am 22. August 1839 erschienenen Schrift Friedrich August Wilhelm Nettos Vollständige Anweisung zur Verfertigung Daguerre'scher Lichtbilder - im eigentlichen Sinne eine Beschreibung zur Herstellung von Bildern mit Silbernitrat wird auf zwei Varianten fotografischer Bilderzeugung verwiesen: auf die Möglichkeit der „Abbildung durch Bedeckung“ und auf eine „Abbildung mittelst der Camera obscura oder mittelst eines Sonnenmikroscops“. ${ }^{135}$ Mit erstgenannter Methode ließen sich gemäß Netto „Pflanzen, Zeichnungen, Handschriften, Membranen, Insektenflügeln, Spitzen und andern flachen netzartigen Gegenständen mehr" abbilden, wohingegen zweitgenannte Technik zur Reproduktion von „Werken der Bau- oder Bildhauerkunst, Insecten, Portraits u. dgl. m.“ dienen sollte. ${ }^{136}$ In dieser Schrift werden derartige Verfahren jedoch nicht auf ihr Innovationspotenzial hin bewertet, sondern als Praxis anschaulich vermittelt. 


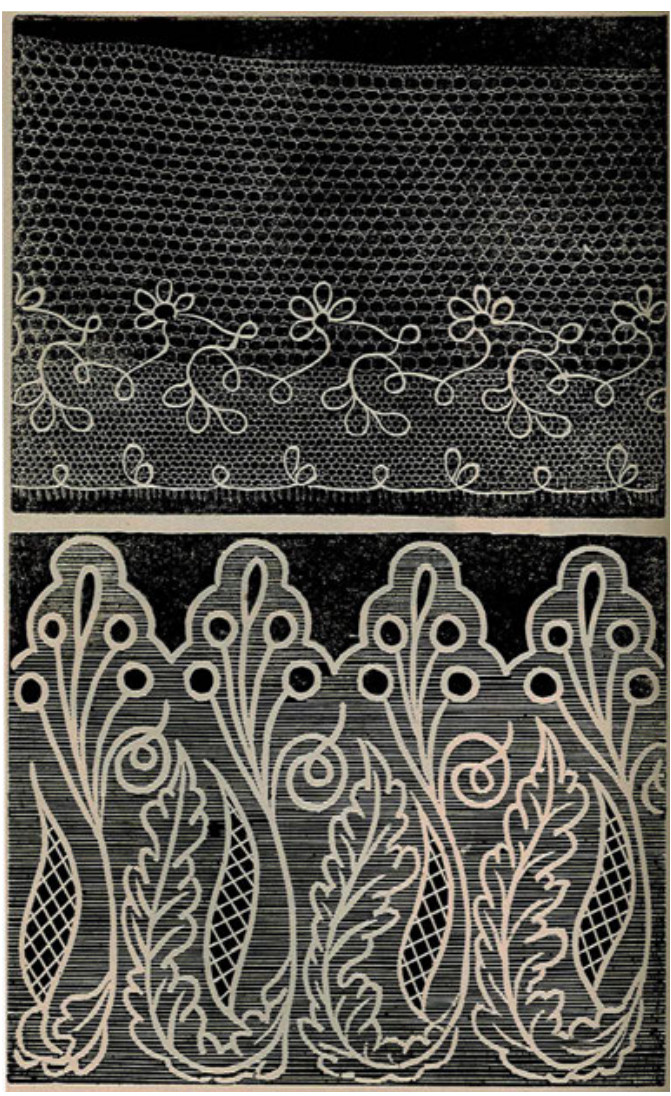

33 Illustration photogenischer Zeichnungen von Spitzenmustern, aus: Nathaniel Whittock, Photogenic Drawing Made Easy, London 1843, Plate II.

Die bei Netto veranschlagten Objekte zur Herstellung von Fotogrammen ziehen sich wie ein roter Faden durch die nachfolgend skizzierte Anleitungsliteratur. ${ }^{137}$ Anhand der genannten Naturalia wie Artificialia werden die Exaktheit kameraloser Fotografie, ihre jeweiligen Darstellungsoptionen sowie ihre möglichen Anwendungsgebiete verdeutlicht. So bezeichnete William Thornthwaite Talbots Technik kameraloser Bildproduktion in seinem 1843 erschienenem Werk Photographic Manipulation aufgrund des geringen Materialaufwands als „einfachsten Zweig der Fotografie“. ${ }^{138}$ Aufgrund der Möglichkeit, Objekte wie Pflanzenblätter abzudrucken, sei dieses neue Verfahren zudem ein unerlässliches Handwerkszeug für den reisenden Naturwissen-

137 Siehe unter anderem auch: Francis 1842, S. 120; Henry Snelling, The History and Practice of the Art of Photography, New York 1849, S. 93.

138 William Thornthwaite, Photographic Manipulation, London 1843, S. 7. 
34 Illustration eines negativen sowie eines positiven Fotogramms, aus: Robert Hunt, A Manual of Photography, London 1854.

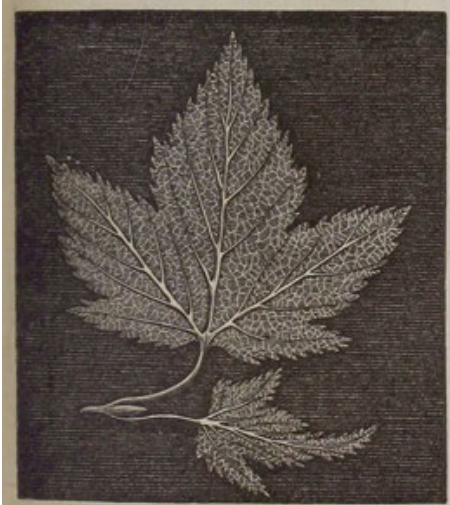

Fig. 12.

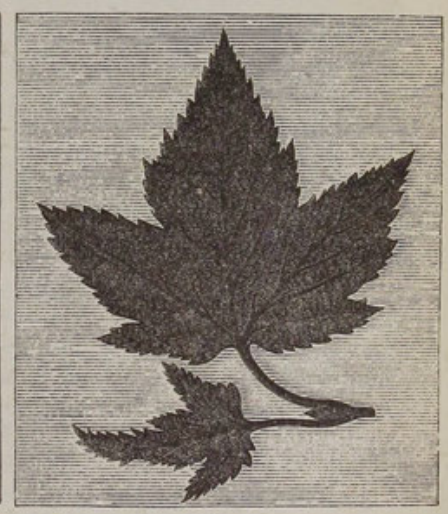

Fig. 13.

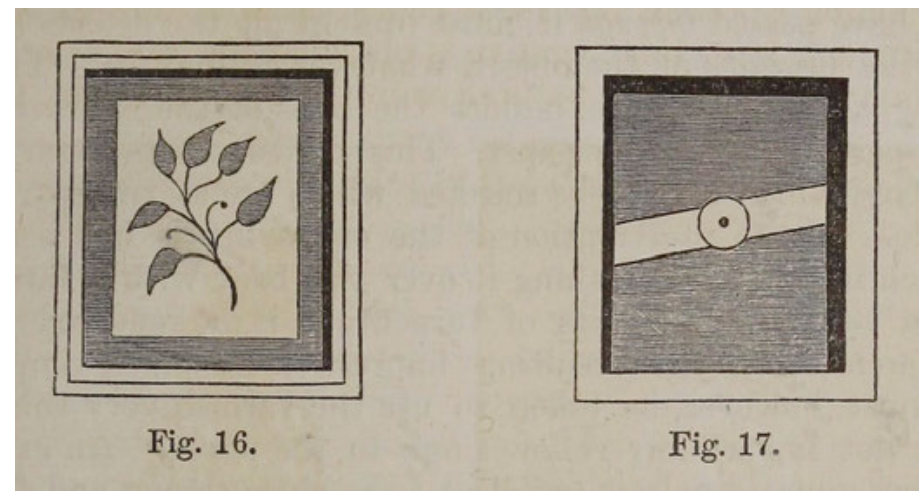

schaftler, um „correct copies from Nature's self“ zu erhalten. ${ }^{139}$ Diese vom Autor ferner als „fac-similes“ bezeichneten Kopien eigneten sich durch die klare Darstellung der Umrisslinie wie der Zeichnung von Details für eine taxonomische Bestimmung. ${ }^{140}$ Nathaniel Whittock wiederum stellte sich mit seiner um das Jahr 1843 erschienenen Schrift Photogenic Drawing Made Easy der Aufgabe, jene durch Talbot erfundene Technik für jedermann auf einfache Weise nachvollziehbar zu machen. ${ }^{141}$ Neben dem auszugsweisen Wiederabdruck von Schriften Talbots lieferte der Autor ebenfalls konkrete Anweisungen zur Herstellung fotosensiblen Papiers sowie der Erzeugung kameraloser wie kamerabasierter Fotografien. Im Unterschied zu den bereits erwähnten Publikatio-

139 Ebenda, S. 6.

140 Ebenda, S. 6f.

141 Nathaniel Whittock, Photogenic Drawing Made Easy. A Manual of Photography. A Plain and Practical Introduction to Drawing and Writing by the Action of Light, London 1843. 
nen wurden dem Buch zum Zweck der Anschaulichkeit seitenfüllende Illustrationen photogenischer Zeichnungen in druckgrafischer Übersetzung beigefügt, auch in diesem Werk als „Facsimiles“ bezeichnet. ${ }^{142}$ Eine dieser Illustrationen (Abb. 33) zeigt zwei unterschiedliche Spitzenmusterfotogramme in druckgrafischer Reproduktion, über die sich der Autor direkt an die weibliche Leserschaft wendet: „,...] ladies will at once see the applicability of this art to procuring patterns. They require no further directions: all that is necessary is place the objects upon the prepared paper under the glass, and in three minutes while the sun shines, or about ten minutes if the day happens to be cloudy, the drawings will be produced." ${ }^{143}$

Auch hier wird das Material wie die Einfachheit des Verfahrens als Argument für Frauen ins Spiel gebracht. Abbildung 32 wiederum stellt unterschiedliche, quer über das Blatt verteilte sowie nummerierte Pflanzenblattformationen samt ihrer klar differenzierbaren Nervatur in photogenischer Ausführung dar. Didaktische Vermittlungsfunktion für den fotografischen Prozess erhält das Verfahren des Fotogramms durch die Möglichkeit der direkten Beobachtung des allmählichen Verfärbungsprozesses des lichtempfindlichen Papiers. Für Fotografieneulinge sei die photogenische Zeichnung in dem Moment als fertig erkennbar, so Whittock, sobald die Verfärbung des nicht durch Pflanzenproben bedeckten Teils des Papiers durch die Glasplatte hindurch als ,ausreichend dunkel“ und eine der dem Buch beigefügten Illustrationen vergleichbare Färbung aufweise. ${ }^{144}$

Auch für Robert Hunt stellt das Fotogramm die Grundlage der photographischen Vermittlungsarbeit dar. In seinem 1854 erschienenem Manual of Photography erklärt er anhand der Darstellung einer positiven und einer negativen Abdruckfotografie nicht nur die grundsätzliche Wirkungsweise der Fotografie (Abb. 34), sondern führt damit auch in sein Kapitel zur „ersten Ausübung“ der Praxis auf Papier ein. ${ }^{145}$ Laut Hunt handle es sich dabei um die „einfachste Methode“ die Technik der Fotografie zu erlernen. ${ }^{146}$ Zur Herstellung solcher Bilder sei fotosensibles Papier sowie ein mit einer Glasfront und Schraubelementen versehener Kopierrahmen (Abb. 35) notwendig, der auch im Rahmen des Umkopierens von negativen in positive Kameraaufnahmen Verwendung finde. Wie elementar seiner Ansicht nach das Erlernen kameraloser Fotografie ist, verdeutlicht Hunt mit folgender Bemerkung: „A great number of experiments should be made with the copying frame before there is any attempt at using the camera obscura. ${ }^{\text {“147 }}$ Das Verfahren der direkten Abdruckfotografie wurde demnach

142 Siehe die gleichlautende Buchuntertitelung.

143 Whittock 1843, S. 14.

144 Ebenda, S. 13.

145 Robert Hunt, A Manual of Photography, London 1854, S. $183 \mathrm{ff}$.

146 Ebenda, S. 183.

147 Ebenda, S. 186. 
als Vorstufe zur kamerabasierten Fotografie verstanden. Durch den praktischen Vollzug dieser Technik könne ein grundlegendes Verständnis für Fotografie entwickelt und somit auf die schwierigere Aufgabe der Kamerafotografie vorbereitet werden.

Auf den Lerneffekt der Technik des Fotogramms geht auch ein Artikel mit dem Titel „How to Commence Photography“ der Zeitschrift The Photographic News von 1858 ein. Dort heißt es:

„Do not on any account begin with attempting portraiture by the collodion process, or you will never be a photographer; but commence with obtaining an insight into the laws and phenomena of the science by super-position, then proceed to the talbotype negative process, and keep to it, at all events until you are so thoroughly au fait at the process as to be competent to decide upon the merits of the waxed paper or any other paper process. ${ }^{148}$

Auch in einem Artikel in The Boy's Own Magazine von 1857 verweist der anonyme Autor auf die sogenannten „Anfangsgründe“ der Fotografie, die in der Erzeugung kameraloser Fotografien bestünden. ${ }^{149} \mathrm{Nach}$ der konsequenten Ausübung derselben könnten schwierigere Prozesse im Feld der Fotografie bewerkstelligt werden. Grundlegend für die Erörterung in jenem Jugendmagazin war die einfache Durchführbarkeit der Experimentalanordnung. Dazu zählten die relativ kostengünstige Anschaffung der erforderlichen Utensilien sowie die allgemein leicht zugänglichen Materialien „Gräser, Spitzenmuster, Drucke, Algen und zahlreiche andere Dinge“. ${ }^{150}$ Mit diesem kurzen Querschnitt durch fotografische Anleitungsbücher bis ca. 1860 sollte aufgezeigt werden, dass dem Fotogramm nicht nur eine wichtige didaktische Funktion im Rahmen der Unterrichtung in fotografischen Techniken zukam, sondern dass es auch als einfaches und preiswertes Verfahren angesehen wurde.

\section{Bilder der Selbsttätigkeit}

Obwohl sich die einzelnen fotografischen Techniken in ihren Herstellungsbedingungen deutlich voneinander unterschieden, griffen sowohl Niépce, Daguerre, als auch Talbot in ihren schriftlichen Formulierungen auf das Beschreibungsmodell autopoie-

148 Anonym, How to Commence Photography, in: The Photographic News, 17. September 1858, S. 23.

149 Anonym, Sun Pictures, in: The Boy's Own Magazine, Bd. 3, 1857, S. 348-349, hier S. 348.

150 Ebenda, S. 349. 
tischer Bilderzeugung zurück. ${ }^{151}$ Gemäß Niépce besaßen Heliographien das Vermögen, „sich selbst zu reproduzieren“. ${ }^{152}$ Daguerre wiederum betonte, dass es sich im Falle des „Daguerréotyps“ nicht um ein Instrument handle, „sondern um einen chemischen und physikalischen Prozess, welcher es der Natur ermögliche, sich selbst zu reproduzieren“. ${ }^{153}$ In einem Brief an den Herausgeber der Literary Gazette vom 2. Februar 1839 nannte Talbot als einen eminenten Vorteil seiner Erfindung gegenüber allen bis dato vorhandenen Zeichenapparaturen, dass die Fotografie, wie auch schon Niépce und Daguerre vor ihm äußerten, über die Fähigkeit zur Selbstorganisation verfüge: „[...] the present invention differs totally in this respect (which may be explained in a single sentence), viz. that, by means of this contrivance, it is not the artist who makes the picture, but the picture which makes ITSELF." ${ }^{154}$

Weder die Wissenschaftler seien für jene auf fotochemischem Wege erzeugten Bilder verantwortlich, noch bedürfe es zur Herstellung eine Künstlerperson; vielmehr generierten sich genannte Bilder nach dem Präparieren des Papierträgers mit Silbernitrat und unter Einstrahlung von Sonnenlicht „,von selbst“ . ${ }^{155}$ Fotografie wurde somit einem automatischen beziehungsweise natürlichen Prozess gleichgesetzt. ${ }^{156}$ Zwar problematisierte Talbot damit den Faktor der Autorschaft, doch veranschlagte er im Gegenzug Objektivität und Wirtschaftlichkeit. Das Vorstellungsmodell einer autopoietischen Bildgenese, so meine These, knüpft an mehrere innerhalb der Fotografiegeschichtsschreibung kaum berücksichtigte Traditionsstränge an, deren ideengeschichtlicher Hintergrund sich aus dem Gebiet der Naturphilosophie, der Biologie sowie der Nationalökonomie ableiten lässt. Eine Analyse der Einflussquellen lohnt sich, da mit dem automatisch generierten Bild der Fotografie das Attribut der „Authentizität“ beziehungsweise „Evidenz“ bis in jüngste Zeit immer wieder verknüpft wird. ${ }^{157}$ In den nun folgenden Ausführungen wird versucht, Talbots Beschreibungsweisen von Fotografie in jenen erweiterten Bezugsrahmen zu setzen, um damit bisher kaum beleuchtete Aspekte früher Fotografietheorie herauszuarbeiten.

151 Ich beziehe mich an dieser Stelle auf Friedrich Weltziens Begriff der Autopoiesis als selbsttätige Schöpferkraft innerhalb der Ästhetik, siehe dazu: ders. 2006, 2011. Siehe ebenfalls: Marien 1997; Siegel 2013.

152 Niépce 1999b, S. 285.

153 An Announcement by Daguerre, in: Image. Journal of Photography of the George Eastman House Jg. 8, Nr. 1, März 1959, S. 32-36.

154 Talbot 1839a, S. 73.

155 In Bezug auf das eigentliche Agens der Fotografie bleibt Talbot ungenau. Einerseits würden sich die Bilder selbst produzieren, andererseits spricht er vom Sonnenlicht als hervorbringender Kraft, siehe dazu: Talbot 1844-1846 (2011), Notice to the Reader, o.S.; Talbot 1980, S. 28.

156 Vgl. dazu: Edwards 2006, S. 24-66.

157 So jüngst: Nora Sternfeld/Luisa Ziaja (Hg.), Fotografie und Wahrheit. Bilddokumente in Ausstellungen, Wien 2010; Sabina Becker (Hg.), Visuelle Evidenz. Fotografie im Reflex von Literatur und Film, Berlin 2011. 
In den einleitenden Bemerkungen der 1844 bis 1846 erschienenen und mit unterschiedlichen Fotografien illustrierten Publikation The Pencil of Nature grenzt Talbot Fotografie von anderen künstlerischen Medien ab. Aufgrund dieser Negativdefinition erklärt der britische Wissenschaftler, was Fotografie gerade nicht beziehungsweise wovon sie zu unterscheiden sei. ${ }^{158}$ Er verhandelt dies mit Hilfe der Metapher der „Künstlerhand“ sowie ihres ausführenden „Zeichenstiftes“159:

„The little work now presented to the Public is the first attempt to publish a series of plates or pictures wholly executed by the new art of Photogenic Drawing, without any aid whatever from the artist's pencil. [...] They have been formed or depicted by optical and chemical means alone, and without the aid of any one acquainted with the art of drawing. [...] They are impressed by Nature's hand." $" 160$

Die Nennung des Begriffs der „Hand“ ist insofern von Bedeutung, als sie einerseits als Kürzel für menschliche Arbeitskraft und andererseits als Wissensobjekt sowie Ausdruck und Sitz künstlerischer Meisterleistung angesehen wurde. ${ }^{161}$ Bereits Aristoteles bezeichnete die Hand als „Werkzeug aller Werkzeuge (organum organorum), das aufgrund seines gestischen Vermögens innerhalb der Rhetorik Bedeutung erlangte. ${ }^{162}$ Ab dem 15. Jahrhundert wurde die Hand des Künstlers zu einem schöpferischen Organ aufgewertet, wodurch gleichermaßen eine Vergeistigung des künstlerischen Handwerks und damit eine Einbeziehung der bildenden Künste in den Kanon der „Artes liberales“ erfolgte. ${ }^{163}$ Mit dem Einsetzen anatomischer Studien zu Beginn des 16. Jahrhunderts in Verbindung mit der aus dem Mittelalter übermittelten Lehre der Chiromantie wurde die Hand aber auch zu einem Gegenstand der Epistemologie nobilitiert. So galt sie Lavater in seinen physiognomischen Studien als dem Gesicht ebenbürtig. ${ }^{164}$

158 Vgl. dazu: Geimer 2001.

159 Vgl. zur Metapher des „Pencil of Nature“ den gleichnamigen Artikel: Anonym, The Pencil of Nature. A New Discovery, in: The Corsair, Nr. 5, 13. April 1839, S. 70-72.

160 Talbot $184-1846$, o.S.

161 Vgl. dazu: Löffler 2003; Zimmermann 2004; Mariacarla Gadebusch Bondio (Hg.), Die Hand. Elemente einer Medizin- und Kulturgeschichte, Berlin 2010; Steidl 2017.

162 Vgl. dazu: Andreas Gormans, Argumente in eigener Sache - Die Hände des Künstlers, in: Gadebusch Bondio 2010, S. 189-223.

163 Vgl. dazu: Martin Warnke, Der Kopf in der Hand, in: Werner Hofmann (Hg.), Zauber der Medusa. Europäische Manierismen, Wien 1987, S. 55-61; Maike Christadler, Die Hand des Künstlers, in: Marco Wehr/Martin Weinmann (Hg.), Die Hand. Werkzeug des Geistes, München 2005, S. 325-338.

164 Löffler 2003, S. $213 f$. 
Zudem verlagert Talbot in den einführenden Worten zu The Pencil of Nature photogenische Zeichnungen in den Bereich der Natur. ${ }^{165}$ Entscheidend ist dabei ebenfalls die Konzeption von „Natur“: Im Unterschied zum Begriff der Kultur wurden der Natur allgemein Objekte zugerechnet, die frei von jeglichem menschlichen Einfluss sind sowie selbsttätig entstehen. ${ }^{166}$ Damit konnte das künstlerische Potenzial in eines der Natur verlagert werden, der man die Fähigkeit zusprach, mit ihrer eigenen immateriellen „Hand“ automatische und vor allem präzise Bilder zu erzeugen. ${ }^{167}$ Natur wurde somit nicht nur als eigenständige Größe erkannt, sondern trat zudem als autonome Zeichenmeisterin auf. Andererseits kann mit Ralf Klausnitzer argumentiert werden, dass Talbot die bedeutungsvolle Metapher der Hand zur bildlichen Beschreibung eines zum damaligen Zeitpunkt noch „komplizierten und nicht vollständig explizierbaren Zusammenhang[s] " einsetzte und sich der Trope bewusst zur Erläuterung eines weitgehend verborgenen Herstellungsvorgangs bediente. ${ }^{168}$

Aus Talbots metaphorischer Beschreibungsweise von Fotografie lassen sich vor allem zwei zentrale ideengeschichtliche Theoriekomplexe ableiten, die bis dato innerhalb der Fotografietheorie zu wenig bis kaum beachtet wurden: Einerseits kann das aus der Naturphilosophie stammende Vorstellungsgefüge einer zeichnenden oder malenden Natur als historische Wurzel lokalisiert werden, andererseits aber auch das innerhalb der sich etablierenden Nationalökonomie eingeführte Konzept der sogenannten „unsichtbaren Hand“.

Wie Edwards in seiner Studie zur Entwicklung britischer Fotografie herausarbeiten konnte, wurde wirtschaftlicher Fortschritt zur Zeit Talbots vor allem auf den Aspekt selbsttätig agierender Maschinen beziehungsweise auf die Fabrik als

165 Der Ausdruck „Pencil of Nature“ ist keine Wortschöpfung Talbots, sondern war bereits vor Erscheinen des gleichnamigen Buches in literarischem, philosophischem und instrumentellem Sprachgebrauch, vgl. dazu Anm. 159. Siehe auch: Heinz Henisch, The Photographic Experience 1839-1914: Images and Attitudes, Pennsylvania 1994, S. 198ff.; Schaffer 2013, S. 274f.; Secord 2013, Anm. 53.

166 Siehe dazu exemplarisch: „Natur“, in: Brockhaus Konversationslexikon 1894-1896, Bd. 12, S. 199-200. Darin heißt es: „Natur (von dem lat. nasci, d.i. werden oder entstehen), im weitesten Sinne alles, was sich nach eigenen Trieben und Gesetzen, ohne fremdes Zuthun, gestaltet. [...] das Natürliche steht dem Gemachten und Gekünstelten als das von selbst Entstehende gegenüber."

167 Eine weitere auf diese Referenzfigur zielende Beschreibung findet sich bei: Talbot 1980, S. 27: "Contemplating the beautiful picture which the solar microscope produces, the thought struck me, whether it might not be possible to cause that image to impress itself upon the paper, and thus to let Nature substitute her own inimitable pencil, for the imperfect, tedious, and almost hopeless attempt of copying a subject so intricate."

168 Ralf Klausnitzer, Unsichtbare Fäden, unsichtbare Hand. Ideengeschichte und Figuration eines Metaphernkomplexes, in: Lutz Danneberg (Hg.), Begriffe, Metaphern und Imaginationen in Philosophie und Wissenschaftsgeschichte, Wiesbaden 2009, S. 145-176, hier S. 149. 
automatisierte Produktionsstätte bezogen. ${ }^{169}$ Menschliche Arbeitskraft sollte durch Erfindungen ersetzt werden, die im Stande waren, autonom zu agieren. Dahinter steht das erklärte Ziel der industriellen Revolution, Produktivität und Umsatz durch Automatisierung zu steigern. Talbots Beschreibung selbstgenerierender Bilder lässt sich insofern mit zeitgenössischen kapitalistischen Theorien zur Optimierung von Arbeitsprozessen vergleichen. So bemerkte der schottische Arzt und Ökonom Andrew Ure in seinem 1835 erschienenem Werk The Philosophy of Manufactures, dass ideale Waren ,with little or no aid of the human hand“ hergestellt werden sollten. ${ }^{170}$ Fabrikbesitzer sollten laut Ure zur Gänze auf menschliche Arbeitskraft verzichten, um eine profitorientierte Produktionsweise zu garantieren. Das Beispiel der Fabrik nahm in Ures Text eine exemplarische Stellung ein, da es zur Formulierung einer kapitalistischen Utopie der gänzlich selbstorganisierenden Warenherstellung diente. ${ }^{171}$ Auch Talbots Beschreibungen zielten auf eine Ersetzung menschlicher Arbeitskraft durch das automatische und somit ökonomische Verfahren photogenischer Zeichnung. Zudem war auch er an einer Vermarktung seiner Erfindung interessiert, da er in seinen schriftlichen Äußerungen nicht nur konkrete Anwendungsgebiete nannte, sondern sein Verfahren patentieren ließ und gegen Verstöße rechtlich vorging. ${ }^{172}$

Im Kontext der Schilderung von Fotografie als selbsttätiger Technik interessiert nicht nur die in zahlreichen zeitgenössischen Formulierungen anzutreffende Trope menschlicher Arbeitskraft als „hands“ und deren Ersetzung, sondern auch der größere Zusammenhang wirtschaftlicher Theorien, wie sie der Nationalökonom Adam Smith mit seiner Studie Inquiry into the Nature and Causes of the Wealth of Nations 1776 entwickelte. ${ }^{173}$ Darin erwähnt Smith die für die Wirtschaftswissenschaften so folgenreiche Metapher der ,invisible hand“, womit die Selbstregulierung des Marktes angesprochen wird. In dieser Schrift Smiths koordiniert eine unsichtbare Hand laut Klausnitzer „die Gesamtheit der individuellen Intentionen“, sodass „die Tätigkeiten selbstbezogener Einzelsubjekte in gesellschaftliche[r] Wohlfahrt münden“.174 Je mehr jedes einzelne Mitglied einer Gesellschaft nach Reichtum strebe, umso größer wäre der Wohlstand der gesamten Nation. Im Zuge dieses Prozesses würden sich Preis und

169 Edwards 2006.

170 Andrew Ure, The Philosophy of Manufactures, or, Exposition of the Scientific, Moral, and Commercial Economy of the Factory System of Great Britain, London 1835, S. 1.

171 Siehe dazu: Andrew Zimmerman, The Ideology of the Machine and the Spirit of the Factory. Remarx on Babbage and Ure, in: Cultural Critique, Bd. 37, 1997, S. 5-29; Steve Edwards, Factory and Fantasy in Andrew Ure, in: Journal of Design History, Jg. 14, Bd. 1, 2001, S. 17-33.

172 Siehe dazu: Nancy Keeler, Inventors and Entrepreneurs, in: History of Photography, Jg. 26, Bd. 1, 2002, S. 26-33; Edwards 2006, S. 32f; Schaaf/Taylor 2007.

173 Zur Trope der „Hand“, siehe: Edwards 2006, S. 45; Smith 1776; siehe dazu ebenso: Weltzien 2011, S. $310 \mathrm{ff}$.

174 Klausnitzer 2009, S. 145. 
Angebot von selbst regeln. Ohne näher auf Smiths mittlerweile umstrittene Theorie der Selbstregulierungskräfte des Marktes einzugehen, soll festgehalten werden, dass es sich im Falle der Nennung einer ,unsichtbaren Hand“ um eine damals bereits als bekannt vorauszusetzende Metapher handelte. Mit ihrer Hilfe wurden allgemein Vorgänge umschrieben, die ,eigentlich unbeobachtbar sind, da sie in nicht einsehbarer Weise aus partikularen Handlungssequenzen regelmäßige, das heißt vom Standpunkt eines übergeordneten Beobachters sinnvoll geordnete Strukturen hervorgehen lassen“. ${ }^{175}$ Die durch eine nicht näher bestimmte Hand der Natur abgedruckten Bilder Talbots lassen sich jedenfalls nicht nur in den Kontext der industriellen Revolution und ihrer Forderung nach automatisch generierten und massenproduzierten Gütern stellen, sondern auch in den größeren Rahmen ökonomischer Theorien. Talbots Festlegung von Fotografie als autogenerativer Technik steht damit innerhalb einer sich etablierenden kapitalistischen Ideologie.

In der figurativen Beschreibungsweise von Fotografie als von der „Hand der Natur abgedruckt" kann aber auch ein seit Plinius und vor allem seit der frühen Neuzeit stark rezipiertes naturphilosophisches Konzept erkannt werden, welches der Natur eine produktive Kraft zusprach. Dabei sind zwei unterschiedliche Aspekte seit der nachantiken Aristotelesrezeption festzustellen: einerseits das Konzept der natura naturata, der geschaffenen Natur, und andererseits, was mich in dieser Studie besonders interessiert, das schöpferische Vermögen der Natur als natura naturans. Jener aktiven Seite der Natur wurde die Fähigkeit zugesprochen, sogenannte ludi naturae (Spiele der Natur) hervorzubringen, womit Erstaunen oder Verwunderung evozierende Naturobjekte bezeichnet wurden. ${ }^{176}$ Darunter subsumierte man sonderbar geformte Mineralien, Fossilien und dergleichen, sogenannte „Missbildungen“, oder

175 Ebenda, S. 175. Der durch eine „unsichtbare Hand“ der Natur gelenkte Schöpfungsakt kann aber auch als Teil des zu Beginn des 19. Jahrhunderts in der viktorianischen Wissenschaft einsetzenden Säkularisierungsprozesses verstanden werden. Vergleichbar wäre diesbezüglich die Darstellung der Hand als Pars pro toto Gottes im Christentum. Als „dextera dei“ lenkt sie die Geschicke der irdischen Welt und versinnbildlicht als Stellvertreterin ungreifbare Lenkungs- bzw. Schöpfungsvorgänge christlicher Mythologie. Vgl. „Hand Gottes“, in: Engelbert Kirschbaum (Hg.), Lexikon der christlichen Ikonographie, Bd. 2, Freiburg u. a. 1970, Sp. 211-214.

176 Siehe dazu: Jurgis Baltrušaitis, Imaginäre Realitäten. Fiktion und Illusion als produktive Kraft, Tierphysiognomik, Bilder im Stein, Waldarchitektur, Illusionsgärten, Köln 1984; Paula Findlen, Jokes of Nature and Jokes of Knowledge: The Playfulness of Scientific Discourse in Early Modern Europe, in: Renaissance Quarterly, Jg. 43, Bd. 2, 1990, S. 292-331; Lorraine Daston/Katherine Parker, Wunder und die Ordnung der Natur (1150-1750), Frankfurt am Main 2002, S. 387-392; Marie-Theres Federhofer, Vorwort, in: Cardamus. Jahrbuch für Wissenschaftsgeschichte (Natur-Spiele. Beiträge zu einem naturhistorischen Konzept der Frühen Neuzeit), Bd. 6, 2006, S. 7-13; Natascha Adamowsky/Hartmut Böhme/Robert Felfe (Hg.), Ludi Naturae. Spiele der Natur in Kunst und Wissenschaft, München 2011. 
auch in Steinformationen und ähnlichem identifizierte Landschaften und Figuren. Auf diese Weise erkannte man die kreative Kraft der Natur auch als künstlerisches Vermögen an, wodurch das Konzept der ludi naturae ins Ästhetische transformiert wurde. Natur zeigte sich demnach als malende, zeichnende und formende Künstlerin, wovon die lateinischen Formulierungen "natura pictrix" beziehungsweise "natura pingit" künden. ${ }^{177}$ Besonders kam in der Rezeption aber auch jenen organischen und anorganischen Objekten Aufmerksamkeit zu, die eine nicht näher erklärbare Ähnlichkeit mit wesensfremden Dingen aufwiesen. In Krünitz' Oekonomische Encyklopädie von 1806 heißt es unter dem Lemma „Naturspiel“ insofern:

„Ein Nahme, welchen man in der Naturgeschichte solchen natürlichen Körpern gibt, welche einige zufällige Aehnlichkeit mit andern Körpern haben, weil die Natur bey deren Bildung gleichsam spielete. In der Lithologie nennt man insonderheit solche Steine so, die in der Form oder in der Zeichnung andern Naturkörpern oder auch Werken der Kunst ähnlich sehen, und von Unkundigen wohl für die Sache selbst oder für eine solche Versteinerung genommen werden. [...] Es gibt aber nicht nur im Mineralreiche, sondern auch in den andern Naturreichen, nähmlich unter den Menschen, Thieren und Pflanzen, sehr häufige Naturspiele, die sich durch eine abweichend geformte Bildung, oder durch die besondere Beschaffenheit ihrer Theile von andern Individuen ihrer Art auszeichnen. Allein man ist hierauf gewöhnlich nur alsdann aufmerksam, wenn solche Bildungen außerordentlich in die Augen fallen, und sehr wunderbar und entstellend sind.“.178

Der Bezug zu unterschiedliche Naturformen versinnbildlichenden Steinen, die von Betrachter/innen mitunter als "die Sache selbst" angesehen wurden, findet sich in bereits erörterter Schrift Talbots zur Ununterscheidbarkeit von Spitzenmustern und ihren photogenischen Zeichnungen. Talbot beschreibt Fotogramme von Naturobjekten darin als Surrogate, welche den Rezipienten einen augentrügerischen Effekt vermitteln würden.

Als Antriebsquelle natürlicher Bildproduktion galt im Falle der ludi naturae eine unbestimmte "plastische“ oder „generative Kraft" der Natur (vis formativa), die rätselhafte Formen in Stein und ähnlichem entstehen ließ. ${ }^{179} \mathrm{Ab}$ der Spätrenaissance fanden

177 Siehe dazu: Findlen 1990, S. 297; Lorraine Daston, Nature by Design, in: Caroline Jones/Peter Galison (Hg.), Picturing Science, Producing Art, New York 1998, S. 232-253; dies., Nature Paints, in: Bruno Latour/Peter Weibel (Hg.), Iconoclash. Beyond the Image Wars in Science, Religion and Art, Ausst.-Kat. ZKM Karlsruhe, Karlsruhe 2002, S. 136-138.

178 Krünitz 1806, Bd. 101, S. 648-660, hier S. 648.

179 Eine Erklärung für die Bilder der Natur lag im Konzept des Zufalls, den Leon Battista Alberti oder auch Leonardo da Vinci durch das Hineinsehen von Figuren in Marmor oder Mauerwerk 
solche und ähnliche Objekte, die einen oftmals ambiguen Status zwischen Natur- und Kunstobjekt einnahmen, ihren Weg in Kunst- und Wunderkammern von Fürstenhäusern. ${ }^{180}$ Dabei sprach man Werken der Natur aufgrund ihrer exakten Ausführungsund Erscheinungsweise gegenüber künstlerischen Produktionen eine eindeutige Vormachtstellung zu. ${ }^{181}$ Eine weitere Seite der „spielenden Natur“ erläutert Paula Findlen mit dem Konzept der ,jokes of knowledge“. ${ }^{182}$ Damit belegt sie Laborversuche des 16. und 17. Jahrhunderts, die sich der experimentellen Nachahmung beziehungsweise Neuerschaffung von Naturphänomenen widmeten. Vergleichbar mit Talbots Konzeption photogenischer Zeichnungen ist sowohl der Aspekt einer bildenden Natur, welche selbständig Kunstwerke oder Bildwerke schuf - Talbot spricht von einem ,natural process“ -, wie auch der Aspekt der dem Menschen zugesprochenen Fähigkeit, natürliche Phänomene künstlich nachzuahmen. ${ }^{183}$ Obwohl das Konzept der ludi naturae bereits im 18. Jahrhundert aus dem wissenschaftlichen Bereich verschwand, sind Spuren bis in die Moderne zu verzeichnen, wie Natascha Adamowsky, Hartmut Böhme und Robert Felfe in ihrem 2011 erschienenen Sammelband nachweisen konnten..$^{184}$

Festzuhalten ist, dass Talbot jene noch nachwirkende Metaphorik in seine schriftlichen Äußerungen miteinbezog, um photogenische Zeichnungen als sich automatisch erzeugende Naturprodukte zu beschreiben. Verstärkt wird dies durch Talbots Bezeichnung der Fotografie als „Entdeckung“. Zugleich aber versteht sich der englische Wissenschaftler als Urheber mit patentrechtlichen Ansprüchen, welche er in seinen Schriften durch die synonyme Angabe „Erfindung“ deutlich macht. In dieser Beschreibung von Fotografie als Natur- sowie Kulturprodukt erkenne ich jedoch keinen Widerspruch. Talbot bediente sich zur Erörterung der Entstehungs- wie Erscheinungsweise von Fotografie bewusst der zeitgenössischen Metapher einer zeichnenden

als Inspirationsquelle künstlerischer Entwürfe empfahlen, siehe dazu: Kemp 1995; Dario Gamboni, Potential Images. Ambiguity and Indeterminacy in Modern Art, London 2002; Weltzien 2006; Claudia Blümle, Mineralischer Sturm. Steinbilder und Landschaftsmalerei, in: Werner Busch/Oliver Jehle (Hg.), Vermessen. Landschaft und Ungegenständlichkeit, Zürich 2007, S. 73-96; Weltzien 2011.

180 Zum Themenbereich der frühneuzeitlichen „Natur- und Wunderkammern“ erschienen in den letzten Jahren zahlreiche Publikationen, exemplarisch: Andreas Grote (Hg.), Macrocosmos in Microcosmo. Die Welt in der Stube. Zur Geschichte des Sammelns 1450-1800, Opladen 1994.

181 Siehe dazu: Daston 1998, S. 237.

182 Findlen 1990.

183 Vgl. Talbot 1841, S. 140; Talbot 1980.

184 Vgl. dazu: Adamowsky/Böhme/Felfe 2011. Die Referenz einer sich selbst malenden Natur findet sich auch in Abhandlungen zur Perspektivlehre, siehe dazu: Fiorentini 2006, S. 21. 
Natur, welche in der Lage war, präzise Bilder hervorbringen, ${ }^{185}$ wobei die Einbeziehung der Vorstellungsfigur einer weiblich kodierten Natur zur Umschreibung eines verfahrenstechnischen Sachverhaltes - wie im Falle Talbots - eine allgemeine wissenschaftliche Praxis darstellt, die sich ganz bewusst bildsprachlicher Wendungen bediente. ${ }^{186}$ Analogien oder Metaphern verhalfen im Bereich der Wissenschaft dazu neue Phänomene zu erläutern, indem sie auf vorhandenes Alltagswissen zurückgriffen und somit innerhalb als auch außerhalb der Wissenschaftswelt verstanden werden konnten. Mit Hilfe elementarer, in einer sozialen Sprachgemeinschaft gefestigter Ausdrucksweisen, wurde unter gleichzeitiger Ausblendung anderer Gesichtspunkte auf ein konkretes Verfahrensdetail fokussiert. Die von Talbot oftmals unternommene metaphorische Inbezugnahme von künstlerischen Werken und photogenischen Zeichnungen zielte aufgrund deren Detailgenauigkeit auf die Vorrangstellung letzterer ab. Insofern lässt sich in Talbots Erörterungen von Fotografie eine Parallele zu jenen Bildwerken der Natur beobachten, denen im Vergleich zu Produktionen aus Künstlerhand ebenfalls ein höherer Rang zugesprochen wurde. Eine Erweiterung des Topos der künstlerisch tätigen Natur erhalten die zahlreichen Fotogramme von Naturobjekten durch die Bezeichnung nicht nur als Bilder der Natur, sondern auch durch die Natur. ${ }^{187}$ Das Fotogramm kann insofern als „zweite Natur“188 und materielle Verdopplung beschrieben werden, da Natur nicht durch eine zwischengeschaltete Instanz abgebildet oder repräsentiert wird. Dieser Aspekt wird durch einen Rezensenten des Pencil of Nature hervorgehoben, wenn es hinsichtlich des kameralosen Bildes eines Pflanzenblattes heißt: „The leaf of a plant obtained by laying the object on slightly sensitive paper, and covering it with glass screwed with some force down, is nature itself - how valuable for botanical science!" ${ }^{189}$

\section{Dynamisierung des Lebens um 1800}

Zur Bewertung photogenischer Zeichnungen und für die Einordnung der Schriften Talbots hinsichtlich möglicher Einflüsse ist es notwendig, den Aspekt sich selbst generierender Bilder beziehungsweise die attestierte „Selbsttätigkeit“ von Fotografie

185 Im Gegensatz dazu: Peter Geimer, Fotografie als Fakt und Fetisch. Eine Konfrontation von Latour und Natur, in: David Gugerli/Barbara Orland (Hg.), Ganz normale Bilder. Historische Beiträge zur visuellen Herstellung von Selbstverständlichkeit, Zürich 2002, S. 183-194; ders. 2010.

186 Vgl. Paulitz 2012.

187 Vgl. dazu: Armstrong 2004; Steidl 2017.

188 Norbert Rath, Zweite Natur. Konzepte einer Vermittlung von Natur und Kultur in Anthropologie und Ästhetik um 1800, Münster 1996.

189 Anonym, The Pencil of Nature. By H. Fox Talbot, F.R.S., No. 2, in: The Literary Gazette and Journal of the Belles Lettres, Arts, Sciences, \&c, 1. Februar 1845, S. 73. 
näher zu betrachten. Um 1800 begann sich die Biologie als Wissenschaft vom selbsttätigen Leben allmählich zu etablieren. In dieser Zeit widmete man sich vor allem der Untersuchung organischer Entwicklung sowie deren Verzeitlichungs- und Dynamisierungsprozessen. ${ }^{190}$ Natur galt nun nicht mehr als Teil des göttlichen Schöpfungsaktes, sondern wurde als temporalisierte, gottesunabhängige Kraft gewertet. Andererseits konnten Phänomene der Zeugung, Fortpflanzung, Embryogenese und des Wachstums mit mechanistischen Theorien nicht mehr hinreichend erklärt werden. Was zunächst als Auswicklung und Vergrößerung präformierter, göttlich bestimmter Formen gedacht wurde, verlagerte sich als Ideenkonzept der Entwicklung und Reproduktion nun ins Innere der Organismen. Entscheidend war dabei die Annahme vitaler Kräfte, die im Bereich der Embryologie nach der Zeugung lebendige Organismen selbsttätig entstehen ließen. Als prominenter Vertreter des Selbstorganisationskonzeptes ist Caspar Friedrich Wolff zu nennen, der im Zuge seiner 1759 erschienenen Dissertation die Theorie der Epigenesis begründete. ${ }^{191}$ Diese Theorie organischer Entwicklung setzte sich von der Präformationstheorie ab und vertrat die Vorstellung einer sukzessiven Formentstehung aus einer homogenen Masse. Damit lehnte man die Auffassung von bereits im Samen oder im Ei präfigurierten und somit vollständig angelegten Embryonen ab. Wesentliches Merkmal des Epigenesiskonzeptes von Wolff ist die Annahme einer die Entwicklung antreibenden Kraft, die er als „vis essentialis“ bezeichnete, jedoch nicht näher spezifizierte. ${ }^{192}$ In eine ähnliche Richtung ging Johann Friedrich Blumenbach, der sich mit Aspekten der Nutrition, Generation sowie Reproduktion beschäftigte und das zugrunde liegende Wirkungsvermögen mit dem Begriff des „Bildungstriebes“ (nisus formativus) belegte. ${ }^{193}$ Das epigenetische Modell samt seinen Begrifflichkeiten wie „Bildung“, „Bildungstrieb“ und „Entwicklung“ hielt insbesondere aufgrund Blumenbachs Schlüsseltext Einzug in die Lebenswissenschaften und verbreitete sich von dort aus in andere Wissensgebiete. ${ }^{194}$

190 Siehe dazu: Wolf Lepenies, Das Ende der Naturgeschichte. Wandel kultureller Selbstverständlichkeiten in den Wissenschaften des 18. und 19. Jahrhunderts, München 1976; Lenoir 1989; Janina Wellmann, Die Form des Werdens. Eine Kulturgeschichte der Embryologie, 17601830, Göttingen 2010.

191 Caspar Friedrich Wolff, Theoria generationis, Halle 1759. Der Begriff der Epigenesis geht auf William Harvey zurück, siehe dazu: Wellmann 2010, S. 109.

192 Stefan Willer spricht insofern von einer „Virtualisierung“, die Unbestimmtheit in das Denken über Reproduktion einfügt, siehe dazu: Stefan Willer, Zur Poetik der Zeugung um 1800, in: Sigrid Weigel u.a. (Hg.), Generation. Zur Genealogie des Konzepts - Konzepte von Genealogie, München 2005, S. 125-156, hier S. 129.

193 Johann Friedrich Blumenbach, Der Bildungstrieb oder das Zeugungsgeschäfte, Göttingen 1781. Siehe dazu: Robert Richards, The Romantic Conception of Life. Science and Philosophy in the Age of Goethe, Chicago 2002, S. $216 \mathrm{ff}$.

194 Siehe dazu: Helmut Müller-Sievers, Self-Generation. Biology, Philosophy, and Literature Around 1800, Stanford 1997, S. 42 f. 
Eben jene Dynamisierung des Lebens beeinflusste um 1800 nicht nur die Biologie, sondern sie führte zu einer allgemeinen vitalistischen Geisteshaltung. Shirley Roe spricht in diesem Zusammenhang von einem „developmental paradigm“, das mechanistische Vorstellungsgefüge ablöste und zu einer weltanschaulichen Wende des Vitalismus führte. ${ }^{195}$ Timothy Lenoir wiederum belegte die Umbruchsphase Anfang des 19. Jahrhunderts mit dem Begriff des „epigenetic turn“, der sich in Philosophie, Literatur und zahlreichen anderen Fachgebieten niederschlug. ${ }^{196}$ Allgemein bezog man sich dabei auf die reproduktiven Funktionsweisen des Organismus bzw. konzentrierte sich auf Phänomene der eigengesetzlichen Bildung, wodurch der Fokus ebenfalls auf der geistigen „Bildung“ des Menschen lag. ${ }^{197}$ Kurz angeführt sei hier Johann Gottfried von Herders 1784 erschienenes Werk Ideen zur Philosophie der Geschichte der Menschheit, in dem er von einer „genetischen Kraft" spricht, womit er allgemeine Entstehungsbedingungen umschreibt, die er jedoch explizit an zeitgenössische Theorien der Embryologie angelehnt sieht. ${ }^{198}$ Immanuel Kant wiederum widmet sich in Bezug auf Blumenbach dem Organismus als einer sich selbst organisierenden Einheit. ${ }^{199}$ Er ist es auch, der die Betrachtungsweise des Kunstwerks als Organismus initiiert, womit er an bedeutender Stelle der Assoziation von biologischer Reproduktion und Ästhetik steht. ${ }^{200}$ Nochmals deutlicher wird dieser Ansatz bei August Wilhelm Schlegel, der Natur in ihren (re)produzierenden Qualitäten betont. ${ }^{201}$ Der Leitsatz für die Künstlerperson war somit, Natur nicht als Gegebenes (natura naturata) nachzuahmen, sondern sich an ihrer Produktivität (natura naturans) zu messen. So schrieb Schlegel: „Die Kunst soll die Natur nachahmen. Das heißt nämlich, sie soll wie die Natur selbständig schaffend, organisirt und organisirend, lebendige Werke bilden,

195 Shirley Roe, Matter, Life and Generation. Eighteenth-Century Embryology and the HallerWolf Debate, Cambridge 1981, S. 152; siehe ebenfalls: Wellmann 2010, S. $112 \mathrm{ff}$.

196 Lenoir 1989, S. 4; siehe ebenfalls: Weltzien 2011.

197 Zum Aspekt des Bildungsbegriffs um 1800, siehe: Ebgert Witte, „Bildung“ und „Imagination“. Einige historische und systematische Überlegungen, in: Thomas Dewender/Thomas Welt (Hg.), Imagination - Fiktion - Kreation. Das kulturschaffende Vermögen der Phantasie, München/Leipzig 2003, S. 317-340.

198 Johann Gottfried von Herder, Ideen zur Philosophie der Geschichte der Menschheit, Riga/ Leipzig 1784.

199 Zu Kants Begriff der Selbsttätigkeit auch in Bezug auf die Ästhetik, siehe: Weltzien 2011, S. $120 \mathrm{ff}$.

200 Siehe dazu: Lars-Thade Ulrichs, Das ewig sich selbst bildende Kunstwerk. Organismustheorien in Metaphysik und Kunstphilosophie um 1800, in: Internationales Jahrbuch des deutschen Idealismus, Bd. 4, 2006, S. 256-290; Blümle 2007.

201 Siehe dazu: Weltzien 2011, S. $142 \mathrm{ff}$. 
die nicht erst durch einen fremden Mechanismus [...], sondern durch inwohnende Kraft [...] vollendet in sich selbst zurückkehren.“202

Diese Skizzierung der Wissenslandschaft um 1800 soll dazu dienen, den Kontext beziehungsweise das Diskursfeld generativ-vitalistischen Denkens als Einflusshorizont der Schriften Talbots in Betracht zu ziehen. So spricht Talbot in einem Brief an William Jerdan dem Konzept einer bildenden Natur vergleichbar von „the art of photogenic drawing or of forming pictures and images of natural objects by means of solar light", von Bildern also, die sich mit Hilfe des Sonnenlichtes formen oder bilden würden. ${ }^{203}$ Die These eines selbsttätigen Bildungstriebs wird in bereits eingangs erörtertem Zitat deutlich, wenn es heißt, dass nicht eine Künstlerperson für die Entstehung von Fotografie verantwortlich sei, sondern die Bilder sich von selbst erzeugten. Zentrales Argument für die Einordnung von Talbots fotografischen Verfahren in zeitgenössische Entwicklungstheorien ist die Namensgebung „photogenic drawing“. Dabei bezieht sich der Begriff „photogenic“ auf die griechischen Wortstämme „photo“ sowie „genos“, die man mit „aus Licht geboren/hervorgebracht“ übersetzen kann. ${ }^{204}$ Wie bereits Steve Edwards ansatzweise herausarbeiten konnte, impliziert das Beschreibungsmodell der fotografischen Selbstproduktion Bezüge zur Fortpflanzung und kann somit auch in seinen geschlechtsspezifischen Verweisen untersucht werden. So habe Talbot oftmals auf die „Geburt“ der Fotografie verwiesen, Fototheoretiker wiederum bezeichneten ihn als „Vater“ der Fotografie, und Faraday warf den Vergleich zur weiblich kodierten Natur auf. ${ }^{205}$ Damit werden zugleich seit der Antike dominierende Ursprungsszenarien, Gebärphantasien und Vorstellungen des künstlerischen Schaffensprozesses aufgerufen, die den Zeugungsakt in Kunst und Biologie parallel setzen. ${ }^{206}$ So verglich Aristoteles den sukzessiven Wachstumsprozess eines Embryos mit der Anfertigung eines Gemäldes, wohingegen Platon in einer Rede von „Geisteskindern" sprach. ${ }^{207}$ In der Romantik gewann der Mythos der prometheischen Selbstzeugung des Künstlers an Bedeutung, womit dem Künstler-Geist eine selbsttätige Gebärfähigkeit zugesprochen wurde. Um 1800 führten biologische Prokreation und künstlerische Produktion gehäuft zu Vorstellungen des männlichen Formprinzips,

202 August Wilhelm Schlegel, Vorlesung über Ästhetik, hg. v. Ernst Behler, Paderborn 1989, Bd. 1, S. 258.

203 Talbot 1839a, S. 73, Hervorhebung durch die Autorin.

204 Siehe dazu: Gray 2001.

205 Edwards 2006, S. 41ff.

206 Vgl. dazu: Kris/Kurz 1995; Christian Begemann, Gebären, in: Konersmann, Ralf (Hg.): Wörterbuch der philosophischen Metaphern, Darmstadt 2007, S. 121-134, hier S. 122; Christine Kanz, Maternale Moderne. Männliche Gebärphantasien zwischen Kultur und Wissenschaft (18901933), München 2009; Zimmermann 2014.

207 Siehe dazu: Krüger/Ott/Pfisterer 2013. 
das auf einen weiblichen Stoff einwirken und in einer Kreation kulminieren würde. ${ }^{208}$ Insofern muss von einem ,produktionsästhetischen Denkmodell einer ,Biologie der Kreativität “" ausgegangen werden, wie dies Krüger, Ott und Pfisterer feststellten. ${ }^{209}$ Im Falle von Talbots Fotografietheorie kann daher von einer „masculinization of reproduction" gesprochen werden. ${ }^{210}$

In Talbots Schriften zur Kalotypie wird der Bezug zu vitalistischen Konzepten noch deutlicher. Bei diesem um 1840 entwickelten Verfahren, entstand im Zuge der Belichtung ein zunächst verborgenes Bild, welches erst durch den Entwicklungsvorgang hervorgebracht und dadurch erkennbar wurde. ${ }^{211}$ Untersuchungen zur Lichtempfindlichkeit von Papier sowie die zufällige Entdeckung des latenten Bildes beschreibt Talbot in einem Brief an William Jerdan vom 19. Februar 1841. Darin heißt es, dass er Aufnahmeproben nach der Belichtung in einer Camera obscura als misslungen eingestuft und daher unbeachtet in einem dunklen Raum zurückgelassen habe. „Returning some time after“, so Talbot, „I took up the paper, and was very much surprised to see upon it a distinct picture. I was certain there was nothing of the kind when I had looked at it before. “212 Diesem plötzlich vorgefundenen Bild versucht er sodann mit folgender Erklärung näher zu kommen: „[...] therefore (magic apart), the only conclusion that could be drawn was, that the picture had unexpectedly developed itself by a spontaneous action.“" ${ }^{213}$ Laut Talbot habe sich jenes zufällig aufgefundene Bild somit durch einen spontanen Prozess selbst entwickelt, womit nicht nur zeitgenössische Entwicklungstheorien, sondern ebenso das Konzept der Spontan- oder Urzeugung aufgerufen werden. Bereits Albertus Magnus, Thomas von Aquin und William von Ockham widmeten sich dem Entwurf der sogenannten „generatio aequivoca“ oder "generatio spontanea“, das eine spontane Entstehung oder Zeugung von Organismen aus dem Erdboden bezeichnete. ${ }^{214}$ Trotz großer Kritik fand die Theorie der Urzeugung auch im 18. Jahrhundert noch einige Anhänger, zumal sie im Zuge der Polemik zwischen den Befürwortern der Präformations- und Epigenesistheorie zur

208 Vgl. dazu: Christian Begemann (Hg.), Kunst - Zeugung - Geburt, Theorien und Metaphern ästhetischer Produktion in der Neuzeit, Freiburg im Breisgau 2002.

209 Krüger/Ott/Pfisterer 2013, S. 13.

210 Siehe dazu: Edwards 2006, S. 42.

211 Siehe dazu: Nadja Lenz, The Hidden Image. Latency in Photography and Cryptography in the 19th Century, in: Photoresearcher, Bd. 17, 2012, S. 3-13.

212 Talbot 1841, S. 139.

213 Ebenda, Hervorhebung durch die Autorin. Die Bezeichnung „to develop“ verwendet Talbot bereits in einem Notizbucheintrag vom 21. September 1839. Alternativ bedient er sich des Ausdrucks „to bring out" siehe dazu: Schaaf 1996b, P121, P139.

214 Siehe dazu: Georg Toepfer, Historisches Wörterbuch der Biologie. Geschichte und Theorie der biologischen Grundbegriffe, Stuttgart und Weimar 2011, Bd. 3, „Urzeugung“, S. 608-619. 
Stärkung letztgenannter strategisch ins Feld geführt wurde. ${ }^{215}$ Der zweite in diesem Zitat aufgeworfene Begriff ist jener der „Entwicklung“. Im 18. Jahrhundert greift dieser von einer ursprünglich biologisch-deterministischen Bezeichnung des individuellen Wachstums auf allgemeine und kollektive Prozesse beziehungsweise „terminologisch unerschlossene Gebiete des Denkens und der Wissenschaften “ über. ${ }^{216}$ Grundlegend ist hierbei die Vorstellung eines prozesshaften Wachsens und „Auseinanderwickelns“, wie es unter anderem auch Goethe in seiner Metamorphosenlehre als Phänomen der Bildung und Umwandlung beschrieb. ${ }^{217}$ Besonders in der Zeit um 1800 zeigte sich eine reflexive Verwendung des Verbs „entwickeln“ sowie des Substantivs „Entwicklung“, wodurch Subjekt und Objekt gleichgesetzt wurden und zu Begrifflichkeiten wie „Selbstentwicklung“ führten. Damit wurden dem Beschreibungsobjekt dynamische Funktionen in Form eines Entwicklungstriebes zugesprochen. Auf den Menschen bezogen bedeutete dies die Möglichkeit der Entfaltung des „Geistes“, aber auch die biopolitische Adaptierung von „Selbstpflichten“. ${ }^{218}$ In gesellschaftlich-ökonomischer Hinsicht wiederum ging damit gleichermaßen eine Naturalisierung kultureller Phänomene einher beziehungsweise ein kapitalistisch geprägter Fortschrittsoptimismus der stetigen „Weiterentwicklung“. ${ }^{219}$ In Kontrast zu den Theorien Andrew Ures setzten sich Theoretiker wie John Ruskin und William Morris für die Betonung des Handwerks ein und positionierten sich gegenüber einer voranschreitenden Industrialisierung. ${ }^{220}$ Aufgrund der durch Ure vorangetriebenen Naturalisierung von Massenproduktion und dem Ideal der Fabrik war den Gegnern jedoch auf längere Sicht wenig Erfolg beschieden.

215 Die Urzeugungstheorie vermochte Entwürfe der Spontanität und somit Ungerichtetheit gegenüber Vorbestimmung und Planung im Verlauf der organischen Entwicklung zu ersetzten, siehe dazu: Matthias Rothe, „Spontan“. Modifikation eines Begriffs im 18. Jahrhundert, in: Schneider 2008, S. 415-424.

216 Andreas Blödorn, „Entwicklungs“-Diskurse. Zur Metaphorik des Entwicklungsbegriffs im 18. Jahrhundert, in: Elena Agazzi (Hg.), Tropen und Metaphern im Gelehrtendiskurs des 18. Jahrhunderts, Hamburg 2011, S. 33-45, hier S. 34; Georg Toepfer, Entwicklung, in: ders. 2011, Bd. 1, S. 391-437.

217 Zur Metamorphosenlehre siehe: Olaf Breidbach, Goethes Metamorphosenlehre, München 2006.

218 Siehe dazu: Wolfgang Wieland, Entwicklung, Evolution, in: Otto Brunner/Werner Conze/ Reinhart Koselleck (Hg.), Geschichtliche Grundbegriffe. Historisches Lexikon zur politischsozialen Sprache in Deutschland, 1975, S. 199-228; Toepfer 2011, S. 414ff.

219 Bereits Andrew Ure und andere Theoretiker sorgten für eine Naturalisierung von Massenproduktion, siehe dazu: Freedgood 2003, S. 8ff. Zu Selbst-Prekarisierung und Biopolitik im Kulturbereich: Isabel Lorey, Vom immanenten Widerspruch zur hegemonialen Funktion. Biopolitische Gouvernementalität und Selbst-Prekarisierung von KulturproduzentInnen, in: Gerald Raunig/Ulf Wuggenig (Hg.), Kritik der Kreativität, Wien 2007, S. 121-136. Ebenso: Michel Foucault, Technologien des Selbst, Frankfurt am Main 1993.

220 Siehe dazu: Freegood 2003. 
Die Erfindung der photogenischen Zeichnung Talbots samt ihrer Begrifflichkeiten der Selbsttätigkeit steht als paradigmatisches Beispiel im Bezugsfeld der Ökonomie beziehungsweise ihrer kapitalistischen Theorien. So kann auch Talbots Verwendung des Begriffs der „Entwicklung“ für jenen erweiterten Gebrauch festgemacht werden. Neben der Beschreibung eines sich selbst entwickelnden Bildes spricht in Texten der Fotografiepraxis hierfür unter anderem die Wortschöpfung des „Entwicklers“ (engl. „developer“), einer Flüssigkeit, die das latente Bild zum Vorschein bringt. ${ }^{221}$ Entscheidend bei Talbots Beschreibung des neuen chemischen Verfahrens ist die direkte Beobachtung des entstehenden Bildes: „I know few things in the range of science more surprising than the gradual appearance of the picture on the blank sheet, especially the first time the experiment is witnessed." ${ }^{222}$ Durch direkte Anschauung ist er somit nicht nur in der Lage, den Zeitpunkt des fertig entwickelten Bildes zu bestimmen, sondern „Entwicklung“ zuallererst beschreibbar zu machen. Insofern bezeichnet er das Verfahren der Kalotypie als „natural process“, der Fotografien hervorbringt oder sichtbar macht und durch ein Fixiermittel in ihrem Belichtungsfortschritt stilllegen kann. ${ }^{223}$ Zudem bestehe die Möglichkeit, verblassenden Bildern mit Hilfe eines „Wiederbelebungsprozesses“ (revival) zu mehr Tiefenschärfe und Detailgenauigkeit zu verhelfen und sie dadurch zu reaktivieren. ${ }^{224}$

Visuell lassen sich eine Vielzahl von Fotogrammen Talbots wiederum in den Kontext von Goethes Metamorphosenlehre und des von ihm begründeten Konzepts der Morphologie setzen. Im Rahmen der Metamorphose ist nicht nur die Annahme einer „Urpflanze“ grundlegend, aus der sich in Folge alle Pflanzen ableiten ließen, sondern auch die Vorstellung des Blattes als zentrale Grundform, von dem jegliche vegetabile Form ausgeht. Diese Theorie umschrieb Goethe mit seiner Hypothese "Alles ist Blatt“. ${ }^{225}$ Talbots Blattfotogramme, wie jenes in Abbildung 15, können als verbildlichte „Ikonen“ der Theorienkonzepte von „Reproduktion“, „Umwandlung“, „Bildung“ und „Entwicklung“, wie sie um 1800 dominierten, angesehen werden. Indem Talbot zahlreiche Pflanzenblätter als kameralos hergestellte Lichtbilder zum Abdruck

221 Das Oxford English Dictionary gibt unter dem Eintrag „developer“ in Bezug auf die Fotografie das Jahr 1869 als Terminus post quem an, eine Verwendung vor diesem Datum ist jedoch wahrscheinlich, siehe dazu: Oxford English Dictionary, Onlineversion, Oxford University Press, Eintrag „developer” (6.3.2018).

222 Talbot 1841, S. 140; vgl. dazu: ders., An Account of Some Recent Improvements in Photography, in: Abstracts of the Papers Printed in the Philosophical Transactions of the Royal Society of London, Bd. 4 (1837-1843), S. 312-316.

223 Zur Beschreibung jenes Wachstums- oder Entwicklungsprozesses bediente sich Talbot Begriffen wie ,to bring out", „render visible“ oder „coming out".

224 Talbot 1841, S. 140.

225 Siehe dazu: Thomas Pfau, „All is Leaf“. Difference, Metamorphosis, and Goethe's Phenomenology of Knowledge, in: Studies in Romanticism, Jg. 49, Bd. 1, 2010, S. 3-41. 
brachte, wirkt die fotogrammatische Kopie gegenüber ihrem Original als reproduzierte Bildung oder Umbildung eines Urblattes, ganz im Sinne des natura naturans-Konzeptes. Folgt man den Formulierungen Talbots, ist es den reproduktiven Qualitäten der Natur zuzuschreiben, Naturobjekte vervielfältigen und umwandeln zu können.

In ihrer Studie zur wissenschaftlichen Objektivität wählten Daston und Galison die frühe Fotografie hingegen als paradigmatisches Beispiel der Kategorie „mechanischer Objektivität“ aus, womit sie eine apparative und somit unverfälschte Aufzeichnung von Wirklichkeit belegen. ${ }^{226}$ Diese Kategorisierung möchte ich jedoch am Beispiel Talbots problematisieren. Daston und Galison nehmen mit jenem Konzept explizit auf die Apparatur der Fotografie Bezug. In Talbots Publikationen war es jedoch nicht die Kamera oder der Kopierrahmen, der im Vordergrund der Herstellung präziser respektive objektiver Bilder stand, sondern eine selbsttätig produzierende Natur und damit, wie ich darzulegen versucht habe, ein vitalistisches Konzept. Steve Edwards, Vered Maimon und Joel Snyder stellten in ihren Studien den Aspekt des „Mechanischen “ innerhalb früher Fotografie bereits in Frage. ${ }^{227}$ So wies Edwards darauf hin, dass Daston und Galison mit jenem Konzept viel zu sehr auf den apparativen Moment fokussieren. ${ }^{228}$ Wenn Fotografie in frühen Texten allgemein als mechanisch beschrieben wird, ist damit weniger die Kameratechnik angesprochen, sondern - so Snyder die Qualität der originalgetreuen, oftmals händischen Reproduktion. ${ }^{229}$ Die Beschreibung des Mechanischen rekurriert dabei auf eine bereits bestehende handwerkliche Zeichenpraxis und bedeutet im Falle der Fotografie eine ästhetische Bestimmung. „To call daguerreotypes mechanical is to say they are correct, particular, and precise in their details; it is to qualify them as copies of some thing or group of things. The machinery of photographic production is in no way central to this use of ,mechanical'“. ${ }^{330}$

Auch wenn die Herstellung von Fotografien und Fotogrammen in Folge an eine konkrete „Apparatur“ - eine Kamera beziehungsweise einen Kopierrahmen - gebunden war, bezieht sich Talbots Argumentation auf das Konzept der davon unabhängig gedachten Selbsttätigkeit. Nicht mechanische Gerätschaften ließen Bilder auto-

226 Daston/Galison 2007. Siehe dazu auch: dies., Das Bild der Objektivität, in: Geimer 2002, S. 29-99, hier S. 94.

227 Joel Snyder, Res Ipsa Loquitur, in: Lorraine Daston (Hg.), Things that Talk. Object Lessons from Art and Science, New York 2004, S. 195-205; Edwards 2006; Maimon 2011, 2015.

228 Edwards 2006, S. 49.

229 Siehe dazu bspw.: William Henry Fox Talbot, Calotype (Photogenic) Drawing. To the Editor of the Literary Gazette, in: Literary Gazette and Journal of the Belles Lettres, Arts, Sciences, \&c, 13. Februar 1841, S. 108.

230 Snyder 2004, S. 202. Siehe dazu die anteilige Korrektur durch Daston/Galison: dies. 2007, S. 143ff. Siehe dazu ebenfalls: Laura Saltz, Keywords in the Conception of Early Photography, in: Sheehan/Zervigón 2015, S. 195-207. 
matisch entstehen, sondern fotografische Aufnahmen würden sich mit Hilfe unterschiedlicher Agenten wie Sonnenlicht und Fotochemie einem Organismus gleich am Papierträger selbst erzeugen. Anhand der autogenerativen Beschreibungsformel kann Talbot seine fotografischen Verfahren nicht nur in den Kontext der Industrialisierung und ihrer Forderung nach automatisierter Güterproduktion stellen, sondern auf ein breites Fundament vitalistischer Metaphern zurückgreifen, das sich aus der Biologie sowie der Naturphilosophie zusammensetzt. 
